\title{
WestVirginiaUniversity
}

THE RESEARCH REPOSITORY @ WVU

Graduate Theses, Dissertations, and Problem Reports

2014

\section{Gender and Financial Risk Tolerance across the Life Span}

Philip Lemaster

Follow this and additional works at: https://researchrepository.wvu.edu/etd

\section{Recommended Citation}

Lemaster, Philip, "Gender and Financial Risk Tolerance across the Life Span" (2014). Graduate Theses, Dissertations, and Problem Reports. 7326.

https://researchrepository.wvu.edu/etd/7326

This Dissertation is protected by copyright and/or related rights. It has been brought to you by the The Research Repository @ WVU with permission from the rights-holder(s). You are free to use this Dissertation in any way that is permitted by the copyright and related rights legislation that applies to your use. For other uses you must obtain permission from the rights-holder(s) directly, unless additional rights are indicated by a Creative Commons license in the record and/ or on the work itself. This Dissertation has been accepted for inclusion in WVU Graduate Theses, Dissertations, and Problem Reports collection by an authorized administrator of The Research Repository @ WVU.

For more information, please contact researchrepository@mail.wvu.edu. 
Gender and Financial Risk Tolerance across the Life Span

\author{
Philip Lemaster
}

Dissertation submitted to the Eberly College of Arts and Sciences at West Virginia University

in partial fulfillment of the requirements for the degree of Doctor of Philosophy in Psychology

\author{
JoNell Strough, Ph.D., Chair \\ Julie Hicks Patrick, Ph.D. \\ Barry Edelstein, Ph.D. \\ Miranda Reed, Ph.D. \\ Scott Fleming, Ph.D.
}

Department of Psychology

\author{
Morgantown, West Virginia \\ 2014
}

Keywords: Financial risk tolerance, gender, aging, life span Copyright 2014 Philip Lemaster 
UMI Number: 3618119

All rights reserved

INFORMATION TO ALL USERS

The quality of this reproduction is dependent upon the quality of the copy submitted.

In the unlikely event that the author did not send a complete manuscript and there are missing pages, these will be noted. Also, if material had to be removed, a note will indicate the deletion.

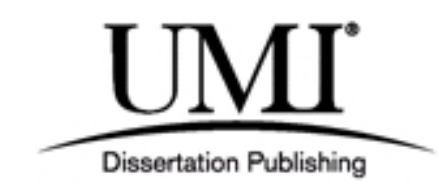

UMI 3618119

Published by ProQuest LLC (2014). Copyright in the Dissertation held by the Author.

Microform Edition () ProQuest LLC.

All rights reserved. This work is protected against unauthorized copying under Title 17, United States Code

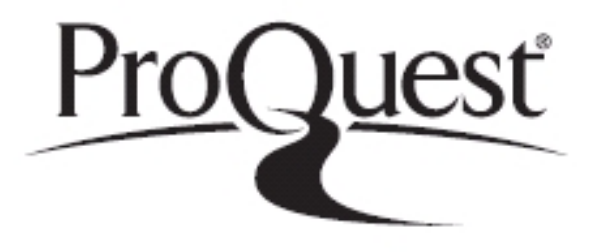

ProQuest LLC.

789 East Eisenhower Parkway

P.O. Box 1346

Ann Arbor, MI 48106 - 1346 


\section{ABSTRACT \\ Gender and Financial Risk Tolerance across the Life Span}

\section{Philip Lemaster}

Past research indicates that men tend to be more financially risk tolerant than women, and declines in self-reported risk tolerance are common with age. A life-span sample of adult men and women were recruited to investigate these gender- and age-related patterns using an ecologically valid measure of financial risk tolerance. As previously found, men reported greater risk tolerance than women, and risk tolerance declined with age. Biological mechanisms, such as testosterone, are often implicated in men's tendency to be more financially risk tolerant than women. In the present study, psychological gender mechanisms (i.e., masculine traits and roles, feminine traits, gender identification and typicality) were tested against a widely used biological measurement of testosterone, 2D:4D digit ratio. The biological measure was unrelated to risk tolerance, but psychological gender mechanisms were associated with risk tolerance. Masculinity (traits and roles) was associated with greater risk tolerance in men and women across the life span, but no gender mechanisms mediated the association between age and financial risk tolerance. Next, the associations between financial risk tolerance and future time perspective (i.e., focus on opportunities, focus on limitations) and the affect heuristic were tested. A greater focus on opportunities and less reliance on the affect heuristic (i.e., not viewing risk and benefits as inversely related) were associated with increased risk tolerance in men and women across the life span. Focus on opportunities fully mediated the association between age and financial risk tolerance. Implications of these findings and future directions are discussed. 


\section{Table of Contents}

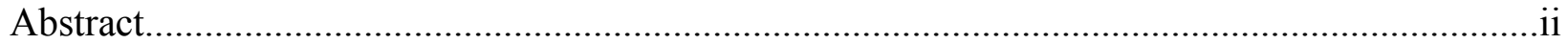

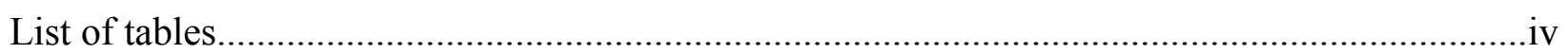

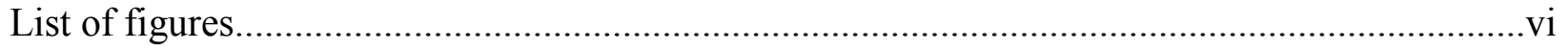

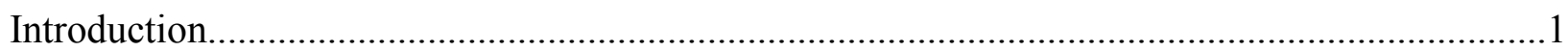

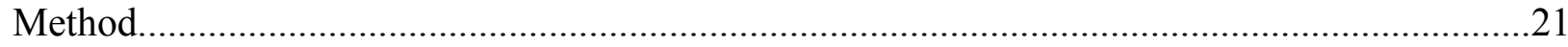

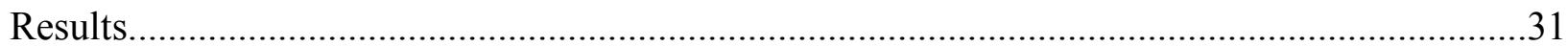

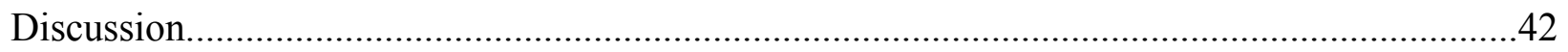

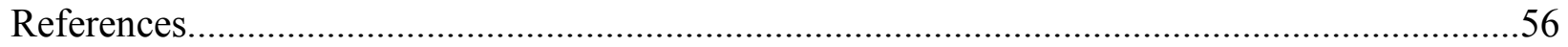

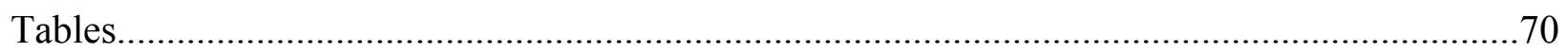

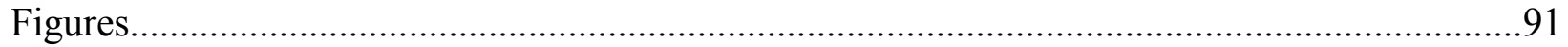

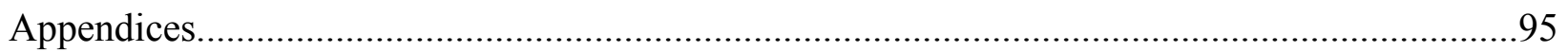




\section{List of Tables}

Table 1. MANOVA: Gender and age group main effects and interactions for variables of interest

Table 2. Main effects of gender on variables of interest

Table 3. Main effects of age group on variables of interest

Table 4. Gender by age group interactions for variables of interest

Table 5. Correlations for variables of interest: Overall sample

Table 6. Correlations for variables of interest by gender

Table 7. Correlations for variables of interest: Young adults

Table 8. Correlations for variables of interest: Middle-aged adults

Table 9. Correlations for variables of interest: Older adults

Table 10. Hierarchical linear regression of financial risk tolerance: Psychological gender mechanisms (full model)

Table 11. Hierarchical linear regression of financial risk tolerance: Psychological gender mechanisms (trimmed model)

Table 12. Hierarchical linear regression of financial risk tolerance: Psychological gender mechanisms with individually added masculine roles subscales

Table 13. Hierarchical linear regression of financial risk tolerance: Psychological gender mechanisms (trimmed model for men)

Table 14. Hierarchical linear regression of financial risk tolerance: Psychological gender mechanisms (trimmed model for women)

Table 15. Indirect effects of age on financial risk tolerance through psychological gender mechanisms 
Table 16. Hierarchical linear regression of financial risk tolerance: Future time perspective and the affect heuristic

Table 17. Indirect effects of age on financial risk tolerance through focus on opportunities, focus on limitations, and reliance on the affect heuristic 


\section{List of Figures}

Figure 1. A conceptual model of psychological gender mechanisms accounting for agerelated differences in financial risk tolerance

Figure 2. A conceptual model of future time perspective and the affect heuristic accounting for age-related differences in financial risk tolerance

Figure 3. The model of age and financial risk tolerance with psychological gender mechanisms

Figure 4. The model of age and financial risk tolerance with future time perspective and the affect heuristic 


\section{Introduction}

A vast literature has found gender differences in risky behaviors from a number of different domains, with men engaging in greater alcohol and drug use, risky sex, and risky driving (Byrnes, Miller, \& Schafer, 1999). Much research has also focused on financial risk taking and tolerance across the life span. Financial risk taking encompasses a range of behaviors with potential desirable and undesirable financial outcomes (Byrnes et al., 1999), including investing and gambling. Though the word "risk" has a negative connotation, financial risk taking may result in both negative (e.g., mounting debts) and positive outcomes (e.g., investment profits).

Research has generally supported the common belief that men are more risk tolerant and make riskier decisions about their money than women (Eckel \& Grossman, 2002; Martin, 1987; Siegrist, Cvetkovich, \& Gutscher, 2002). For example, women have been shown to make more conservative financial decisions in laboratory gambling tasks (Denburg et al., 2009; Overman, 2004; Overman, Frassrand, Ansel, Trawalter, Bies, \& Redmond, 2004; Van Leijenhorst, Westenberg, \& Crone, 2008), hypothetical investment scenarios (Ertac \& Gurdal, 2011; Garbarino, Slonim, \& Sydnor, 2011; Garrison \& Gutter, 2010; Levin, Snyder, \& Chapman, 1988; Powell \& Ansic, 1997), and real-world studies of investments (Almenberg \& Dreber, 2012; Bernasek \& Shwiff, 2001; Jianakoplos \& Bernasek, 1998; Meier-Pesti \& Penz, 2008). Similarly, life-span research suggests that financial risk tolerance declines across the life span in both men and women, with women less risk tolerant than same-aged men (Faff, Hallahan, \& McKenzie, 2011; Hallahan, Faff, \& McKenzie, 2003).

Despite this large body of literature, no comprehensive rationale exists to account for gender differences in financial risk tolerance across the life span. Researchers who have explored 
underlying mechanisms for gender differences have primarily done so outside the discipline of psychology, explaining gender differences through broad sociological mechanisms (e.g., gender income disparity; Bajtelsmit \& Bernasek, 1996; Hira \& Loibl, 2008), and more recently, as biological differences. This view of gender neglects the current psychological conceptualization of gender as a multifaceted construct composed of biological and psychological dimensions (Ashmore, 1990; Huston, 1983; Twenge, 1999). In the present study, biological and psychological factors related to gender and aging were examined in two models of financial risk tolerance with a life-span sample (see Figures 1 and 2). Primarily, this study aimed to understand how psychological dimensions of gender (e.g., stereotypically masculine and feminine traits), biological dimensions of gender (e.g., prenatal testosterone exposure), and other age- and gender-related variables (i.e., future time perspective and reliance on the affect heuristic) are associated with financial risk tolerance using an ecologically valid measure, the FinaMetrica Risk Tolerance Profile.

\section{A Brief Review of Gender and Financial Risk Tolerance across the Life Span}

Researchers have operationalized the construct in a number of ways, but financial risk tolerance has most commonly been assessed with standard laboratory tasks. For example, the Iowa Gambling Task (Bechara, Damasio, Damasio, \& Anderson, 1994) involves maximizing hypothetical winnings based on card draws from four decks, two of which are advantageous (i.e., gains are likely), and two of which are disadvantageous (i.e., losses are likely). Participants come to learn through their card draws which decks are "good" and which are "bad." Risk taking is operationalized as card draws from disadvantageous decks. Tasks such as the Iowa Gambling Task are deemed experiential because participants learn about risk through their card draws. Therefore, poorer performance on the task may indicate poorer learning about risk. 
Another procedure, the Cambridge Gambling Task (Rogers et al., 1999), involves maximizing hypothetical winnings by making safe or risky choices based on proportions of colored cards (or in its child-friendly analogue, colored cake slices; Van Leijenhorst et al., 2008). Participants also bet hypothetical money with their choice that they then win or lose based on the outcome of the draw. Risk taking on these tasks is operationalized as making a choice that is less likely to occur, though some have also studied how betting changes through the course of the procedure. In contrast to the experiential nature of the Iowa Gambling Task, the Cambridge Gambling Task has been called descriptive because information about probabilities and outcomes is embedded within the task and visible to participants.

Gender differences on the Iowa and Cambridge Gambling Tasks emerge during childhood and remain consistent during adolescence. Boys tend to make riskier choices than girls on the Cambridge Gambling Task (Van Leijenhorst et al., 2008), and girls exhibit greater risk aversion than boys on the Iowa Gambling Task (i.e., greater likelihood to switch decks after experiencing a loss; Cauffman et al., 2010; Hooper, Luciana, Conklin, \& Yarger, 2004; Van Duijvenvoorde et al., 2012). During adolescence, girls first come to exhibit riskier card draws on the Iowa Gambling Task (Overman et al., 2004), a gender difference also found in adulthood (Denburg et al., 2009; Overman, 2004). Because of its experiential nature, these Iowa results suggest that girls learn about and distinguish risk more poorly than boys beginning in adolescence. Compared to men, women's greater risk aversion and poorer learning about risk may reinforce their decreased levels of risk tolerance across the life span. Risk taking on both the Iowa and Cambridge Gambling Tasks increases in older adulthood, an age difference that has been attributed to normative cognitive decline in working memory, processing speed, and numeracy (Denburg et al., 2009; Fein, McGillivray, \& Finn, 2007; Henninger, Madden, \& 
Huettel, 2010; Mata, Josef, Samanez-Larkin, \& Hertwig, 2012; Peters, Västfjäll 1, Slovic, Mertz, Mazzocco, \& Dickert, 2006).

Across adulthood, researchers have also used other measures of financial risk tolerance, including risk tolerance questionnaires, hypothetical investment vignettes, and actual investment behavior. Such studies have yielded uniformly consistent results: men make riskier financial decisions, and women are less risk tolerant (Charness \& Gneezy, 2012; Dreber, Rand, Garcia, Wernerfelt, Lum, \& Zeckhauser, 2010; Ertac \& Gurdal, 2011; Faff et al., 2011; Garbarino et al., 2011; Garrison \& Gutter, 2010; Hallahan et al., 2003; Levin et al., 1988; Meier-Pesti \& Penz, 2008; Powell \& Ansic, 1997). Although older adults make riskier choices on the Iowa and Cambridge Gambling Tasks, willingness to take financial risks with their investment portfolios and on hypothetical questionnaires declines during adulthood (Finke \& Huston, 2003; Faff et al., 2011; Hallahan et al., 2003). Such a discrepancy between laboratory findings and actual behavior may be due to older adults' reluctance to put their wealth at risk as they approach retirement or live through their retirement years. Importantly, this disagreement highlights the need for ecologically valid measures of financial risk tolerance.

\section{Theoretical Framework}

Gender is a multifaceted psychological and social construct. That is, "maleness" or "femaleness" is composed of dimensions including stereotypical traits, identification with one's gender, and adherence to culturally prescribed roles for men and women (Ashmore, 1990; Huston, 1983; Twenge, 1999). According to social constructionist theory (Deaux \& Major, 1987), gender differences in these dimensions are due to men's and women's interactions in their immediate context (e.g., with whom they are interacting), differential socialization across the life 
span, and broad cultural roles and expectations. However, biological theorists suggest that men's and women's differences are driven by underlying biological mechanisms.

Although researchers have found gender differences in financial risk taking and risk tolerance across the life span, researchers have less frequently explored why such gender differences are found. In recent years, this question has been explored by scholars outside the discipline of psychology, namely, economics and finance. This work has largely focused on biological—rather than psychological—mechanisms. To explain gender differences in financial risk tolerance, research has focused on gender differences in frontal lobe activation (Bolla, Eldreth, Matochik, \& Cadet, 2004), dopamine (Dreber, Apicella, Eisenberg, Garcia, Zamore, Lum, \& Campbell, 2009; Dreber, Rand, Wernerfelt, Garcia, Vilar, Lum, \& Zeckhauser, 2011), and most predominantly, testosterone (Apicella, Dreber, Campbell, Gray, Hoffman, \& Little, 2008; Coates, Gurnell, \& Rustichini, 2009; Dreber \& Hoffman, 2007; Garbarino et al., 2011; Sapienza, Zingales, \& Maestripieri, 2009).

Biologically based research has produced conflicting findings. For example, researchers linked the DRD4 dopamine receptor gene to financial risk taking in a simulated investment among male college students and male bridge players, but this association was not found between the DRD4 dopamine receptor gene and actual investment behavior in the same population (Dreber et al., 2009; Dreber, Rand, Wernerfelt, Garcia, Lum, et al., 2011; Dreber, Rand, Wernerfelt, Garcia, Vilar et al., 2011). Similar conflicting results have been found in research linking testosterone to financial risk tolerance.

Despite mixed support in biological research, other explanations for gender differences (e.g., psychological differences) have been left relatively unexplored, and the multifaceted nature of gender (Ashmore, 1990; Huston, 1983; Twenge, 1999) has not been integrated into this 
literature. Following a social-constructionist line of thinking, men and women may be more similar than different depending on the immediate and broader contexts of development. This perspective stands in stark contrast to the essentialist differences that are sometimes implied by biologically based research. Over and above biological associations, psychological factors may also be related to financial risk tolerance across the life span. The present study will address this hypothesis.

\section{Gender and Age Differences in Financial Risk Tolerance: Why?}

Testosterone. Much of the literature on financial risk taking has left the underlying mechanisms of gender differences underexplored. Those researchers who have investigated this area have largely grounded their work in a biological perspective. That is, from this perspective, men and women have biological differences that facilitate risk decisions in men and inhibit risk decisions in women. The most widely studied biological mechanism, testosterone, is a hormone primarily produced in the male testes but also present in lower levels within females. The hormone precipitates an organizational effect in men with long-term outcomes during critical periods in prenatal development (e.g., sexual differentiation; Jost, Price, \& Edwards, 1970) and puberty (e.g., activation of reproductive behavior; Sisk \& Zehr, 2005). Much research has focused on testosterone's role in stereotypically masculine attributes and behaviors, including aggression (Archer, 2006), sensation seeking (Roberti, 2004), and dominance (Mazur \& Booth, 1998). Because testosterone is present in much higher levels within men and has been related to other stereotypically masculine traits and behaviors, researchers have hypothesized that the hormone could explain gender differences in financial risk tolerance.

Some researchers have approached the study of testosterone supposing that prenatal testosterone exposure predicts later risk tolerance. As a proxy for prenatal exposure, researchers 
have measured digit ratios (2D:4D; see Apicella et al., 2008 for a detailed procedure). In individuals with high prenatal testosterone exposure, the ratio of the second to fourth fingers is smaller. Therefore, it has been hypothesized that a small 2D:4D ratio may be associated with a greater preference for risk. This association between digit ratio and simulated investments using lottery scenarios has been established in a mixed-gender sample of Swedish Caucasians (Dreber \& Hoffman, 2007), a mixed-gender sample of college students (Garbarino et al., 2011), and male financial traders (Coates et al., 2009). Still, such results are not unanimous; no association between 2D:4D ratio and financial risk tolerance was found in a heterogeneous American sample (Dreber \& Hoffman, 2007), a male sample of American college students (Apicella et al., 2008), or a male sample of MBA students (Sapienza et al., 2009).

In addition to prenatal testosterone exposure, others have focused on pubertal testosterone exposure. The underlying premise for such research is the assumption that testosterone exposure during adolescence predisposes individuals toward greater risk tolerance across the life span (Apicella et al., 2008). Testosterone exposure during adolescence alters the shape of the face (Apicella et al., 2008), so researchers have used facial masculinization to retrospectively measure adolescent hormone exposure. In this procedure, flat-affect photographs are taken of participants' faces, then certain distances (e.g., cheekbone prominence; Little et al., 2008) are measured and used to create a composite facial masculinity score. This literature indicates that greater pubertal exposure to testosterone is associated with greater financial risk tolerance on an investment game (Apicella et al., 2008).

In the present study, 2D:4D digit ratios were measured to include a biological measure of prenatal testosterone exposure in a single model along with psychological gender mechanisms. This variable was included to permit further clarification of conflicting 2D:4D findings, but more 
importantly, to investigate how psychological dimensions of gender relate to financial risk tolerance over and above the effect of 2D:4D digit ratio (i.e., the effect of prenatal testosterone exposure). Due to logistical constraints, facial masculinization profiles were not collected for this study.

Stereotypically masculine and feminine traits. In addition to its biological foundations, gender is conceptualized as a psychological construct composed of dimensions such as stereotypically masculine, instrumental traits (e.g., independent, strong) and stereotypically feminine, communal traits (e.g., warm, affectionate). Because risk taking is viewed as a masculine trait in Western society (Wilson \& Daly, 1985), Meier-Pesti and Penz (2008) hypothesized that instrumental, masculine attributes are stronger correlates of financial risk tolerance than biological sex. Indeed, their findings confirmed this hypothesis; masculine traits (as measured by the Bem Sex Role Inventory; Bem, 1974) mediated the relation between biological sex and actual and hypothetical investment behaviors. That is, both men and women who more strongly endorsed masculine attributes exhibited greater financial risk tolerance, simulated risk-taking behavior on a hypothetical investment scenario, and real-world investment behavior. Feminine traits, however, were unrelated to risk tolerance and investment behavior. In a related study, trait dominance, a masculine attribute related to power and control, was found to be a better predictor than biological sex of risk tolerance on a hypothetical gambling task (Demaree, DeDonno, Burns, Feldman, \& Everhart, 2009). Masculine traits have also been linked to another form of financial risk: greater likelihood of evading taxes in a hypothetical lab study (Kastlunger, Dressler, Kirchler, Mittone, \& Voracek, 2010). A recent study synthesizing existing work tested how stereotypically masculine and feminine traits were associated with an ecologically valid measure of financial risk tolerance, the FinaMetrica Risk Tolerance Profile, 
among college students. This work revealed that among men and women, greater masculine, but not feminine traits, was associated with increased financial risk tolerance (Lemaster \& Strough, 2014).

Age differences. Endorsement of gendered traits may change with age or differ by historical cohort. Theorists have posited that a reduction in male hormones (e.g., testosterone) in adulthood may precipitate the development of a less masculine and aggressive, but more caring, personality (Gutmann, 1987; Henry, 1988). Therefore, some have suggested that men's endorsement of masculine traits and feminine traits may decline and rise, respectively, during adulthood. The hypothesized decline in men's masculine traits may be related to a similar decline in financial risk tolerance. However, the hypotheses derived from this theoretical work have only been partially supported by empirical findings. For example, researchers have found that men's endorsement of masculine traits remains stable across ages, but that older men endorse feminine traits to a greater degree than younger men (Strough, Leszczynski, Neely, Flinn, \& Margrett, 2007). Additionally, older women are less likely to endorse masculine traits than younger women (Strough et al., 2007).

Endorsement of masculine traits has previously been linked to financial risk tolerance (Meier-Pesti \& Penz, 2008). Lesser endorsement of masculine traits in older women may be linked to women's declines in risk tolerance in adulthood. Based on the work of Strough and colleagues (2007), it is not expected that men's expression of masculine traits will differ across ages in the present study. However, if men's endorsement of masculine traits remains stable across ages but financial risk tolerance declines, the association between men's endorsement of masculine traits and financial risk tolerance may weaken across the life span. In this study, the 
associations between masculine and feminine traits and financial risk tolerance will be examined across the life span in conjunction with other biological and psychological dimensions of gender.

Gender identification and typicality. The degree to which one identifies as male or female may also influence financial risk tolerance. Michaelieu (1997) described gender identification as reaching clarity of what it means to be male or female, connecting and identifying with that gender, and thinking that one's gender is valued by others and is a positive part of the self. Others, such as Egan and Perry (2001), have suggested that gender typicality, or the degree to which one feels like a typical example of one's gender group, is another component of gender identification. Men who strongly identify with other men are more likely to engage in stereotypically masculine behaviors (Lemaster, Strough, Stoiko, \& DiDonato, 2014), so men's greater gender identification may be related to increased risk tolerance as well. Conversely, women who less strongly identify with other women are more likely to engage in masculine behaviors (Lemaster et al., 2014), so women's decreased gender identification may be related to increased risk tolerance.

Although gender identification and typicality have not been studied directly in the financial risk tolerance literature, there is some indirect evidence that gender identification and typicality may be related to financial risk tolerance in another way: more highly male-identified men may be more susceptible to group threats. Some have stated that masculinity is a status that must be continually reaffirmed (Vandello, Bosson, Cohen, Burnaford, \& Weaver, 2008). Therefore, men are thought to monitor their masculinity, and when threatened, act in a hypermasculine way to reassert their masculinity. Risk behaviors are an especially effective method of reassertion because they are seen as masculine (Prentice \& Carranza, 2002) and are difficult to fake (Weaver, Vandello, \& Bosson, 2013). Therefore, taking risks may dispel perceived 
femininity or threats to one's masculinity. In one study, men who had their masculinity threatened by using a feminine hand lotion made riskier bets on a gambling task than men who had their masculinity affirmed by using a power drill (Weaver et al., 2013). In a related experiment, men who had their masculinity threatened in the same way (i.e., by using a feminine hand lotion) made more impulsive financial decisions, preferring smaller, immediate rewards over larger, distant gains (Weaver et al., 2013). In the present study, the associations between gender identification, typicality, and financial risk tolerance were tested in a single model with other biological and psychological dimensions of gender.

Age differences. Courtenay (2000) has posited that as men exit the workforce, vacate the breadwinner role, and spend more time in the domestic sphere, they may lose some of their collective identification with other men. If true, older men's weakened identification with their gender may directly relate to the decreased risky investment behavior observed in real-world studies.

As women age, they may also identify less with their gender group. In one study of middle-aged and older adult women, nearly $20 \%$ of participants stated that they felt as though their femininity had diminished or that they had only "passed" as feminine in earlier years (Huyck, 1994). Additionally, about 55\% of respondents believed they had become more masculine, either in their personality or in their behaviors and activities (Huyck, 1994). Following research by Lemaster and colleagues (2014) in younger women, identifying less with one's gender would be associated with traits and activities typical of the other gender. Therefore, it may be hypothesized that older women come to identify less with other women and then adopt more masculine traits and behaviors, perhaps even financial risk tolerance. However, this hypothesis does not align with current findings suggesting that older women make less risky 
financial decisions. Therefore, the associations of financial risk tolerance with gender identification and typicality among women may weaken with age. In this study, it was posited that gender identification and typicality would be less related to financial risk tolerance in older women than in younger and middle-aged women. These associations were investigated alongside other psychological and biological dimensions of gender.

Stereotypically masculine roles. Distinct from endorsing traits and identifying with a gender group is the embodiment of gender roles. Across the life span, men and women adopt social roles for their gender that guide how they behave (Eagly, 1987). The stereotypical masculine gender role casts men as risk takers and winners (Mahalik et al., 2003). However, these aspects of masculine roles are not limited exclusively to men. In fact, women may also adopt elements of a masculine role, but usually not to the same degree as men (Smiler, 2006). In a recent study of college students, greater embodiment of masculine roles among college men and women was associated with increased financial risk tolerance (Lemaster \& Strough, 2014). This association has not been studied in a life-span sample, and the present study addressed this gap in the literature.

Age differences. Similar to other dimensions of gender, age differences have been found in the adoption of stereotypically masculine roles. For example, one study found that young men and young women were more likely to endorse statements commensurate with the masculine roles of risk taker (e.g., “Taking dangerous risks helps me to prove myself”), winner (e.g., “In general, I will do anything to win"), aggressor (e.g., "I like fighting”), and status pursuer (e.g., "It feels good to be important") than their middle-aged and older adult counterparts. Men also embodied such roles to a greater degree than same-aged women across age groups (Smiler, 2006). Gender differences in the embodiment of stereotypically masculine roles may explain 
why men are relatively more risk tolerant than women. Similarly, lesser adoption of these roles in older adults may explain why they are less willing to make financial gambles in later life compared to younger adults. In the present study, the association between stereotypically masculine roles and financial risk tolerance were assessed alongside other psychological and biological dimensions of gender.

Future time perspective. As people age, the subjective sense of the time they have left becomes more limited (Carstensen, 2006). A limited future time perspective has been linked to other types of decisions, including being more likely to abandon situations that are no longer proving fruitful (e.g., stopping a movie that one no longer enjoys; Strough, Schlosnagle, Karns, Lemaster, \& Pichayayothin, 2014). Additionally, Jaggia and Thosar (2000) have noted that a lower "investment horizon," the time remaining before retirement, predicts decreased risk tolerance in real-world investments. The current study builds on this research to investigate how a limited time perspective about life in general relates to financial risk tolerance. Based on prior research, it was hypothesized that those with a more limited time perspective would be less risk tolerant.

Although research has repeatedly shown that men are more risk tolerant than women, there is some evidence to suggest that men have a more limited time perspective than women (Lemaster, Strough, Parker, Bruine de Bruin, Pichayayothin, \& Karns, 2012). If men have a more limited time perspective than women, and a more limited time perspective is associated with less risk tolerance, then one may conclude that men would be less risk tolerant than women. This association contrasts with the literature indicating that a limited time perspective predicts less risk tolerance. These relations will be examined in the current study. 
Reliance on the affect heuristic. Decision making is thought to be a result of dual processes: rational, deliberative thought and gist-based, affective thought rooted in intuition and experience (Hanoch, Wood, \& Rice, 2007; Peters \& Bruine de Bruin, 2012; Peters, Dieckmann, \& Weller, 2011; Peters, Hess, Västfjäll, \& Auman, 2007; Reyna, 2004; Reyna \& Brainerd, 2011). As people age, they may experience normative cognitive decline and accumulate experiences that allow them to make decisions in a more automated fashion (Strough, Parker, \& Bruine de Bruin, 2014). Thus, with age, people may become more likely to use gist-based processing and make decisions more as a result of their "gut feelings" and emotions (Reyna \& Brainerd, 2011).

Risk is intuitively perceived as uncertain and confusing (Slovic, 1986). Though risks and benefits are positively correlated in the real world, people tend to believe they are negatively correlated (Alhakami \& Slovic, 1994; Slovic, Finucane, Peters, \& MacGregor, 2002). That is, people are prone to believe that high-risk activities have little benefit, and that highly beneficial activities carry low risk, perhaps out of need for consistency in their judgments (Alhakami \& Slovic, 1994). When people rely on affect to guide their risk decisions, they are even more likely to believe in a negative risk-benefit association - this type of thinking has been deemed the affect heuristic. If older adults are more reliant on affective processing when making decisions, then it may be posited that with age, people are more likely to believe that risks and benefits are inversely correlated (risky activities have low benefits). Reliance on the affect heuristic, then, may explain age-related decreases in financial risk tolerance because older people may be more likely to believe that risky investments carry few benefits.

Stereotypically, women are thought to make more affectively based decisions than men, so gender may also be related to the affect heuristic. Women are typically raised from childhood 
to be more emotionally attuned to themselves and to others (Leaper \& Friedman, 2007;

Maccoby, 1998). Additionally, some have found that women are more intuitive decision makers than men (Sadler-Smith, 2011; Sinclair, Ashkanasy, \& Chattopadhay, 2010), though this finding has mixed support (Baiocco, Laghi, \& D’Alessio, 2009; Phillips, Pazienza, \& Ferrin, 1984). If reliance on the affect heuristic is related to financial risk tolerance, and women make more affectively based decisions, then the affect heuristic may lead women to be less risk tolerant compared to men. These relations will be tested in the current study.

\section{Individual-difference Control Variables}

Numeracy. To make complex financial decisions, people must make calculations and work with numbers. Declining cognitive abilities such as numeracy have been suggested as a cognitive basis for age-related decline in performance on laboratory tasks such as the Iowa and Cambridge Gambling Tasks (Mata et al., 2012). A survey measure of risk tolerance, rather than a laboratory risk task, was used in the present study, but numeracy was still measured and used as a control variable in the proposed analyses.

Education and income. Willingness to take financial risks is related to education and income (Bajtelsmit \& Bernasek, 1996). For example, investing is impossible if a lower education leads to paycheck-to-paycheck employment. Because women generally make less money than men (England, 2010; Renzetti, Curran, \& Maier, 2012), income has been noted as a significant factor relating to women's lesser likelihood to take financial risks (Bajtelsmit \& Bernasek, 1996). Because the focus of this project is on psychological aspects of gender, not gender differences in personal income and education, these variables were measured and controlled for in the proposed analyses.

\section{Statement of the Problem}


A large body of research has documented gender differences in financial risk tolerance.

Few have sought to explain these differences, but most of this research has focused on biological mechanisms. Psychological mechanisms have been relatively unexplored, though some have considered psychological measures of gender (e.g., Bex Sex Role Inventory) and concluded that masculine traits (Demaree et al., 2009; Kastlunger et al., 2010; Meier-Pesti \& Penz, 2008) are significantly associated with financial risk tolerance. Still, gender has not been considered as a multifaceted construct in this literature. The purpose of the proposed study was to examine the associations of biological (i.e., 2D:4D digit ratio) and psychological dimensions of gender (i.e., gender identification and typicality, endorsement of gender-typed traits, adherence to masculine roles) with financial risk tolerance in a single model (Figure 1). Additionally, future time perspective and the affect heuristic are related to decision making, aging, and (potentially) gender. However, such constructs have not yet been examined in the financial risk tolerance literature. These variables were also included in a model of age and risk tolerance (Figure 2).

\section{Research Questions and Hypotheses}

Research Question 1. Are biological and psychological dimensions of gender associated with financial risk tolerance?

Hypothesis 1a. After accounting for psychological dimensions of gender (i.e., stereotypically masculine and feminine traits, gender identification, adherence to stereotypically masculine roles), 2D:4D digit ratio will not be related to financial risk tolerance.

Rationale. The link between 2D:4D digit ratios and financial risk tolerance has mixed support in published literature (Apicella et al., 2008; Coates et al., 2009; Dreber \& Hoffman, 2007; Garbarino et al., 2011; Sapienza et al., 2009). Additionally, others have identified links between psychological dimensions of gender (i.e., stereotypically masculine traits; Demaree et 
al., 2009; Kastlunger et al., 2010; Meier-Pesti \& Penz, 2008) and financial risk tolerance. It may be expected that after accounting for psychological aspects of gender, 2D:4D digit ratios will not be associated with financial risk tolerance.

Hypothesis 1b. After accounting for psychological dimensions of gender (i.e., stereotypically feminine traits, gender identification, adherence to stereotypically masculine roles) and biological factors (i.e., 2D:4D digit ratio), stereotypically masculine traits will be positively associated with financial risk tolerance. The association between stereotypically masculine traits and financial risk tolerance was expected to be less strong among older adult men than in younger and middle-aged adult men. Thus, moderation of risk tolerance by gender and age group was investigated.

Rationale. Masculine traits have already been identified as correlates of financial risk tolerance (Demaree et al., 2009; Kastlunger et al., 2010; Meier-Pesti \& Penz, 2008); this finding was expected to replicate in the current study. Age and gender may moderate these associations. Older adult men endorse masculine traits as strongly as younger and middle-aged men (Strough et al., 2007), yet are less financially risk tolerant. Therefore, the association between masculine traits and financial risk tolerance may become weaker with age. In contrast, older adult women are less financially risk tolerant and endorse masculine traits less strongly than younger women. Thus, women who are less financially risk tolerant are also less likely to endorse masculine traits, and women who are more financially risk tolerant are more likely to endorse masculine traits. The association between masculine traits and financial decisions may be similar in women across ages.

Hypothesis 1c. After accounting for psychological dimensions of gender (i.e., stereotypically masculine traits, gender identification, stereotypically masculine roles) and 
biological factors (i.e., 2D:4D digit ratio), stereotypically feminine traits will be unrelated to financial risk tolerance across the life span.

Rationale. Previous research suggests that feminine traits are not related to financial risk tolerance (Lemaster \& Strough, 2014; Meier-Pesti \& Penz, 2008).

Hypothesis 1d. Men's greater gender identification and typicality may be related to more masculine attributes and behaviors (Lemaster et al., 2014), including risk tolerance. Conversely, lower gender identification and typicality in women may be associated with more masculine attributes and behaviors (Lemaster et al., 2014) such as risk tolerance. After accounting for other psychological dimensions of gender (i.e., stereotypically masculine and feminine traits, stereotypically masculine roles) and biological factors (i.e., 2D:4D digit ratio), gender identification and typicality will be positively related to financial risk tolerance in men and negatively related to financial risk tolerance in women across the life span. The associations of gender identification and typicality with risk tolerance are expected to be less strong in older women than in younger and middle-aged women. Thus, moderation of financial risk tolerance by gender and age group was examined.

Rationale. Research indicates that greater gender identification in men is related to greater engagement in masculine behaviors (Lemaster et al., 2014). Because risk taking is considered a masculine behavior (Eckel \& Grossman, 2002; Martin, 1987; Siegrist et al., 2002), it is hypothesized that men with greater gender identification and typicality will also be more financially risk tolerant. Men are thought to identify with their gender less as they age (Cortenay, 2000), just as they tend to become less financially risk tolerant (Finke \& Huston, 2003; Faff et al., 2011; Hallahan et al., 2003). Therefore, the associations of gender identification and gender 
typicality with financial risk tolerance among men were expected to be similar across the life span.

Women are thought to identify with their gender less as they age (Huyck, 1994). Lesser gender identification in women is associated with more masculine attributes and behaviors (Lemaster et al., 2014), so such women may exhibit greater risk tolerance. However, older women are known to report less risk tolerance with age. Therefore, the association between gender identification and financial risk tolerant may become weaker with age.

Hypothesis 1e. After accounting for other psychological dimensions of gender (i.e., stereotypically masculine and feminine traits, gender identification) and biological factors (i.e., 2D:4D digit ratio), adherence to stereotypically masculine roles will be positively related to financial risk tolerance in men and women across the life span.

Rationale. The traditional masculine role casts men as winners and risk takers (Mahalik et al., 2003), so endorsement of these masculine roles may be positively related to financial risk tolerance. Although men adhere to stereotypically masculine roles more than women across the life span, women may also endorse these roles to an extent, usually less so than men (Smiler, 2006). Adherence to masculine roles declines across the life span for both men and women (Smiler, 2006), mirroring the age and sex differences in financial risk tolerance. Therefore, the relation between adherence to masculine roles and financial risk tolerance may be similar for men and women across the life span. Previous research on college students has also shown a positive correlation between endorsement of masculine roles and financial risk tolerance (Lemaster \& Strough, 2014).

Research Question 2. How do future time perspective and reliance on the affect heuristic predict financial risk tolerance across the life span? 
Hypothesis 2a. More limited future time perspective will be related to less financial risk tolerance across the life span.

Rationale. Younger adults have a more expansive time perspective (Carstensen, 2006) and are more risk tolerant. Conversely, older adults have a more limited time perspective (Carstensen, 2006), and are less risk tolerant (Finke \& Huston, 2003; Faff et al., 2011; Hallahan et al., 2003). Therefore, limited time perspective may be related to less financial risk tolerance. Others have suggested that as retirement approaches (i.e., the "investment horizon" declines), people are more hesitant to invest their money in risky assets (Jaggia and Thosar, 2000).

Hypothesis 2b. Greater reliance on the affect heuristic will be related to less financial risk tolerance across the life span.

Rationale. People perceive risk as uncertain and confusing (Slovic, 1986). With age, people may use more affective processes in making decisions, so these negative perceptions of risks and benefits may result in age-related decreases in financial risk tolerance.

\section{Additional Exploratory Analyses}

In addition to formal research questions and hypotheses, other exploratory analyses were proposed. First, models of psychological gender mechanisms (Figure 1) and of future time perspective and the affect heuristic (Figure 2) were tested to determine how these variables may mediate the association between age and financial risk tolerance. Particularly, future time perspective becomes more limited with age (Carstensen, 2006), and reliance on the affect heuristic is thought to increase with age. Thus, future time perspective and reliance on the affect heuristic may mediate the association between age and financial risk tolerance. Theoretical work has suggested that psychological gender mechanisms differ with age, so stereotypically masculine and feminine traits, gender identification and typicality, and stereotypically masculine 
roles were also investigated as mediators of the association between age and financial risk tolerance. Assuming that these models fit well, these models were also tested for moderation by gender, age group, and gender by age group.

\section{Method}

\section{Participants}

Method of recruitment. Participants were recruited from Amazon’s Mechanical Turk program. An IP address restriction was imposed, so only people living within the United States could view the study. A series of HITs (i.e., human intelligence tasks) were advertised for young adults aged 25-39, middle-aged adults aged 40-59, and older adults aged 60 and over. After completing the HIT, participants entered a unique code and received $\$ 1.50$ for their participation within 48 hours of completion. All data were collected between September and November 2013.

Use of Mechanical Turk. Amazon's Mechanical Turk has grown from a crowdsourcing tool for the completion of menial tasks into a hub for recruiting participants for behavioral and social science research (Goodman, Cryder, \& Cheema, 2013). Benefits include a large, diverse participant pool, relatively inexpensive compensation compared to traditional data collection methods, and rapid collection of data (Buhrmester, Kwang, \& Gosling, 2011; Mason \& Suri, 2012). Some have questioned the validity of data collected using this website, but comparisons of data collected through Mechanical Turk and through traditional methods suggest that data collected through the site are at least as reliable and valid as other methods (Buhrmester et al., 2011; Goodman et al., 2013; Mason \& Suri, 2012; Paolacci, Changler, \& Ipeirotis, 2010).

Following recommendations by Goodman and colleagues (2013), numerous trap questions were inserted throughout the study to gauge participants' attention. 
Exclusion criteria. Before beginning the study, participants affirmed that they did not meet any predetermined exclusionary criteria. Criteria included having arthritis (due to potential issues with measuring 2D:4D) and taking L-DOPA, Adderall, cocaine, amphetamines, or other stimulants (due to potential confounds with the risk tolerance measure).

A total of 722 individuals participated in the study, but not all were included in data analysis. To be included, participants must have completed the survey (excluding 92 participants), entered a valid age that matched their given birth year and subsequent requests for their age (excluding an additional eight participants), consistently entered their gender (excluding one additional participant), been at least 25 years old (excluding an additional two participants), and passed at least five of seven trap questions (excluding an additional 13 participants). Participants who were excluded did not differ from those included by gender $\left(\chi^{2}(1)=2.34, p=\right.$ $.132)$ or in age $(F(1,686)=.06, p=.806)$, income $(F(1,686)=.13, p=.715)$, or education $(F(1$, $686)=.16, p=.686)$.

Next, multivariate outliers were identified. A linear regression was computed with a random number as the outcome variable, and the variables of interest as predictor variables: age, financial risk tolerance, masculine traits, feminine traits, masculine roles, gender identification, gender typicality, left 2D:4D ratio, right 2D:4D ratio, focus on opportunities, focus on limitations, reliance on the affect heuristic, and numeracy. Using a chi-square table, the Mahalanobis distance value cutoff was determined to be 34.53 (13 degrees of freedom for each variable in the model, $p=.001)$. Participants who were identified as multivariate outliers were additionally excluded from analysis, removing an additional 22 participants from the sample. Those excluded multivariate outliers did not differ from included participants by gender $\left(\chi^{2}(1)=\right.$ 
$.064, \mathrm{p}=1.00)$ or in age $(F(1,605)=.03, p=.865)$, income $(F(1,605)=1.48, p=.224)$, or education $(F(1,605)=2.89, p=.090)$.

Final sample. A total of 584 participants were included in data analysis. The sample was composed of slightly more women $(n=313,53.6 \%)$ than men $(n=271,46.4 \%)$. Participants ranged in age from $25-89$, with a mean age of $47.38(S D=14.05)$. Though age was measured continuously, age group divisions were imposed for recruitment purposes; young adults were defined as between 25-39 years old, middle-aged adults as between 40-59 years old, and older adults as at least 60 years old. In the final sample, there were 94 young men $(16.1 \%$; $M$ age $=$ 31.31, $S D=4.16), 106$ young women $(18.15 \% ; M$ age $=31.48, S D=4.14), 81$ middle-aged men $(13.87 \% ; M=46.88, S D=5.44), 124$ middle-aged women $(21.23 \% ; M$ age $=48.96, S D=5.54)$ 96 older men $(16.44 \% ; M$ age $=64.11, S D=3.03)$, and 83 older women $(14.21 \%$; $M$ age $=$ 64.67, $S D=4.34)$

A large majority of the sample was Caucasian $(n=523,89.6 \%)$, though $3.9 \%$ were African American $(n=23), 2.7 \%$ were Asian $(n=16), 2.1 \%$ were bi- or multiracial $(n=12)$, $0.7 \%$ were American Indian $(n=4)$, and $0.3 \%$ were Hawaiian/Pacific Islander. Four participants $(0.7 \%)$ indicated an "other" race. A majority of participants were married $(n=305,52.2 \%)$, but $27.1 \%$ were single $(n=158), 16.1 \%$ were divorced $(n=94)$, and $4.6 \%$ were widowed $(n=27)$.

Participants came from a range of educational backgrounds, with $0.9 \%$ not completing high school $(n=5), 13.9 \%$ completing high school or receiving a GED $(n=81), 22.9 \%$ completing some college $(n=134), 13.0 \%$ receiving an associate's or vocational degree $(n=76)$, $30.5 \%$ receiving a bachelor's degree $(n=178), 14.4 \%$ receiving a master's degree $(n=84)$, and $4.5 \%$ receiving a doctoral or professional degree $(n=26)$. 
About half of participants were employed part-time $(n=287,49.1 \%)$, but $16.1 \%$ were partially retired (i.e., retired but working part-time; $n=94), 14.0 \%$ were unemployed $(n=82)$, $5.7 \%$ were employed full-time $(n=33)$, and $5.5 \%$ were fully retired $(n=32)$. Several participants indicated an "other" employment status $(n=56,9.6 \%)$. Participants reported a range of income levels; $12.2 \%$ reported earning less than $\$ 10,000$ per year $(n=71) ; 17.0 \%$ between $\$ 10,000-\$ 19,999(n=99) ; 16.1 \%$ between $\$ 20,000-\$ 29,999(n=94) ; 13.9 \%$ between $\$ 30,000$ $\$ 39,999(n=81) ; 10.3 \%$ between $\$ 40,000-\$ 49,999(n=60) ; 8.9 \%$ between $\$ 50,000-\$ 59,999(n$ $=52) ; 6.5 \%$ between $\$ 60,000-\$ 69,999(n=38)$; and $14.2 \%$ over $\$ 70,000(n=83)$. A few participants did not know their income $(n=6,1.0 \%)$.

\section{Procedure}

Participants signed up for the study via Mechanical Turk and were redirected to Survey Monkey to complete all measures. Once finished, participants were given a unique code to enter in the Mechanical Turk HIT to indicate completion of the study. Measures were randomly ordered by the researcher and presented to participants in the order that follows below.

\section{Measures}

Demographic information. Participants first entered basic information about themselves, including their gender, age, birth year, race and ethnicity, highest level of education, marital status, and employment status (Appendix A). Income and education were used as control variables for financial risk tolerance. Income was measured on a scale from 1 (earning less than $\$ 10,000$ per year) to 8 (earning greater than $\$ 70,000$ per year), with evenly spaced $\$ 10,000$ intervals between. The mean income score was $4.18(S D=2.30$, range $=1-8)$, indicating that participants, on average, earned approximately $\$ 40,000$ per year. This figure is lower than the reported 2012 U.S. median income of \$51,017 (DeNavas-Walt, Proctor, \& Smith, 2013). 
Education was measured in a similar fashion on a scale from 1 (not completing high school) to 7 (doctoral or professional degree). The mean education score was $4.19(S D=1.45$, range $=1-7)$, indicating that participants had an approximate average education of an associate's degree, which is slightly higher than the average high-school level education attained in the U.S. (United Status Census Bureau, 2013).

Financial risk tolerance. Many studies have used standard laboratory tasks to assess financial risk taking. However, in an effort to measure the construct in a more ecologically valid way, the FinaMetrica Risk Tolerance Profile (Bright \& Adams, 2000; Appendix B) was used. This questionnaire was derived from Roszkowski's (1992) Survey of Financial Risk Tolerance (SOFRT). The SOFRT, a widely used measure (for recent uses, see Roszkowski, Delaney, \& Cordell, 2009; Roszkowski \& Grable, 2005; Roszkowski \& Grable, 2010) is quite long, so the FinaMetrica Risk Tolerance Profile was created to be a shorter, less burdensome measure. The FinaMetrica measure is primarily used as a diagnostic tool by personal financial planners to determine their clients' risk tolerance and has been validated on a large life-span sample (see Bright \& Adams, 2000 for specific details of validation, psychometric properties, and a list of survey items). Results of the survey are often used to classify people into risk tolerance groups, from extremely risk avoidant to extremely risk seeking, to clarify what types of risks they may be most comfortable with. Scores on the FinaMetrica Risk Tolerance Profile are related to increased risk taking on laboratory risk tasks (Faff, Mulino, \& Chai, 2008; Guillemette, Finke, \& Gilliam, 2012), and similar self-report risk tolerance measures have been associated with riskier investments (Corter \& Chen, 2006; Gilliam, Chatterjee, \& Grable, 2010).

The scale is composed of 25 items on varying scales that ask questions about participants' subjective views of risk tolerance, hypothetical financial vignettes, and preferences 
for degrees of risk (e.g., "What degree of risk are you currently prepared to take with your financial decisions?"; 1 = very small, 5 = very large). Because items are measured on different scales, all individual items were first standardized. These standardized scores were then used to create a mean financial risk tolerance score $(M=.00, S D=.50$, range $=1.23-1.84)$. The scale was found to be internally consistent $(\alpha=.88)$. Higher scores indicated a greater tolerance for financial risk.

Future time perspective. To measure future time perspective, Carstensen and Lang's (1996) Future Time Perspective Scale was used (with two additional items added by Cate \& John, 2007, and Lemaster et al., 2012b; Appendix C). This 12-item measure is composed of two subscales (Cate \& John, 2007; Lemaster et al., 2012b) that assess participants' views of future opportunities (e.g., "Many opportunities await me in the future") and limitations (e.g., "I feel the importance of time passing"). Items were presented on a 1 (very untrue) to 7 (very true) scale. A "focus on opportunities" score was computed using the mean of the eight opportunities subscale items $(M=4.67, S D=1.42$, range $=1.00-7.00)$. Likewise, a "focus on limitations" score was computed using the mean of the four limitations subscale items $(M=4.51, S D=1.44$, range $=$ 1.00-7.00). Higher scores indicated a greater focus on future opportunities and limitations, respectively. Both focus on opportunities $(\alpha=.94)$ and limitations $(\alpha=.86)$ subscales were internally consistent

Stereotypically masculine and feminine traits. To replicate Meier-Pesti and Penz's (2008) findings that instrumental, masculine traits, but not communal, feminine traits, predict financial risk tolerance, the Bem Sex Role Inventory (Bem, 1974; Appendix D) was used to assess stereotypically masculine and feminine traits. Since its inception in the 1970s, a number of critiques have been leveled against the Bem Sex Role Inventory. Much of this criticism has 
centered on the scale's validity as a measure of masculinity and femininity; its use in populations beyond college students, with whom the scale was originally used; and its questionable utility as a classifying device, labeling people as "masculine," "feminine," and "androgynous" (Hoffman \& Borders, 2001). Still, this questionnaire is the most widely used measure within gender research (Hoffman \& Borders, 2001). Despite its critics, the scale was included in the present study because it has been used in past research on gender and financial risk tolerance (i.e., Meier-Pesti \& Penz, 2008), and one purpose of this study was to replicate these findings in an ecologically valid measure of risk tolerance.

This scale is composed of 60 items total: 20 stereotypically masculine items (e.g., "Is this like you: aggressive?"), 20 stereotypically feminine items (e.g., "Is this like you: sensitive to the needs of others?"), and 20 neutral items (e.g., "Is this like you: friendly?"). Each item was rated on a 1 (never or almost never true) to 7 (almost always true) scale. A mean masculine traits score was computed using the 20 masculine items $(M=4.47, S D=.87$, range $=1.95-7.00)$. Likewise, a mean feminine traits score was computed using the 20 feminine items $(M=4.59, S D$ $=.80$, range $=1.10-6.65)$. Higher scores indicated a greater endorsement of stereotypically masculine or feminine traits, respectively. Both masculine $(\alpha=.89)$ and feminine traits $(\alpha=.87)$ subscales were internally consistent.

Affect heuristic. Risks and benefits are positively correlated, yet people often perceive risks and benefits as inversely related (Alhakami \& Slovic, 1994). That is, people perceive highrisk activities as less beneficial, and low-risk activities as more beneficial. Known as the affect heuristic, this type of thinking has been deemed an automatic, intuitive process. With age, people may become more likely to use affective processing and make decisions more as a result of their "gut feelings" and emotions (Reyna \& Brainerd, 2011). Greater reliance on this automatic 
process with age may exaggerate the perceived negative correlation between risks and benefits and encourage aversion toward risk. To assess the affect heuristic, a measure developed by Alhakami and Slovic (1994) was used (Appendix E). Composed of 33 "risky” hazards (e.g., cigarette smoking, alcohol, nuclear power), participants were asked to rate the risk $(1=$ not at all risky, $7=$ very risky) and benefit levels $(1=$ not at all beneficial, $7=$ very beneficial $)$ of each. To compute an affect heuristic score, Alhakami and Slovic's (1994) distance scoring protocol was used. That is, first the "distance" between perceived risk and benefit was calculated for each item (i.e., the absolute value of perceived risk minus perceived benefit). Next, the average distance was computed using the mean of all 33 item distances to create an affect heuristic score $(M=$ $2.67, S D=.90$, range $=.00-5.58)$. Thus, a greater affect heuristic score indicated that participants viewed risks and benefits as inversely related, and a smaller affect heuristic score indicated that participants viewed risks and benefits similarly. The scale was found to be internally reliable ( $\alpha$ $=.91)$.

Stereotypically masculine roles. To assess adherence to stereotypically masculine roles, Mahalik et al.'s (2003) Conformity to Masculine Norms Index was used (Appendix F). This 94item scale measures how much participants embody 11 different stereotypically masculine roles, including winning (e.g., "In general, I will do anything to win”), emotional control (e.g., "I tend to share my feelings" [reverse scored]), risk taking (e.g., "Taking dangerous risks helps me to prove myself"), violence (e.g., "I am willing to get into a physical fight if necessary"), power over women (e.g., “Women should be subservient to men”), dominance (e.g., “I make sure people do as they say"), playboy (e.g., "Emotional involvement should be avoided when having sex"), self-reliance (e.g., "It bothers me when I have to ask for help"), primacy of work (e.g., "I am often absorbed in my work"), disdain for homosexuality (e.g., "I would be furious if someone 
thought I was gay"), and pursuit of status (e.g., "It feels good to be important"). Each item was rated on a 1 (strongly disagree) to 4 (strongly agree) scale. A mean masculine roles score was computed using the mean of all 94 items $(M=2.22, S D=.30$, range $=1.40-3.44)$, with higher scores indicated greater adherence to stereotypically masculine roles. The scale was found to be internally reliable $(\alpha=.94)$. Mean subscale scores were also computed: winning $(M=2.27, S D=$ .52$, range $=1.00-4.00, \alpha=.87)$, emotional control $(M=2.43, S D=.58$, range $=1.00-4.00, \alpha=$ $.93)$, risk taking $(M=2.16, S D=.58$, range $=1.00-3.70, \alpha=.89)$, violence $(M=2.18, S D=.56$, range $=1.00-3.75, \alpha=.76)$, power over women $(M=1.88, S D=.48$, range $=1.00-3.78, \alpha=.84)$, dominance $(M=2.28, S D=.55$, range $=1.00-3.75, \alpha=.76)$, playboy $(M=1.90, S D=.59$, range $=1.00-3.75, \alpha=.92)$, self-reliance $(M=2.34, S D=.55$, range $=1.00-4.00, \alpha=.84)$, primacy of work $(M=2.29, S D=.47$, range $=1.00-3.75, \alpha=.77)$, disdain for homosexuality $(M=2.35, S D$ $=.67$, range $=1.00-4.00, \alpha=.92)$, pursuit of status $(M=2.56, S D=.49$, range $=1.00-4.00, \alpha=$ .77).

Gender identification. To measure participants' identification with their gender, Michaelieu's 13-item gender identification scale (Appendix G) was used. This questionnaire assesses gender-group salience (e.g., "Being a female/male is an important reflection of who I am”), public gender positivity (e.g., "Overall, females/males as a group are considered to be good by other people"), and own-/other-gender identity (e.g., "Usually I identify with females/males more than males/females"). All items were scaled from 1 (strongly disagree) to 5 (strongly agree), and wording was gender-specific for all participants. A gender identification score was computed using the mean of all 13 items $(M=3.61, S D=.54$, range $=2.00-5.00)$; higher scores indicated greater identification with one's gender. Sufficient internal consistency was found $(\alpha=.76)$. 
Gender typicality. Similar to gender identification, gender typicality was assessed using Egan and Perry's (2001) six-item Gender Typicality Scale (Appendix H). This questionnaire measures how much participants feel they are typical examples of their gender. The scale has traditionally been administered in children, but was adapted for adults in this study by changing child-specific "boys"/"girls" item wording to "men"/“women." Sample items included "I feel like I fit in with other men/women"). Items were measured on a 1 (very untrue for me) to 4 (very true for me) scale, and gender-specific wording was used. The scale exhibited internal consistency $(\alpha=.88)$. A gender typicality score was computed using the mean of all six items $(M$ $=2.85 ., S D=.61$, range $=1.00-4.00)$. Higher scores indicated that participants perceived themselves to be more typical members of their gender group.

Egan and Perry (2001) originally designed their scale to be scored in a different way. In the original scale, participants were presented with an item such as "Some boys/girls don't feel they fit in with other boys/girls BUT other boys/girls do feel they fit in with other boys/girls..." First participants chose which of the two statements was most like them, then they indicated whether that chosen statement was very true or sort of true for them. To simplify the scale for use in the present study, participants were given the statement "Ifeel like I fit in with other men/women" and were asked to indicate whether than statement was very untrue, sort of untrue, sort of true, or very true for them.

Numeracy. Numeracy was measured as a control for all analyses. To assess this construct, the Berlin Numeracy Test (Cokely, Galesic, Schulz, Ghazal, \& Garcia-Retamero, 2012; Appendix I) was used. This four-item questionnaire measures mathematical ability with word problems (i.e., "Imagine you are throwing a five-sided die 50 times. On average, out of these 50 throws, how many times would this five-sided die show an odd number?"). Participants 
were instructed to complete the problems without the aid of a calculator. Each item was scored as correct or incorrect, and a sum numeracy score was computed based on the total of correct items $(M=1.15, S D=1.21$, range $=0-4)$. Higher scores indicated greater numeracy.

Digit ratio. As a proxy for prenatal testosterone exposure, participants measured the length of their second (i.e., index) and fourth (i.e., ring) fingers on their left and right hands. Participants measured their own fingers in millimeters with either a ruler they had on hand or a ruler presented on screen within the survey. Detailed instructions were provided (Appendix J). As per Apicella et al. (2008), participants were asked to measure from the center of the flexion crease between palm and finger to the tip of their digit. A left 2D:4D digit ratio was computed using the ratio of the second and fourth digits on the left hand $(M=1.03, S D=.12$, range $=.57$ 1.50). The same procedure was used to compute the right $2 \mathrm{D}: 4 \mathrm{D}$ ratio with the second and fourth digits on the right hand $(M=1.03, S D=.10$, range $=.71-1.46)$. Because it has been assumed that right 2D:4D ratio is more highly related to prenatal testosterone exposure (Manning et al., 2002), the left 2D:4D ratio was excluded from analysis.

\section{Results}

\section{Power}

To calculate an appropriate sample size, guidelines advocated by Bentler and Chou (1987) were followed: five participants per each freely estimated path. In the larger model to be tested (Figure 1), there were 19 freely estimated paths (including covariances), so a minimum of 95 participants was needed. To test for multi-group differences between younger men and women, middle-aged men and women, and older men and women, a six-fold sample size of 570 or more was needed. The final sample of 584 exceeded this minimum.

\section{Missing Data}


To be included in the study, participants must have completed all measures. Participants who did not meet this criterion were excluded. There were no missing data in the final sample used in analyses.

\section{Preliminary Analyses}

Descriptive statistics. First, descriptive statistics were computed for all variables of interest: financial risk tolerance, stereotypically masculine traits, stereotypically feminine traits, stereotypically masculine roles, gender identification, gender typicality, left 2D:4D, right 2D:4D, focus on opportunities, focus on limitations, reliance on the affect heuristic, numeracy, income, and education. Table 2 contains descriptive statistics for the overall sample and for men and women separately; Table 3 includes descriptive statistics separated by younger adults (i.e., age 25-39), middle-aged adults (i.e., age 40-59), and older adults (i.e., age 60 or older); and Table 4 contains descriptive statistics separated by younger men, younger women, middle-aged men, middle-aged women, older men, and older women.

Skewness. Next, skewness was examined in all variables of interest. Stereotypically feminine traits, gender typicality, and focus on opportunities were negatively skewed, and left 2D:4D, right 2D:4D, numeracy, and income were positively skewed. These variables were transformed logarithmically. Because results were identical using raw, untransformed scores to those using transformed values, results using untransformed scores were reported throughout.

Correlations. For exploratory purposes, correlations of all variables of interest were computed for the entire sample (see Table 5), for men and women separately (see Table 6), for young men and young women separately (see Table 7), for middle-aged men and women separately (see Table 8), and for older men and women separately (see Table 9). 
MANOVA. As an exploratory analysis, gender and age group differences were examined for all variables. To examine the main effects of gender and age group (i.e., younger, middleaged, and older adults) and the interaction of gender and age group on all variables of interest, a MANOVA was computed (see Table 1). Gender and age group were independent variables, and financial risk tolerance, stereotypically masculine traits, stereotypically feminine traits, stereotypically masculine roles, gender identification, gender typicality, left 2D:4D, right 2D:4D, focus on opportunities, focus on limitations, reliance on the affect heuristic, numeracy, income, and education were dependent variables. There were significant multivariate main effects of gender and age group, but no multivariate interaction of gender and age group was identified.

ANOVA. As an exploratory analysis, the univariate main effects of gender (see Table 2) and age group (see Table 3) were examined. Men significantly reported more of the following: financial risk tolerance, endorsement of stereotypically masculine traits, adherence to stereotypically masculine roles, gender typicality, numeracy, and income. Women significantly reported greater endorsement of stereotypically feminine traits and reliance on the affect heuristic. No gender differences were found in gender identification, left 2D:4D, right 2D:4D, focus on opportunities, focus on limitations, or education. These statistics are reported in Table 2.

There were significant univariate main effects of age on financial risk tolerance, gender typicality, focus on opportunities, and focus on limitations. Young adults reported significantly greater financial risk tolerance than older adults, though younger and middle-aged adults and middle-aged and older adults did not significantly differ in their risk tolerance. Older adults reported significantly greater gender typicality than both younger and middle-aged adults, but younger and middle-aged adults reported similar gender typicality. All three age groups 
significantly differed in their focus on opportunities, with younger adults reporting the greatest focus on opportunities, followed by middle-aged adults, and older adults reporting the least. Middle-aged and older adults significantly indicated a greater focus on limitations than younger adults, though middle-aged and older adults did not significantly differ on this variable. No age group differences were found in stereotypically masculine traits, stereotypically feminine traits, stereotypically masculine roles, gender identification, left 2D:4D, right 2D:4D, reliance on the affect heuristic, numeracy, income, or education.

\section{Research Question 1: Model of Psychological Gender Mechanisms}

The purpose of the first research question was to examine the associations of financial risk tolerance with biological (i.e., digit ratio) and psychological dimensions of gender (i.e., stereotypically masculine traits, stereotypically feminine traits, stereotypically masculine roles, gender identification, gender typicality). The following were hypothesized:

(1) Digit ratio would be unrelated to financial risk tolerance (Hypothesis 1a) after accounting for psychological dimensions of gender in men and women.

(2) Stereotypically masculine traits would be positively associated with financial risk tolerance in men and women, but this association would be less strong in older adult men compared to younger and middle-aged men (Hypothesis 1b).

(3) Stereotypically feminine traits would be unrelated to financial risk tolerance in men and women (Hypothesis 1c).

(4) Gender identification and typicality would be positively associated with financial risk tolerance in men, but would be negatively associated with financial risk tolerance in women. It was additionally expected that this association would be less strong among older adult women than in younger and middle-aged women (Hypothesis 1d). 
(5) Stereotypically masculine roles would be positively associated with financial risk tolerance in men and women (Hypothesis 1e).

To address this research question and its hypotheses, a hierarchical linear regression was computed with financial risk tolerance as the dependent variable. Hierarchically, the following were entered: (1) gender and age; (2) numeracy, income, and education as control variables; (3) masculine traits, feminine traits, masculine roles subscales (winning, emotional control, risk taking, violence, power over women, dominance, playboy, self-reliance, primacy of work, disdain for homosexuality, and pursuit of status), gender identification, gender typicality, and right 2D:4D; (4) the hypothesized two-way interactions of gender and age, gender and masculine traits, age and masculine traits, gender and gender identification, age and gender identification, gender and gender typicality, and age and gender typicality; and (5) the hypothesized three-way interactions of gender, age, and masculine traits; gender, age, and gender identification; and gender, age, and gender typicality. Entering the masculine roles subscale scores simultaneously introduced multicollinearity in the model, so the composite masculine roles score was entered instead. Results of this full model are presented in Table 10. No three-way interactions were significant, so they were removed from the model. Two-way interactions were not significant except for the interaction of gender and gender identification; non-significant two-way interaction terms were then removed. No multicollinearity issues were then identified; tolerance values ranged from .43-.99, and VIF values ranged from 1.01-2.35. Table 11 contains the results of this final model.

To probe the significant interaction of gender and gender identification, separate hierarchical linear regression models were computed for men and for women. Stepwise, the following were entered: (1) age; (2) numeracy, income, and education; and (3) stereotypically 
masculine traits, stereotypically feminine traits, stereotypically masculine roles, gender identification, gender typicality, and right 2D:4D. Table 13 contains the results of this model for men, and Table 14 contains the results of this model for women.

Financial risk tolerance. Before discussing specific hypotheses, findings on financial risk tolerance must be noted. As expected, men $(M=.12, S D=.50)$ exhibited greater financial risk tolerance than women $(M=-.10, S D=.48), F(1,572)=29.67, p<.001$; see Table 2 . In the overall sample, financial risk tolerance decreased with age $(\beta=-.08, p=.022$; see Table 11$)$. There was no interaction of gender and age on risk tolerance (see Table 10). However, while probing interaction models separately for men and women in another hypothesis, it was revealed that men's risk tolerance decreased with age $(\beta=-.13, p=.023$; see Table 13$)$, and women's risk tolerance remained consistently, steadily low with age $(\beta=-.05, p=.311$; see Table 14$)$.

Hypothesis 1a. It was hypothesized that digit ratio (a biological measure of prenatal testosterone exposure) would be unrelated to financial risk tolerance after accounting for psychological dimensions of gender in men and women (i.e., stereotypically masculine traits, stereotypically feminine traits, stereotypically masculine roles, gender identification, gender typicality). This hypothesis was supported. Right 2D:4D was not associated with financial risk tolerance $(\beta=-.04, p=.269$; see Table 11$)$. There was not even a bivariate correlation between right 2D:4D and financial risk tolerance, $r(582)=.03, p=.465$; see Table 5 .

Hypothesis 1b. It was hypothesized that stereotypically masculine traits (e.g., independent, strong) would be associated with greater financial risk tolerance in men and women. This hypothesis was supported. In the combined sample of men and women, masculine traits were associated with greater financial risk tolerance $(\beta=.10, p<.001$; see Table 11$)$. Additionally, it was hypothesized that the association between masculine traits and financial risk 
tolerance would be less strong among older adult men than among younger and middle-aged men. This hypothesis was not supported; the interaction of gender, age, and masculine traits on financial risk tolerance was not significant (see Table 10).

Hypothesis 1c. It was hypothesized that stereotypically feminine traits (e.g., affectionate, warm) would be unrelated to financial risk tolerance in men and women. This hypothesis was supported; there was no association between these two variables $(\beta=.01, p=.798$; see Table $11)$.

Hypothesis 1d. It was hypothesized that greater gender identification (identifying with one's gender group and viewing that gender as an important, positive part of the self) would be positively related to financial risk tolerance in men and negatively related to risk tolerance in women. This hypothesis was not supported. There was a main effect of gender identification $(\beta=$ $-.11, p=.029)$ that was qualified by a significant interaction of gender and gender identification $(\beta=.13, p=.011$; see Table 11). Probing this interaction, it was found that gender identification was negatively associated with financial risk tolerance for men-in the opposite direction as predicted $(\beta=-.13, p=.034$; see Table 13). Therefore, men who identified less with being male and viewed being male as a less important and positive part of the self were more financially risk tolerant. Gender identification was not associated with financial risk tolerance in women $(\beta=$ $.08, p=.190$; see Table 14). It was further hypothesized that the association between gender identification and financial risk tolerance would be less strong among older women than in younger and middle-aged adults. This hypothesis was not supported. The interaction of gender, age, and gender identification was not significant (see Table 10).

Similarly, it was hypothesized that gender typicality (viewing oneself as a typical member of one's gender group) would be positively related to financial risk tolerance in men and 
negatively related to risk tolerance in women. This hypothesis was not supported; there was no association between gender typicality and financial risk tolerance $(\beta=.02, p=.794$; see Table 11). It was expected that the association between gender typicality and financial risk tolerance would be less strong among older adult women than in younger and middle-aged women. This hypothesis was not supported; the interaction of gender, age, and gender typicality on financial risk tolerance was not significant (see Table 10).

Hypothesis 1e. It was hypothesized that stereotypically masculine roles (culturally prescribed roles for men; e.g., winner, risk taker) would be positively associated with financial risk tolerance in men and women. Using a composite score collapsing across masculine roles subscales, this hypothesis was supported $(\beta=.35, p<.001$; see Table 11$)$.

Next, the composite masculine roles score was removed from the model, and subscale scores were entered individually into the model to investigate which specific subscales were related to financial risk tolerance (see Table 12). Participants' endorsement of winning, risk taking, violence, power over women, dominance, playboy, and pursuit of status subscales were positively associated with financial risk tolerance. Emotional control, self-reliance, primacy of work, and disdain for homosexuality subscales were unrelated to financial risk tolerance.

\section{Testing a conceptual model of age and financial risk tolerance with psychological}

gender mechanisms. Next, a conceptual model was tested in which psychological gender variables (i.e., stereotypically masculine traits, stereotypically feminine traits, stereotypically masculine roles, gender identification, gender typicality) mediated the association between age and financial risk tolerance (see Figure 1). Numeracy, income, and education were entered as covariates with financial risk tolerance in the model. Unsurprisingly because age was unrelated to most gender variables, this model was a poor fit of the data, $\chi^{2}(34)=246.77, \mathrm{CMIN} / \mathrm{df}=7.26$; 
$\mathrm{CFI}=.776 ; \mathrm{RMSEA}=.104$, thus this model was abandoned and not modified in an attempt to achieve a better fit. See Figure 3 for path values of this poor-fitting model.

Though the model was a poor fit of the data, further multiple mediation analyses were computed using Hayes' PROCESS (2013) macro for SPSS (model 4). Age was entered as the independent variable, masculine traits, feminine traits, masculine roles, gender identification, and gender typicality as mediators, and financial risk tolerance as the outcome. Numeracy, income, and education were entered as covariates to partial out of their shared variance with financial risk tolerance. Again, unsurprisingly, no gender variable mediated the association between age and financial risk tolerance. The total effect of age on financial risk tolerance (total effect $=-.003, S E$ $=.001, p=.021)$ remained significant with the introduction of mediating variables to the model $($ direct effect $=-.003, S E=.001, p=.026)$. There was no indirect effect of age on financial risk tolerance through any of the gender variables, and all Sobel tests for mediation were nonsignificant (see Table 15).

\section{Research Question 2: Model of Future Time Perspective and the Affect Heuristic}

In the second research question, the associations of financial risk tolerance with future time perspective (i.e., focus on opportunities, focus on limitations) and reliance on the affect heuristic were assessed. The following were hypothesized:

(1) More limited future time perspective would be related to less financial risk tolerance across the life span. Using a two-dimensional conceptualization of future time perspective (Cate \& John, 2007; Lemaster et al., 2012b), it was hypothesized that focus on opportunities would be positively associated with financial risk tolerance, and focus on limitations would be negatively associated with financial risk tolerance (Hypothesis 2a). 
(2) Greater reliance on the affect heuristic would be related to less financial risk tolerance across the life span (Hypothesis 2b).

To address this research question and its hypotheses, a hierarchical linear regression was computed with financial risk tolerance as the dependent variable. Hierarchically, the following were entered: (1) gender and age; (2) numeracy, income, and education as control variables; (3) focus on opportunities, focus on limitations, and reliance on the affect heuristic. No multicollinearity issues were identified; tolerance values ranged from .57-.94, and VIF values ranged from 1.07-1.76. Table 16 contains the results from this regression model.

Hypothesis 2a. It was hypothesized that focus on opportunities would be positively related to financial risk tolerance, and focus on limitations would be negatively related to financial risk tolerance. This hypothesis was partially supported. Focus on opportunities was positively associated with greater financial risk tolerance as expected $(\beta=.34, p<.001$; see Table 16). However, focus on limitations was unrelated to financial risk tolerance $(\beta=.04, p=$ $.426)$.

Hypothesis 2b. It was hypothesized that reliance on the affect heuristic would be negatively related to financial risk tolerance. This was hypothesis was supported $(\beta=-.12, p=$ .001 ; see Table 16).

Additional analyses. Next, a conceptual model was tested in which focus on opportunities, focus on limitations, and reliance on the affect heuristic mediated the association between age and financial risk tolerance (see Figure 2). Numeracy, income, and education were entered as covariates of financial risk tolerance. This model was an adequate fit of the data, $\chi^{2}(13)=64.08, \mathrm{CMIN} / \mathrm{df}=4.93 ; \mathrm{CFI}=.918 ; \mathrm{RMSEA}=.082$. 
The model was further examined for gender differences. A model in which path values were constrained to be equal for men and women was compared to an unconstrained model in which path values were allowed to vary by gender. These two models were not significantly different, indicating that path values were similar for men and women, $\Delta \chi^{2}(10)=12.58, p=.248$. Next, the model was examined for age group differences. A model in which path values were constrained to be equal for younger, middle-aged, and older adults was compared to an unconstrained model in which path values were allowed to vary by age group. These three models were also not significantly different, indicating that path values were similar for younger, middle-aged, and older adults, $\Delta \chi^{2}(20)=21.98, p=.342$. Finally, this model was examined for interactions of gender and age group. A model in which path values were constrained to be equal for younger men, younger women, middle-aged men, middle-aged women, older men, and older women was compared to an unconstrained model in which path values were allowed to vary by all six combinations of gender and age group. These models did not significantly differ, suggesting that the path values were similar for younger, middle-aged, and older adult men and women, $\Delta \chi^{2}(50)=60.53, p=.146$. See Figure 4 for path values in this model.

To determine whether focus on opportunities, focus on limitations, and reliance on the affect heuristic mediated the association between age and financial risk tolerance, multiple mediation analyses were computed using Hayes' (2013) PROCESS macro (model 4). Age was entered as the independent variable; focus on opportunities, focus on limitations, and reliance on the affect heuristic as mediating variables; and financial risk tolerance as the outcome. Numeracy, income, and education were entered as covariates of financial risk tolerance in the model. The total effect of age on financial risk tolerance (total effect $=-.003, S E=.001, p=$ .022) became non-significant with the introduction of the mediating variables (direct effect $=$ 
$.000, S E=.002, p=.859)$. There was an indirect effect of focus on opportunities $(B=-.004, S E$

$=.001,95 \%$ CI $[-.006,-.003]$, Sobel test $=-5.31, p<.001)$, but there were no indirect effects of focus on limitations or reliance on the affect heuristic (see Table 17).

\section{Discussion}

\section{Gender, Age, and Financial Risk Tolerance}

As expected, men reported greater financial risk tolerance than women across the life span. No significant gender by age interaction was found on financial risk tolerance, but results indicated that risk tolerance only decreased with age in men. Women's risk tolerance remained low and stable across ages. Much work in this literature has focused on either gender or age, indicating that men, on average, tend to be more risk tolerant than women, and that risk tolerance decreases with age. Looking at aggregate statistics, these data suggested the same. Little work has focused on men's and women's risk tolerance across ages separately. The data presented here suggest the potential importance of examining age trends on risk tolerance separately by gender, especially for women. If women, on average, are consistently low in financial risk tolerance, then young adulthood may be a key period to intervene and increase financial risk tolerance for investments, allowing ample time to accrue wealth before retirement.

\section{Accounting for Financial Risk Tolerance Using Psychological Gender Mechanisms}

Stereotypically masculine traits. Endorsing instrumental, stereotypically masculine traits was associated with greater risk tolerance across the life span. In the little psychological work linking gender and financial risk tolerance (Demaree et al., 2009; Kastlunger et al., 2010; Meier-Pesti \& Penz, 2008), masculine traits have been positively linked to financial risk tolerance in each. Traits such as independence, assertiveness, and strength may be especially likely to promote tolerance for financial risks. Men and women with these masculine traits may 
feel as though they have primary responsibility in their financial affairs and may be less concerned with potential losses they could potentially experience.

Because others have found masculine traits to be stable in men across ages (Strough et al., 2007), but financial risk tolerance declines with age (Faff et al., 2011; Hallahan et al., 2003), it was hypothesized that perhaps the association between masculine traits and financial risk tolerance may weaken in older adulthood. However, this was not found; masculine traits were similarly related to financial risk tolerance in younger, middle-aged, and older men. This evidence suggests that masculine traits are not a likely mechanism for understanding age-related decreases in men's financial risk tolerance.

Stereotypically feminine traits. As expected, communal, stereotypically feminine traits were unrelated to financial risk tolerance in men and women across the life span. This finding replicates prior work by Meier-Pesti and Penz (2008), who identified that masculine, but not feminine, traits were associated with hypothetical risk taking, actual investment behavior, and self-reported financial risk tolerance in an adult sample. Masculinity and femininity are contemporarily considered orthogonal constructs. Data presented here bolster that claim: there was only a very small positive correlation $(r=.09)$ between masculine and feminine traits. Thus, financial risk tolerance, stereotyped within the masculine domain (Wilson \& Daly, 1985), may be independent of the ways in which men and women enact femininity. The Bem Sex Role Inventory measure used to assess instrumental, masculine traits and communal, feminine traits was created in the 1970 s and takes a very stereotypical view of masculinity and femininity. For the femininity subscale, participants indicated how much they "love children," and are “yielding," “sympathetic," “soft spoken," and "gentle.” These interpersonal characteristics are likely unrelated to people's tolerance for risky financial decisions. 
Stereotypically masculine roles. The ways in which men and women adhered to stereotypically masculine roles was a strong predictor of their financial risk tolerance. Men and women who endorsed masculine roles exhibited greater financial risk tolerance across the life span. In particular, participants who highly embodied the winning, risk taking, violence, power over women, dominance, playboy, and pursuit of status were roles were more likely to report greater financial risk tolerance. Perhaps some men and women are more comfortable with financial risks because risky financial decisions help them enact masculinity. Taking financial risks may also confer greater financial resources that allow people to pursue social status and dominance over others. It appears that people who are more risk tolerant in the financial domain are more risk tolerant in dangerous situations and in romantic relationships. Alternatively, people who are more financially risk tolerant may be in careers that encourage them to embody masculine roles such as winner, risk taker, playboy, and status pursuer. Either way, research linking risk tolerance to masculine traits and roles provides further empirical evidence that financial risk tolerance may be considered within the masculine domain (Wilson \& Daly, 1985).

Gender identification and typicality. The associations between risk tolerance and two cognitive components of gender-gender identification (i.e., identifying as one's biological sex and viewing it as a positive part of the self), and typicality (i.e., feeling like a typical member of one's biological sex)—were assessed. Initially, it was hypothesized that greater gender identification would be related to greater risk tolerance among men and less risk tolerance among women. In women, gender identification was unrelated to financial risk tolerance. In men, an interaction in the opposite direction was found. Among men, those who identified with their biological sex as a less important, positive part of themselves reported greater financial risk tolerance. This potentially idiosyncratic finding was identified in one other study of financial risk 
tolerance in college students (Lemaster \& Strough, 2014). However, these results could reflect that men were asked to reflect on and evaluate their own male identity. Weaver and colleagues (2013) found that when men's masculine identity was threatened (by being asked to wear and then describe women's hand lotion), they made riskier financial decisions on a gambling task than men who were not threatened. Though men's identification was not threatened in the present study, men who evaluate their male identity less positively may feel threatened and tolerate greater risks as an attempt to assert their masculinity. Findings for women suggest that the ways in which they view themselves as female are unrelated to their willingness to take financial risks.

Similar to hypotheses for gender identification, it was also hypothesized that viewing oneself as a more typical example of one's biological sex (i.e., greater gender typicality) would be related to greater financial risk tolerance in men and less financial risk tolerance in women. Neither of these was found in the life-span data presented here. These results suggest that the way men and women view themselves as male or female in comparison to other men and women is independent of the financial risks they may tolerate across the life span.

2D:4D digit ratio. In this study, the associations of psychological gender mechanisms were tested against a biological mechanism: prenatal testosterone exposure, as measured by 2D:4D digit ratio. Though some have found an association between 2D:4D digit ratio and risk taking on laboratory tasks (Coates et al., 2009; Dreber \& Hoffman, 2007; Garbarino et al., 2011), many others have not (Apicella et al., 2008; Dreber \& Hoffman, 2007; Sapienza et al., 2009). Results found here suggest that this biological variable is unrelated to an ecologically valid measure of financial risk tolerance used by financial planners as a diagnostic tool for their clients. The literature on 2D:4D digit ratio and risk is riddled with conflicting findings that may 
be elucidated through procedures such as meta-analysis. Notably, the present study does not conclude that testosterone is unrelated to financial risk tolerance. Only one measure of testosterone was used, and alternative measures exist. Other researchers have linked financial risk tolerance with pubertal testosterone exposure (operationalized as facial masculinization; see Apicella et al., 2008) and current circulating testosterone (Apicella et al., 2008). These testosterone measures have been used much less frequently than 2D:4D in the study of risk, and further research is needed to clarify their associations with financial risk tolerance.

\section{Psychological gender mechanisms as mediators of age and financial risk tolerance.}

In the model presented in Figure 1, it was expected that gender-related mechanisms may be associated with both age and financial risk tolerance. Exploratory analyses were computed to investigate whether these gender-related mechanisms may mediate the association between age and financial risk tolerance. Testing the hypothesized model revealed that it was a poor fit of the data. Because age was not associated with any gender variable except for gender typicality, further modifications of the model were abandoned. Subsequent mediation analyses were computed, but no indirect effects were identified. Though gender-related variables accounted for financial risk tolerance, they did not account for the association between age and financial risk tolerance. In considering why psychological gender mechanisms did not differ by age, it may be helpful to consider the context of gender and aging in the participants sampled for the present study.

Gender and aging. In this sample of the U.S. population, how people enact their gender appears to be independent of their age. Past cross-sectional research on U.S. cohorts found that women who lived their early years during or were born after the U.S. second wave of feminism endorsed more masculine traits than those who were middle-aged or older during this social 
movement (Strough et al., 2007). Within the present sample, women of all ages endorsed similar levels of masculine and feminine traits, adhered to similar levels of masculine roles, and reported similar levels of gender identification as others in their gender group. A similar pattern was found for men across ages. Considering the present study, these findings do align with and extend prior research. In this study, older adults were aged, on average, in their mid-60s, and were therefore young adults during the U.S. feminist movement of the 1970s. These findings suggest that contemporary cohorts of women aged between their mid-20s and mid-60s endorse similar levels of masculine and feminine traits, adhere to similar levels of masculine roles, and identify similarly with being female. Past work has indicated that men endorse masculine traits at similar levels between cohorts (Strough et al., 2007); this research suggests that feminine traits, masculine roles, and gender identification may also be stable with age between contemporary cohorts of U.S. men.

\section{Implications of the associations between psychological gender mechanisms and}

financial risk tolerance. Research on gender, aging, and financial risk tolerance is especially timely. Men, on average, tend to take greater financial risks than women and accrue greater wealth than women. Women, who tend to live longer than men (Shrestha, 2006), may enter the retirement years with fewer financial resources and be forced to stretch these resources over a longer span of time. With the uncertain future status of federal entitlement programs in the U.S. (e.g., Social Security), subsequent cohorts may also need to increasingly rely on their personal savings during the retirement years. A goal of the present research was to inform potential interventions that may facilitate better financial decision making and wealth accumulation in all people, especially women. 
This study aligns with past work in uniformly linking masculinity to financial risk tolerance. According to social constructionist theory (Deaux \& Major, 1987), people enact their gender by responding to the immediate and broader social contexts. This theoretical work suggests that gender may be subtly changed in men and women depending on the context of their interactions. Interventions may potentially be designed to enhance women's masculinity in financial decision-making contexts to facilitate increased financial risks. The hyper-masculine culture of Wall Street has also been implicated in the recent U.S. financial crisis (Weaver et al., 2013). These researchers have suggested that bankers, mostly men, may effectively assert their masculinity by taking greater, more excessive risks. In this context, risk tolerance may be extremely maladaptive. Interventions could be designed to reduce masculinity in these situations to facilitate less financial risk taking. Experimental research with priming suggests that financial risk taking may be modified with subtle gender cues (Weaver et al., 2012). More work in this area is needed.

\section{Accounting for Financial Risk Tolerance Using Future Time Perspective and the Affect}

\section{Heuristic}

Future time perspective. Economists have suggested in theoretical work that viewing a limited time horizon should lead to decreased financial risk tolerance, presumably because there is less time to recoup potential losses (Jaggia \& Thosar, 2000). Therefore, it was hypothesized that a more limited future time perspective would be associated with less risk tolerance in men and women across the life span. Future time perspective was characterized in the present study as two-dimensional (Cate \& John, 2007): a focus on opportunities, in which the future is viewed as expansive, and a focus on limitations, in which the future is viewed as limited. Focuses on opportunities and limitations were expected to be positively and negatively associated with risk 
tolerance, respectively. However, focus on limitations was unrelated to financial risk tolerance, a finding noted in at least one other large life-span study of U.S. adults (Lemaster, Strough, Parker, \& Bruine de Bruin, 2014). As expected, focus on opportunities was a strong predictor of one's financial risk tolerance; as people viewed their futures as being characterized by more opportunities, they also reported greater risk tolerance. This work suggests that people's views of their opportunities ahead, and not the limitations they may perceive, are directly related to their willingness to engage in risky financial behaviors. When people view their futures as more expansive, perhaps they feel more comfortable taking financial risks because they believe they will have sufficient time to recoup losses they may experience. Viewing one's future as having more opportunities may also imply a greater financial burden in the future (e.g., caring for a child or grandchild, moving, going on a vacation), thus encouraging financial risks that could increase wealth. Alternatively, people who are more risk tolerant may come to see their futures as more expansive if they have the financial resources necessary to attain subsequent successes. These variables likely exist in a bidirectional, transactional process.

Future time perspective as a mediator of age and financial risk tolerance. In the model presented in Figure 2, it was expected that future time perspective (i.e., focuses on opportunities and limitations) would be associated with both age and financial risk tolerance. Analyses were computed to investigate whether focuses on opportunities and limitations mediated the association between age and financial risk tolerance.

Future time perspective has long been linked to age, with people tending to view their futures as more limited as they grow older (Carstensen, 2006). Economists have also noted that a limited future time horizon should lead to less financial risk tolerance (Jaggia \& Thosar, 2000). As mentioned above, focus on limitations was unrelated to financial risk tolerance, so 
unsurprisingly, it did not mediate the relation between age and risk tolerance. Mediation analyses revealed that focus on opportunities did indeed mediate the relation between age and financial risk tolerance. In fact, focus on opportunities fully explained the association between age and risk tolerance. These findings suggest that focus on opportunities may be a prime mechanism precipitating lower risk tolerance with age. Future experimental research that manipulates future time perspective may elucidate these relations.

Reliance on the affect heuristic. In dual-process theories of decision making, judgments are thought to be made in two different systems: the first, rooted in gist-based, intuitive thinking, and the second, in deliberative thinking (Hanoch, Wood, \& Rice, 2007; Peters \& Bruine de Bruin, 2012; Peters, Hess, Västfjäll, \& Auman, 2007; Peters, Dieckmann, \& Weller, 2011; Reyna, 2004; Reyna \& Brainerd, 2011). With age, people accumulate experiences that help them make decisions in an automated fashion (Strough et al., 2014), and decisions may be guided more by "gut feelings" and emotions than deliberative analysis (Reyna \& Brainerd, 2011). Risks and benefits are positively correlated in an objective sense (Alhakami \& Slovic, 1994). However, when people rely on affect to guide their risk decisions, they are more likely to believe that risks and benefits are inversely related (i.e., more reliant on the affect heuristic; Alhakami \& Slovic, 1994). If older adults are more reliant on affective processing when making decisions, then it may be posited that with age, people are more likely to believe that risks and benefits are inversely correlated (i.e., risky activities have low benefits). In this study, it was expected that one type of intuitive thinking — using the affect heuristic — would be negatively related to financial risk tolerance, and the affect heuristic could explain the association between age and financial risk tolerance. 
As expected, the affect heuristic was negatively related to financial risk tolerance in men and women across the life span. Those people who viewed risks and benefits of various hazards (e.g., nuclear power, cigarettes) as inversely related in several domains also reported less risk tolerance in financial decisions. Therefore, people who viewed risks and benefits as "distant" from each other reported less willingness to take financial risks. If people believe that risky situations are less beneficial, then it follows that reliance on this heuristic may lead people to become less tolerant of risky decisions, like those in the financial domain. It may also be that people who are less financially risk tolerant justify their reluctance to engage in risky financial decisions by reporting that risky situations provide few benefits.

The affect heuristic as a mediator of age and financial risk tolerance. Because aging is associated with a greater reliance on intuitive thinking (Reyna \& Brainerd, 2011), age was expected to be positively related to reliance on the affect heuristic, which was then expected to be associated with decreased financial risk tolerance. Though reliance on the affect heuristic was associated with less risk tolerance as hypothesized, age was unrelated to the affect heuristic. No mediation was identified between age and risk tolerance through the affect heuristic. Findings suggest that the affect heuristic is not an age-related mechanism useful in understanding why willingness to take financial risks decreases with age.

\section{Implications of the associations of future time perspective and the affect heuristic} with financial risk tolerance. Results presented here suggest that people's willingness to take financial risks is related to their views of the future and how their conceptualize risks and benefits. Interventions may be designed to target these constructs, especially in younger adulthood when there is more time to accumulate wealth before retirement. At least in younger adults, future time perspective may be experimentally manipulated by inducing specific mindsets 
(e.g., asking participants to imagine they have a long life ahead; Allemand, 2008; Strough et al., 2014). This work, along with results presented here, suggests that financial risk tolerance could potentially be modified with simple imaginative exercises. Past research has suggested that people who imagine themselves as older (limiting their time perspective) are more likely to invest hypothetical money in a retirement fund (Hershfield et al., 2011).

Next, if people view risks and benefits as inversely related, then they tend to be less risk tolerant in a number of different domains. Deliberative thinking about risky financial decisions may combat this reliance on the affect heuristic. Prior work has indicated that providing adults, young and old, with decision aids about expected outcomes improves their financial risk decisions (Samanez-Larkin, Wagner, \& Knutson, 2011). However, the expected outcomes for many financial decisions are uncertain or unknown at the time at which decisions are made. Still, studies such as this suggest that financial decision situations may be changed to enhance deliberative capacity and improve financial risk decisions in both younger and older adults. Other potential interventions that enhance deliberating about risk await further research.

\section{Limitations}

This study was limited in a number of notable ways. All findings are based on data collected from a U.S. sample of adults using Amazon's Mechanical Turk. Though others have found this data collection method to be as valid as traditional data collection techniques (Buhrmester et al., 2011; Goodman et al., 2013; Mason \& Suri, 2012), participants in this study may not be representative of the entire U.S. population. For example, few participants had a fulltime job, so they may be less able to actually invest their money compared to people with stable, full-time employment. Additionally, the oldest participants in this study are typically characterized as young-old in other research (e.g., Yang \& Krampe, 2009), and few people over 
age 70 were included. Data were also collected during a historical time when the U.S. economy was still affected the Great Recession, a period in which financial investments were lost and risk tolerance may have decreased as a result.

Data collection through Mechanical Turk prevented in-person 2D:4D digit ratio measurement. Instead, participants measured their own finger lengths using an at-home ruler or one presented to them on their computer screen. Detailed instructions with pictures were provided to aid participants' measurements. Others using self-report 2D:4D methods have warned about the greater prevalence of outliers and the importance of using larger samples to overcome measurement error (Caswell \& Manning, 2009). Following these guidelines, a large sample was used here, and participants with outlying 2D:4D values (and outliers on all other measures) were excluded from analysis

All results presented here are correlational and cannot be used as evidence for causality. The processes described here are likely bidirectional, transactional processes that occur over time. For examples, having an expansive future time perspective may facilitate greater financial risk tolerance, and accruing wealth through investments may promote positive views of time ahead. These associations may be clarified with subsequent longitudinal or experimental research.

\section{Future Directions}

Researchers should continue to study other gender- and age-related mechanisms to explain why men tend to be more financially risk tolerant than women and why financial risk tolerance tends to decrease with age. The research discussed here used a simple measure of prenatal testosterone measure. Subsequent research should use alternative biological measures such as facial masculinization (a measure of pubertal testosterone exposure) and circulating 
testosterone (see Apicella et al., 2008) to clarify how biological and psychological gender mechanisms predict financial risk tolerance across the life span. This study was composed of a cross-sectional sample of U.S. adults. Future longitudinal work may better describe the genderand age-related processes involved in the development of financial risk tolerance over time. Because data were collected during a period of history still affected by the Great Recession, subsequent cross-sequential designs may be useful in disentangling the effects of age, cohort, and historical time on financial risk tolerance.

Notably, a number of gender- and age-related variables were identified that predict financial risk tolerance across the life span. If these variables predict risk tolerance, they may also be related to people's willingness to take advantageous versus disadvantageous risks. For example, if hyper-masculine work cultures lead to inordinately high amounts of risk, a high level of masculine traits and roles may be able to distinguish people prone to taking disadvantageous risks. Future work with laboratory risk paradigms that identify when participants choose risky bets whose expected values are lower than that of safe options (e.g., the Cups Task; Levin, Weller, Pederson, \& Harshman, 2007) may answer such hypotheses. By identifying people who are predisposed to take disadvantageous risks, interventions could potentially be designed to enhance their decision quality.

Others have attributed age differences in risk taking on the Iowa and Cambridge Gambling Tasks to cognitive mechanisms (Denburg et al., 2009; Fein, McGillivray, \& Finn, 2007; Henninger, Madden, \& Huettel, 2010; Mata, Josef, Samanez-Larkin, \& Hertwig, 2012; Peters, Västfjäll 1, Slovic, Mertz, Mazzocco, \& Dickert, 2006). However, numeracy was unrelated to self-reported financial risk tolerance in this study. Future work may clarify whether cognitive processes are related to self-reported risk tolerance. The numeracy measure used here 
was difficult for participants; on average, participants only answered about one out of four

questions correctly. Other numeracy measures may be explored, including those by Schwartz and colleagues (1997), Lipkus and colleagues (2001), and Peters and colleagues (2007).

\section{Conclusions}

A cross-sectional life span sample of adult men and women were recruited to investigate the gender- and age-related patterns in an ecologically valid measure of financial risk tolerance, the FinaMetrica Risk Tolerance Profile. Men reported greater risk tolerance than women, and risk tolerance decreased with age. Several psychological constructs were associated with financial risk tolerance, including psychological gender mechanisms, future time perspective, and the affect heuristic. Much research on financial risk tolerance has implicated biological mechanisms, such as testosterone, as a primary mechanism in understanding men's greater risk tolerance relative to women. Results presented here indicate that studying psychological mechanisms associated with gender and aging are important in developing a comprehensive rationale for gender and age differences in risk tolerance. 


\section{References}

Alhakami, A. S., Slovic, P. (1994). A psychological study of the inverse relationship between perceived risk and perceived benefit. Risk Analysis, 14, 1085-1096.

Allemand, M. (2008). Age differences in forgiveness: The role of future time perspective. Journal of Research in Personality, 42, 1137-1147.

Almenberg, J., \& Dreber, A. (2012). Gender, stock market participation, and financial literacy. Stockholm School of Economics: Economic Research Institute (SSE/EFI Working Paper 737). Retrieved June 25, 2012 from http://swopec.hhs.se/hastef/papers/hastef0737.pdf

Apicella, C. L., Dreber, A., Campbell, B., Gray, P. B., Hoffman, M., \& Little, A. C. (2008). Testosterone and financial risk preferences. Evolution and Human Behavior, 29, 384-390.

Archer, J. (2006). Testosterone and human aggression: An evaluation of the challenge hypothesis. Neuroscience and Biobehavioral Review, 30, 319-345.

Ashmore, R. D. (1990). Sex, gender, and the individual. In L. A. Pervin (Ed.), Handbook of personality: Theory and research (pp. 486-526). New York, NY: Guilford Press.

Baiocco, R., Laghi, F., \& D’Alessio, M. (2009). Decision-making style among adolescents: Relationship with sensation seeking and locus of control. Journal of Adolescence, 32, 963-976.

Bajtelsmit, V. L., \& Bernasek, A. (1996). Why do women invest differently than men? Financial Counseling and Planning, 7, 1-10.

Bechara, A., Damasio, A. R., Damasio, H., \& Anderson, S. W. (1994). Insensitivity to future consequences following damage to human pre-frontal cortex. Cognition, 50, 7-15.

Bem, S. L. (1974). The measurement of psychological androgyny. Journal of Consulting and Clinical Psychology, 42, 155-162. 
Bentler, P. M., \& Chou, C. P. (1987) Practical issues in structural modeling. Sociological Methods \& Research, 16, 78-117.

Bernasek, A., \& Shwiff, S. (2001). Gender, risk, and retirement. Journal of Economic Issues, 35, $345-356$.

Bolla, K. I., Eldreth, D. A., Matochik, J. A., \& Cadet, J. L. (2004). Sex-related differences in a gambling task and its neurological correlates. Cerebral Cortex, 14, 1226-1232.

Bright, J., \& Adams, A. (2000). The FinaMetrica risk profiling system. Sydney, Australia: University of New South Wales.

Buhrmester, M., Kwang, T., \& Gosling, S. D. (2011). Amazon's Mechanical Turk: A new source of inexpensive, yet high-quality data? Perspectives on Psychological Science, 6, 3-5.

Byrnes, J. P., Miller, D. C., \& Schafer, W. D. (1999). Gender differences in risk taking: A metaanalysis. Psychological Bulletin, 125, 367-383.

Carstensen, L. L. (2006). The influence of a sense of time on human development. Science, 312, 1913-1915.

Carstensen, L. L., \& Lang, F. R. (1996). Future time perspective scale. Unpublished manuscript. Stanford, CA: Stanford University.

Caswell, N., \& Manning, J. T. (2009). A comparison of finger 2D:4D by self-report direct measurement and experimenter measurement from photocopy: Methodological issues. Archives of Sexual Behavior, 38(1), 143-148.

Cate, R. A., \& John, O. P. (2007). Testing models of the structure and development of future time perspective: Maintaining a focus on opportunities in middle age. Psychology \& Aging, 22, 186-201. 
Cauffman, E., Shulman, E. P., Steinberg, L., Claus, E., Banich, M. T., Graham, S., \& Woolard, J. (2010). Age differences in affective decision making as indexed by performance on the Iowa Gambling Task. Developmental Psychology, 46, 193-207.

Charness, G., \& Gneezy, U. (2012). Strong evidence for gender differences in risk taking. Journal of Economic Behavior \& Organization, 83, 50-58.

Coates, J. M., Gurnell, M., \& Rustichini, A. (2009). Second-to-fourth-digit ratio predicts success among high frequency financial traders. Proceedings of the National Academy of Sciences, 106, 623-628.

Cokely, E. T., Galesic, M., Schulz, E., Ghazal, S., \& Garcia-Retamero, R. (2012). Measuring risk literacy: The Berlin Numeracy Test. Judgment and Decision Making, 7(1), 25-47.

Corter, J. E., \& Chen, Y. J. (2006). Do investment risk tolerance attitudes predict portfolio risk? Journal of Business and Psychology, 20(3), 369-381.

Courtenay, W. H. (2000). Constructions of masculinity and their influence on men's well-being: A theory of gender and health. Social Science \& Medicine, 50, 1385-1401.

Deaux, K., \& Major, B. (1987). Putting gender into context: An interactive model of genderrelated behavior. Psychological Review, 94, 369-389.

Demaree, H. A., DeDonno, M. A., Burns, K. J., Feldman, P., \& Everhart, D. E. (2009). Trait dominance predicts risk-taking. Personality and Individual Differences, 47, 419-422.

DeNavas-Walt, C., Proctor, B. D., \& Smith, J. C. (2013). Income, poverty, and health insurance coverage in the United States: 2012 (Report no. P60-245). United States Census Bureau Current Population Reports. Retrieved from http://www.census.gov/prod/2013pubs/p60245.pdf 
Denburg, N. L., Weller, J. A., Yamada, T. H., Shivapour, D. M., Kaup, A. R., LaLoggia, A., Cole, C. A., Tranel, D., \& Bechara, A. (2009). Poor decision making among older adults is related to elevated levels of neuroticism. Annals of Behavioral Medicine, 37, 164-172.

Dreber, A., Apicella, C. L., Eisenberg, D. T. A., Garcia, J. R., Zamore, R. S., Lum, J. K., \& Campbell, B. (2009). The 7R polymorphism in the dopamine receptor D4 gene (DRD4) is associated with financial risk taking in men. Evolution and Human Behavior, 30, 8592.

Dreber, A., \& Hoffman, M. (2007). Risk preferences are partly predetermined. Mimeo: Stockholm School of Economics.

Dreber, A., Rand, D. G., Wernerfelt, N., Garcia, J. R., Lum, J. K., \& Zeckhauser, R. (2011). The dopamine receptor D4 gene (DRD4) and self-reported risk taking in the economic domain. Harvard University: John F. Kennedy School of Government (Working Paper RWP11-042). Retrieved June 8, 2012 from http://dash.harvard.edu/bitstream/handle/1/5347066/RWP11-042_Zeckhauser_alia.pdf

Dreber, A., Rand, D. G., Wernerfelt, N., Garcia, J. R., Vilar, M. G., Lum, J. K., \& Zeckhauser, R. (2011). Dopamine and risk choices in different domains: Findings among serious tournament bridge players. Journal of Risk and Uncertainty, 43, 19-38.

Eagly, A. H. (1987). Sex differences in social behavior: A social-role interpretation. Hillsdale, NJ: Lawrence Erlbaum Associates.

Eckel, C. C., \& Grossman, P. J. (2002). Sex differences and statistical stereotyping in attitudes toward financial risk. Evolution \& Human Behavior, 23, 281-295.

Egan, S. K., \& Perry, D. G. (2001). Gender identity: A multidimensional analysis with implications for psychosocial adjustment. Developmental Psychology, 27, 451-463. 
England, P. (2010). The gender revolution: Uneven and stalled. Gender \& Society, 24, 149-166.

Ertac, S., \& Gurdal, M. Y. (2011). Deciding to decide: Gender, leadership, and risk-taking in groups. Journal of Economic Behavior, 83, 50-58.

Faff, R., Hallahan, T., \& McKenzie, M. (2011). Women and risk tolerance in an aging world. International Journal of Accounting and Information Management, 19, 100-117.

Faff, R., Mulino, D., \& Chai, D. (2008). On the linkage between financial risk tolerance and risk aversion. The Journal of Financial Research, 31, 1-23.

Fein, G, McGillivray, S., \& Finn, P. (2007). Older adults make less advantageous decisions than younger adults: Cognitive and psychological correlates. Journal of the International Neuropsychological Society, 13, 480-489.

Finke, M. S., \& Huston, S. J. (2003). The brighter side of financial risk: Financial risk tolerance and wealth. Journal of Family and Economic Issues, 24, 233-256.

Garbarino, E., Slonim, R., \& Sydnor, J. (2011). Digit ratios (2D:4D) as predictors of risky decision making for both sexes. Journal of Risk and Uncertainty, 42, 1-26.

Garrison, S. T., \& Gutter, M. S. (2010). Gender differences in financial socialization and willingness to take financial risks. Journal of Financial Counseling and Planning, 21, 6072.

Gilliam, J., Chatterjee, S., \& Grable, J. (2010). Measuring the perception of financial risk tolerance: A tale of two measures. Journal of Financial Counseling \& Planning, 21, 3043.

Goodman, J. K., Cryder, C. E., \& Cheema, A. (2013). Data collection in a flat world: The strengths and weaknesses of Mechanical Turk samples. Journal of Behavioral Decision Making, 26, 213-224. 
Guillemette, M., Finke, M. S., \& Gilliam, J. (2012). Risk tolerance questions to best determine client portfolio allocation preferences. Journal of Financial Planning, 25, 36-44.

Gutman, D. (1987). Reclaimed powers: Towards a new psychology of men and women in later life. New York, NY: Basic Books.

Hallahan, T., Faff, R., \& McKenzie, M. (2003). An exploratory investigation of the relation between risk tolerance scores and demographic characteristics. Journal of Multinational Financial Management, 13, 483-502.

Hanoch, Y., Wood, S., \& Rice, T. (2007). Bounded rationality, emotions and older adult decision making: Not so fast and yet so frugal. Human Development, 50, 333-358.

Henninger, D. E., Madden, D. J., \& Huettel, S. A. (2010). Processing speed and memory mediate age-related differences in decision making. Psychology and Aging, 25, 262-270.

Henry, J. (1988). The archetypes of power and intimacy. In J. Birren \& V. Bengtson (Eds.), Emergent theories of aging. New York, NY: Springer.

Hershfield, H. E., Goldstein, D. G., Sharpe, W. F., Fox, J., Yeykelis, L., Carstensen, L. L., \& Bailenson, J. N. (2011). Increasing saving behavior through age-progressed renderings of the future self. Journal of Marketing Research, 48, S23-S37.

Hira, T. K., \& Loibl, C. (2008). Gender differences in investment behavior. In J. J. Xiao (Ed.), Handbook of consumer finance research (pp. 253-270). New York, NY: Springer.

Hoffman, R. M., \& Borders, L. D. (2001). Twenty-five years after the Bem Sex-Role Inventory: A reassessment and new issues regarding classification variability. Measurement and Evaluation in Counseling and Development, 34, 39-55. 
Hooper, C. J., Luciana, M., Conklin, H. M., \& Yarger, R. S. (2004). Adolescents' performance on the Iowa gambling task: Implications for the development of decision making and ventromedial prefrontal cortex. Developmental Psychology, 40, 1148-1158.

Huston, A. C. (1983). Sex-typing. In E. M. Hetherington (Ed.), Handbook of child psychology Vol. 4: Socialization, personality and social development (4th ed., pp. 387-467). New York, NY: Wiley.

Huyck, M. H. (1994). The relevance of psychodynamic theories for understanding gender among older women. In B. F. Turner \& L. E. Troll (Eds.), Women growing older: Psychological perspectives. Thousand Oaks, CA: Sage.

Jaggia, S., \& Thosar, S. (2000). Risk aversion and the investment horizon: A new perspective on the time diversification debate. The Journal of Psychology and Financial Markets, 1, 211-215.

Jianakoplos, N. A., \& Bernasek, A. (1998). Are women more risk averse? Economic Inquiry, 36, 620-630.

Jost, A., Price, D., \& Edwards, R. G. (1970). Hormonal factors in the sex differentiation of the mammalian foetus [and discussion]. Philosophical Transactions of the Royal Society of London: Series B, Biological Sciences, 259, 119-130.

Kastlunger, B., Dressler, S. G., Kirchler, E., Mittone, L., \& Voracek, M. (2010). Sex differences in tax compliance: Differentiating between demographic sex, gender-role orientation, and prenatal masculinization (2D:4D). Journal of Economic Psychology, 31, 542-552.

Leaper, C., \& Friedman, C. K. (2007). The socialization of gender. In J. E. Grusec \& P. D. Hastings (Eds.), Handbook of socialization: Theory and research (pp. 561-587). New York, NY: Guilford Press. 
Lemaster, P., \& Strough, J. (2014). Beyond Mars and Venus: Understanding gender differences in financial risk tolerance. Journal of Economic Psychology. Advanced online publication.

Lemaster, P., Strough, J., Parker, A. M., \& Bruine de Bruin, W. (2014). Describing and explaining self-reported risk aversion across adulthood. Manuscript in preparation.

Lemaster, P., Strough, J., Parker, A. M., Bruine de Bruin, W., Pichayayothin, N., \& Karns, T. (2012). Hourglass half-full or half-empty? Predicting focus on opportunities or limitations across adulthood. The Gerontologist, 52, S1, 346.

Lemaster, P., Strough, J., Stoiko, R., \& DiDonato, L. (2014). To have and to do: Masculine facets of gender predict gender attitudes among college students. Psychology of Men \& Masculinity. Manuscript submitted for publication.

Levin, I. P., Snyder, M. A., \& Chapman, D. P. (1988). The interaction of experiential and situational factors and gender in a simulated risky decision-making task. The Journal of Psychology, 122, 173-181.

Levin, I. P., Weller, J. A., Pederson, A., \& Harshman, L. (2007). Age-related differences in adaptive decision making: Sensitivity to expected value in risky choice. Judgment and Decision Making, 2, 225-233.

Lipkus, I. M., Samsa, G., \& Rimer, B. K. (2001). General performance on a numeracy scale among highly educated samples. Medical Decision Making, 21(1), 37-44.

Little, A. C., Jones, B. C., Waitt, C., Tiddeman, B. P., Feinberg, D. R., Perrett, D. I., ... Marlowe, F. W. (2008). Symmetry is related to sexual dimorphism across culture and species. PLoS ONE, 3. 
Maccoby, E. E. (1998). The two sexes: Growing up apart, coming together. Cambridge, MA: Harvard University Press.

Mahalik, J. R., Locke, B., Ludlow, L., Diemer, M., Scott, R. P. J., Gottfried, M., \& Freitas, G. (2003). Development of the Conformity to Masculine Norms Inventory. Psychology of Men and Masculinity, 4, 3-25.

Manning, J. T. (2002). Digit ratio: A pointer to fertility, behaviour, and health. New Brunswick, NJ: Rutgers University Press.

Martin, C. L. (1987). A ratio measure of sex stereotyping. Journal of Personality and Social Psychology, 52, 489-499.

Mason, W., \& Suri, S. (2012). Conducting behavioral research on Amazon's Mechanical Turk. Behavior Research Methods, 44, 1-23.

Mata, R., Josef, A. K., Samanez-Larkin, G. R., \& Hertwig, R. (2012). Age differences in risky choice: A meta-analysis. Annals of the New York Academy of Sciences, 1235, 18-29.

Mazur, A., \& Booth, A. (1998). Testosterone and dominance in men. Behavioral \& Brain Sciences, 21, 353-397.

Meier-Pesti, K., \& Penz, E. (2008). Sex or gender? Expanding the sex-based view by introducing masculinity and femininity as predictors of financial risk taking. Journal of Economic Psychology, 29, 180-196.

Michaelieu, Q. (1997). Female identity, reports of parenting, and adolescent women's self esteem. Unpublished doctoral dissertation, Arizona State University, Tempe, AZ.

Overman, W. H. (2004). Sex differences in early childhood, adolescence, and adulthood on cognitive tasks that rely on orbital prefrontal cortex. Brain and Cognition, 55, 134-147. 
Overman, W. H., Frassrand, K., Ansel, S., Trawalter, S., Bies, B., \& Redmond, A. (2004). Performance on the Iowa card task by adolescents and adults. Neuropsychologia, 42, 1838-1851.

Paolacci, G., Changler, J., \& Ipeirotis, P. G. (2010). Running experiments on Amazon Mechanical Turk. Judgment and Decision Making, 5, 411-419.

Peters, E., \& Bruine de Bruin, W. (2012). Aging and decision skills. In M. K. Dhami, A. Schlottmann, \& M. Waldmann (Eds.), Judgment and decision making as a skill: Learning, development, and evolution. New York, NY: Cambridge University Press.

Peters, E., Dieckmann, N. F., Dixon, A., Slovic, P., Mertz, C. K., \& Hibbard, J. H. (2007). Less is more in presenting quality information to consumers. Medical Care Research and Review, 64(2), 169-190.

Peters, E., Dieckmann, N. E., \& Weller, J. (2011). Age differences in complex decision making. In K. W. Schaie \& S. L. Willis (Eds.), Handbook of the psychology of aging (7th ed., pp. 133-151). San Diego, CA: Elsevier Academic Press.

Peters, E., Hess, T. M., Västfjäll, D., \& Auman, C. (2007). Adult age differences in dual information processes: Implications for the role of affective and deliberative processes in older adults' decision making. Perspectives on Psychological Sciences, 2(1), 1-23.

Peters, E. Västfjäll, D., Slovic, P., Mertz, C. K., Mazzocco, K., \& Dickert, S. (2006). Numeracy and decision making. Psychological Science, 17, 407-413.

Phillips, S. D., Pazienza, N. J., \& Ferrin, H. H. (1984). Decision making styles and problemsolving appraisal. Journal of Counseling Psychology, 31, 497-502.

Powell, M., \& Ansic, D. (1997). Gender differences in risk behavior in financial decisionmaking: An experimental analysis. Journal of Economic Psychology, 18, 605-628. 
Prentice, D. A., \& Carranza, E. (2002). What women should be, shouldn't be, are allowed to be, and don't have to be: The contents of prescriptive gender stereotypes. Psychology of Women Quarterly, 26, 269-281.

Renzetti, C. M., Curran, D. J., \& Maier, S. L. (2012). Women, men, and society (6th ed.). Upper Saddle River, NJ: Pearson.

Reyna, V. F. (2004). How people make decisions that involve risk: A dual-process approach. Current Directions in Psychological Science, 13, 60-66.

Reyna, V. F. \& Brainerd, C. J. (2011). Dual processes in decision making and developmental neuroscience: A fuzzy-trace model. Developmental Review, 31, 180-206.

Roberti, J. W. (2004). A review of behavioral and biological correlates of sensation seeking. Journal of Research in Personality, 38, 256-279.

Rogers, R. D., Owen, A. M., Middleton, H. C., Williams, E. J., Pickard, J. D., Sahakian, B. J., \& Robbins, T. W. (1999). Choosing between small, likely rewards and large, unlikely rewards activates inferior and orbital prefrontal cortex. The Journal of Neuroscience, 20, 9029-9038.

Roszkowski, M. J. (1992). How to assess a client's financial risk tolerance: The basics. Bryn Mar, PA: The American College.

Roszkowski, M. J., Delaney, M. M., \& Cordell, D. M. (2009). Intraperson consistency in financial risk tolerance assessment: Temporal stability, relationship to total score, and effect on criterion-related validity. Journal of Business and Psychology, 24, 455-467.

Roszkowski, M. J., \& Grable, J. E. (2010). Gender differences in personal income and financial risk tolerance: How much of a connection? The Career Development Quarterly, 58, 270275. 
Roszkowski, M. J., \& Grable, J. E. (2005). Estimating risk tolerance: The degree of accuracy and the paramorphic representations of the estimate. Financial Counseling and Planning, 16, $29-47$.

Sadler-Smith, E. (2011). The intuitive style: Relationships with local/global and verbal/visual styles, gender, and superstitious reasoning. Learning and Individual Differences, 21, 263270.

Samanez-Larkin, G. R., Wagner, A. D., \& Knutson, B. (2011). Expected value information improves financial risk taking across the adult life span. Social Cognitive \& Affective Neuroscience, 6, 207-217.

Sapienza, P., Zingales, L., \& Maestripieri, D. (2009). Gender differences in financial risk aversion and career choices are affected by testosterone. Proceedings of the National Academy of Sciences, 106, 15268-15273.

Schwartz, L. M., Woloshin, S., Black, W. C., \& Welch, H. G. (1997). The role of numeracy in understanding the benefit of screening mammography. Annals of Internal Medicine, 127(11), 966-972.

Shrestha, L. B. (2006, August 16). CRS report for Congress: Life expectancy in the United States. Retrieved from http://aging.senate.gov/crs/aging1.pdf

Siegrist, M., Cvetkovich, F., \& Gutscher, H. (2002). Risk preference predictions and gender stereotypes. Organizational Behavior and Human Decision Processes, 87, 91-102.

Sinclair, M., Ashkanasy, N. M., \& Chattopadhyay, P. (2010). Affective antecedents of intuitive decision making. Journal of Management and Organization, 16, 382-298.

Sisk, C. L., \& Zehr, J. L. (2005). Pubertal hormones organize the adolescent brain and behavior. Frontiers in Neuroendocrinology, 26, 163-174. 
Slovic, P. (1986). Informing and educating the public about risk. Risk Analysis, 6, 403-415.

Slovic, P., Finucane, M., Peters, E., \& MacGregor, D. G. (2002). Rational actors or rational fools: Implications of the affect heuristic for behavioral economics. The Journal of SocioEconomics, 31, 329-342.

Smiler, A. (2006). Conforming to masculine norms: Evidence for validity among adult men and women. Sex Roles, 54, 767-775.

Strough, J., Leszczynski, J. P., Neely, T. L., Flinn, J. A., \& Margrett, J. (2007). From adolescence to later adulthood: Femininity, masculinity, and androgyny in six age groups. Sex Roles, 57, 385-396.

Strough, J., Parker, A. M., \& Bruine de Bruin, W. (2014). Understanding life-span developmental changes in decision-making competence. In T. M. Hess, J. Strough, \& C. E. Loeckenhoff (Eds.), Aging and decision making: Applied and empirical perspectives. San Diego, CA: Elsevier Academic Press.

Strough, J., Schlosnagle, L., Karns, T., Lemaster, P., \& Pichayayothin, N. (2014). No time to waste: Restricting life-span temporal horizons decreases the sunk-cost fallacy. Journal of Behavioral Decision Making, 27, 78-94.

Twenge, J. M. (1999). Mapping gender: The multifactorial approach and the organization of gender-related attributes. Psychology of Women Quarterly, 23(3), 485-502.

United States Census Bureau (2013). Educational attainment in the United States: 2013. Retrieved from https://www.census.gov/hhes/socdemo/education/

Van Duijvenvoorde, A. C. K., Jansen, B. R. J., Bredman, J. C., \& Huizenga, H. M. (2012). Agerelated changes in decision making: Comparing informed and noninformed situations. Developmental Psychology, 48, 192-203. 
Van Leijenhorst, L., Westenberg, P. M., \& Crone, E. A. (2008). A developmental study of risky decisions on the cake gambling task: Age and gender analyses of probability estimation and reward evaluation. Developmental Neuropsychology, 33, 179-196.

Vandello, J. A., Bosson, J. K., Cohen, D., Burnaford, R. M., \& Weaver, J. R. (2008). Precarious manhood. Journal of Personality and Social Psychology, 95, 1325-1339.

Weaver, J. R., Vandello, J. A., \& Bosson, J. K. (2013). Intrepid, imprudent, or impetuous? The effects of gender threats on men's financial decisions. Psychology of Men \& Masculinity, 14, 184-191.

Wilson, M., \& Daly, M. (1985). Competitiveness, risk-taking, and violence: The young male syndrome. Ethnology and Sociobiology, 6, 59-73.

Yang, L., \& Krampe, R. T. (2009). Long-term maintenance of retest learning in young old and oldest old adults. Journal of Gerontology: Psychological Sciences, 64, 608-611. 
Table 1

MANOVA: Gender and Age Group Main Effects and Interactions for Variables of Interest

\begin{tabular}{lccccc}
\hline & Wilks' $\lambda$ & $F$ & df & $p$ & $\eta_{\mathrm{p}}{ }^{2}$ \\
\hline Gender & .69 & 18.25 & 14,559 & $<.001$ & .31 \\
Age group & .76 & 5.89 & 28,1118 & $<.001$ & .13 \\
Gender x age group & .94 & 1.28 & 28,1118 & .154 & .03 \\
\hline
\end{tabular}

Note. Variables of interest included financial risk tolerance, masculine traits, feminine traits, masculine roles, gender identification, gender typicality, left 2D:4D, right 2D:4D, focus on opportunities, focus on limitations, affect heuristic, numeracy, income, and education. 
Table 2

Main Effects of Gender on Variables of Interest

\begin{tabular}{|c|c|c|c|c|c|c|}
\hline & Overall & Men & Women & $F$ & $\eta_{\mathrm{p}}^{2}$ & \\
\hline Financial risk tolerance & $\begin{array}{c}.00 \\
(.50)\end{array}$ & $\begin{array}{l}.12 \\
(.50)\end{array}$ & $\begin{array}{l}-.10 \\
(.48)\end{array}$ & $29.67_{c}$ & .05 & $\mathrm{M}>\mathrm{F}$ \\
\hline Masculine traits & $\begin{array}{l}4.47 \\
(.87)\end{array}$ & $\begin{array}{l}4.68 \\
(.87)\end{array}$ & $\begin{array}{l}4.29 \\
(.83)\end{array}$ & $29.30_{c}$ & .05 & $M>F$ \\
\hline Feminine traits & $\begin{array}{l}4.59 \\
(.80)\end{array}$ & $\begin{array}{l}4.29 \\
(.74)\end{array}$ & $\begin{array}{l}4.84 \\
(.77)\end{array}$ & $76.60_{\mathrm{c}}$ & .12 & $\mathrm{M}<\mathrm{F}$ \\
\hline Masculine roles & $\begin{array}{l}2.22 \\
(.30)\end{array}$ & $\begin{array}{l}2.36 \\
(.29)\end{array}$ & $\begin{array}{l}2.09 \\
(.25)\end{array}$ & $149.73_{\mathrm{c}}$ & .21 & $M>F$ \\
\hline Gender identification & $\begin{array}{l}3.61 \\
(.53)\end{array}$ & $\begin{array}{l}3.66 \\
(.59)\end{array}$ & $\begin{array}{l}3.57 \\
(.47)\end{array}$ & 3.76 & .01 & $\mathrm{M}=\mathrm{F}$ \\
\hline Gender typicality & $\begin{array}{l}2.86 \\
(.61)\end{array}$ & $\begin{array}{l}2.93 \\
(.59)\end{array}$ & $\begin{array}{l}2.79 \\
(.63)\end{array}$ & $5.94_{a}$ & .01 & $\mathrm{M}>\mathrm{F}$ \\
\hline Left 2D:4D & $\begin{array}{l}1.03 \\
(.12)\end{array}$ & $\begin{array}{l}1.03 \\
(.11)\end{array}$ & $\begin{array}{l}1.03 \\
(.12)\end{array}$ & .00 & .00 & $\mathrm{M}=\mathrm{F}$ \\
\hline Right 2D:4D & $\begin{array}{l}1.03 \\
(.11)\end{array}$ & $\begin{array}{l}1.03 \\
(.11)\end{array}$ & $\begin{array}{l}1.03 \\
(.10)\end{array}$ & .03 & .00 & $\mathrm{M}=\mathrm{F}$ \\
\hline Focus on opportunities & $\begin{array}{c}4.67 \\
(1.41)\end{array}$ & $\begin{array}{c}4.59 \\
(1.39)\end{array}$ & $\begin{array}{c}4.74 \\
(1.43)\end{array}$ & 1.15 & .00 & $\mathrm{M}=\mathrm{F}$ \\
\hline Focus on limitations & $\begin{array}{c}4.50 \\
(1.43)\end{array}$ & $\begin{array}{c}4.54 \\
(1.42)\end{array}$ & $\begin{array}{c}4.47 \\
(1.45)\end{array}$ & .56 & .00 & $\mathrm{M}=\mathrm{F}$ \\
\hline Affect heuristic & $\begin{array}{l}2.66 \\
(.90)\end{array}$ & $\begin{array}{l}2.53 \\
(.95)\end{array}$ & $\begin{array}{l}2.78 \\
(.84)\end{array}$ & $11.81_{\mathrm{b}}$ & .02 & $\mathrm{M}<\mathrm{F}$ \\
\hline Numeracy & $\begin{array}{c}1.14 \\
(1.21)\end{array}$ & $\begin{array}{c}1.33 \\
(1.30)\end{array}$ & $\begin{array}{c}.97 \\
(1.11)\end{array}$ & $15.81_{\mathrm{c}}$ & .03 & $\mathrm{M}>\mathrm{F}$ \\
\hline Income & $\begin{array}{c}4.23 \\
(2.34)\end{array}$ & $\begin{array}{c}4.83 \\
(2.39)\end{array}$ & $\begin{array}{c}3.71 \\
(2.17)\end{array}$ & $32.15_{c}$ & .05 & $M>F$ \\
\hline Education & $\begin{array}{c}4.19 \\
(1.45)\end{array}$ & $\begin{array}{c}4.23 \\
(1.47)\end{array}$ & $\begin{array}{c}4.16 \\
(1.44)\end{array}$ & .32 & .00 & $\mathrm{M}=\mathrm{F}$ \\
\hline
\end{tabular}

Note. Means are presented within the cells with standard deviations in parentheses. There was 1 between-subjects degree of freedom and 572 error degrees of freedom in each $F$ test.

${ }^{\mathrm{a}} p<.05,{ }^{\mathrm{b}} p<.01,{ }^{\mathrm{c}} p<.001$ 
Table 3

Main Effects of Age Group on Variables of Interest

\begin{tabular}{|c|c|c|c|c|c|c|c|}
\hline & Overall & YA & MA & $\mathrm{OA}$ & $F$ & $\eta_{\mathrm{p}}{ }^{2}$ & \\
\hline $\begin{array}{l}\text { Financial risk } \\
\text { tolerance }\end{array}$ & $\begin{array}{l}.00 \\
(.50)\end{array}$ & $\begin{array}{l}.07 \\
(.52)\end{array}$ & $\begin{array}{l}-.02 \\
(.47)\end{array}$ & $\begin{array}{l}-.05 \\
(.51)\end{array}$ & $3.91_{\mathrm{a}}$ & .01 & $\begin{array}{l}\mathrm{YA}=\mathrm{MA} \\
\mathrm{YA}>\mathrm{OA} \\
\mathrm{MA}=\mathrm{OA}\end{array}$ \\
\hline Masculine traits & $\begin{array}{l}4.47 \\
(.87)\end{array}$ & $\begin{array}{l}4.47 \\
(.89)\end{array}$ & $\begin{array}{l}4.39 \\
(.87)\end{array}$ & $\begin{array}{l}4.57 \\
(.84)\end{array}$ & 1.47 & .01 & $\mathrm{YA}=\mathrm{MA}=\mathrm{OA}$ \\
\hline Feminine traits & $\begin{array}{l}4.59 \\
(.80)\end{array}$ & $\begin{array}{l}4.61 \\
(.80)\end{array}$ & $\begin{array}{l}4.59 \\
(.86)\end{array}$ & $\begin{array}{l}4.55 \\
(.74)\end{array}$ & .45 & .00 & $\mathrm{YA}=\mathrm{MA}=\mathrm{OA}$ \\
\hline Masculine roles & $\begin{array}{l}2.22 \\
(.30)\end{array}$ & $\begin{array}{l}2.22 \\
(.31)\end{array}$ & $\begin{array}{l}2.23 \\
(.29)\end{array}$ & $\begin{array}{l}2.21 \\
(.30)\end{array}$ & 1.71 & .01 & $\mathrm{YA}=\mathrm{MA}=\mathrm{OA}$ \\
\hline $\begin{array}{l}\text { Gender } \\
\text { identification }\end{array}$ & $\begin{array}{l}3.61 \\
(.53)\end{array}$ & $\begin{array}{l}3.58 \\
(.54)\end{array}$ & $\begin{array}{l}3.62 \\
(.50)\end{array}$ & $\begin{array}{l}3.63 \\
(.57)\end{array}$ & .57 & .00 & $\mathrm{YA}=\mathrm{MA}=\mathrm{OA}$ \\
\hline Gender typicality & $\begin{array}{l}2.86 \\
(.61)\end{array}$ & $\begin{array}{l}2.79 \\
(.58)\end{array}$ & $\begin{array}{l}2.78 \\
(.64)\end{array}$ & $\begin{array}{l}3.02 \\
(.58)\end{array}$ & $8.69_{\mathrm{c}}$ & .03 & $\begin{array}{l}\mathrm{YA}=\mathrm{MA} \\
\mathrm{YA}<\mathrm{OA} \\
\mathrm{MA}<\mathrm{OA}\end{array}$ \\
\hline Left 2D:4D & $\begin{array}{l}1.03 \\
(.12)\end{array}$ & $\begin{array}{l}1.03 \\
(.12)\end{array}$ & $\begin{array}{l}1.02 \\
(.10)\end{array}$ & $\begin{array}{l}1.03 \\
(.13)\end{array}$ & .46 & .00 & $\mathrm{YA}=\mathrm{MA}=\mathrm{OA}$ \\
\hline Right 2D:4D & $\begin{array}{l}1.03 \\
(.11)\end{array}$ & $\begin{array}{l}1.02 \\
(.09)\end{array}$ & $\begin{array}{l}1.03 \\
(.11)\end{array}$ & $\begin{array}{l}1.03 \\
(.12)\end{array}$ & .47 & .00 & $\mathrm{YA}=\mathrm{MA}=\mathrm{OA}$ \\
\hline $\begin{array}{l}\text { Focus on } \\
\text { opportunities }\end{array}$ & $\begin{array}{c}4.67 \\
(1.41)\end{array}$ & $\begin{array}{c}5.29 \\
(1.17)\end{array}$ & $\begin{array}{c}4.53 \\
(1.42)\end{array}$ & $\begin{array}{c}4.15 \\
(1.40)\end{array}$ & $35.65_{c}$ & .11 & $\mathrm{YA}>\mathrm{MA}>\mathrm{OA}$ \\
\hline $\begin{array}{l}\text { Focus on } \\
\text { limitations }\end{array}$ & $\begin{array}{c}4.50 \\
(1.43)\end{array}$ & $\begin{array}{c}3.90 \\
(1.38)\end{array}$ & $\begin{array}{c}4.75 \\
(1.32)\end{array}$ & $\begin{array}{c}4.89 \\
(1.40)\end{array}$ & $30.30_{\mathrm{c}}$ & .10 & $\begin{array}{l}\mathrm{YA}<\mathrm{MA} \\
\mathrm{YA}<\mathrm{OA} \\
\mathrm{MA}=\mathrm{OA}\end{array}$ \\
\hline Affect heuristic & $\begin{array}{l}2.66 \\
(.90)\end{array}$ & $\begin{array}{l}2.71 \\
(.92)\end{array}$ & $\begin{array}{l}2.68 \\
(.81)\end{array}$ & $\begin{array}{l}2.60 \\
(.96)\end{array}$ & .46 & .00 & $\mathrm{YA}=\mathrm{MA}=\mathrm{OA}$ \\
\hline Numeracy & $\begin{array}{c}1.14 \\
(1.21)\end{array}$ & $\begin{array}{c}1.21 \\
(1.20)\end{array}$ & $\begin{array}{c}1.23 \\
(1.28)\end{array}$ & $\begin{array}{c}.96 \\
(1.13)\end{array}$ & 3.57 & .01 & $\mathrm{YA}=\mathrm{MA}=\mathrm{OA}$ \\
\hline Income & $\begin{array}{c}4.23 \\
(2.34)\end{array}$ & $\begin{array}{c}4.17 \\
(2.27)\end{array}$ & $\begin{array}{c}4.15 \\
(2.40)\end{array}$ & $\begin{array}{c}4.40 \\
(2.35)\end{array}$ & .09 & .00 & $\mathrm{YA}=\mathrm{MA}=\mathrm{OA}$ \\
\hline
\end{tabular}




\begin{tabular}{lccccccc}
\hline Education & 4.19 & 4.17 & 4.21 & 4.12 & .00 & .00 & $\mathrm{YA}=\mathrm{MA}=\mathrm{OA}$ \\
& $(1.45)$ & $(1.45)$ & $(1.41)$ & $(1.51)$ & & & \\
\hline
\end{tabular}

Note. $\mathrm{YA}=$ younger adults, $\mathrm{MA}=$ middle-aged adults, $\mathrm{OA}=$ older adults. Means are presented within the cells with standard deviations in parentheses. There were 2 between-subjects degree of freedom and 572 error degrees of freedom in each $F$ test. Bonferroni-corrected contrasts were examined to probe age group differences. ${ }^{\mathrm{a}} p<.05,{ }^{\mathrm{b}} p<.01,{ }^{\mathrm{c}} p<.001$ 
Table 4

Gender by Age Group Interactions for Variables of Interest

\begin{tabular}{|c|c|c|c|c|c|c|c|c|c|}
\hline & Overall & $\begin{array}{l}\text { YA } \\
\text { Men }\end{array}$ & $\begin{array}{l}\text { MA } \\
\text { Men }\end{array}$ & $\begin{array}{l}\text { OA } \\
\text { Men }\end{array}$ & $\begin{array}{c}\text { YA } \\
\text { Women }\end{array}$ & $\begin{array}{c}\text { MA } \\
\text { Women }\end{array}$ & $\begin{array}{c}\text { OA } \\
\text { Women }\end{array}$ & $F$ & $\eta_{\mathrm{p}}^{2}$ \\
\hline $\begin{array}{l}\text { Financial risk } \\
\text { tolerance }\end{array}$ & $\begin{array}{c}.00 \\
(.50)\end{array}$ & $\begin{array}{c}.26 \\
(.47)\end{array}$ & $\begin{array}{c}.01 \\
(.51)\end{array}$ & $\begin{array}{c}.07 \\
(.49)\end{array}$ & $\begin{array}{l}-.10 \\
(.51)\end{array}$ & $\begin{array}{l}-.05 \\
(.44)\end{array}$ & $\begin{array}{l}-.18 \\
(.50)\end{array}$ & 4.59 & .02 \\
\hline Masculine traits & $\begin{array}{l}4.47 \\
(.87)\end{array}$ & $\begin{array}{l}4.76 \\
(.73)\end{array}$ & $\begin{array}{l}4.55 \\
(.95)\end{array}$ & $\begin{array}{l}4.74 \\
(.92)\end{array}$ & $\begin{array}{l}4.20 \\
(.94)\end{array}$ & $\begin{array}{l}4.29 \\
(.81)\end{array}$ & $\begin{array}{l}4.40 \\
(.71)\end{array}$ & 1.74 & .01 \\
\hline Feminine traits & $\begin{array}{l}4.59 \\
(.80)\end{array}$ & $\begin{array}{l}4.29 \\
(.66)\end{array}$ & $\begin{array}{l}4.19 \\
(.85)\end{array}$ & $\begin{array}{l}4.37 \\
(.70)\end{array}$ & $\begin{array}{l}4.89 \\
(.81)\end{array}$ & $\begin{array}{l}4.85 \\
(.76)\end{array}$ & $\begin{array}{l}4.77 \\
(.73)\end{array}$ & 1.50 & .01 \\
\hline Masculine roles & $\begin{array}{l}2.22 \\
(.30)\end{array}$ & $\begin{array}{l}2.39 \\
(.29)\end{array}$ & $\begin{array}{l}2.36 \\
(.31)\end{array}$ & $\begin{array}{l}2.34 \\
(.28)\end{array}$ & $\begin{array}{l}2.06 \\
(.24)\end{array}$ & $\begin{array}{l}2.14 \\
(.24)\end{array}$ & $\begin{array}{l}2.06 \\
(.26)\end{array}$ & 1.86 & .01 \\
\hline $\begin{array}{l}\text { Gender } \\
\text { identification }\end{array}$ & $\begin{array}{l}3.61 \\
(.53)\end{array}$ & $\begin{array}{l}3.64 \\
(.63)\end{array}$ & $\begin{array}{l}3.70 \\
(.53)\end{array}$ & $\begin{array}{l}3.63 \\
(.63)\end{array}$ & $\begin{array}{l}3.52 \\
(.44)\end{array}$ & $\begin{array}{l}3.57 \\
(.47)\end{array}$ & $\begin{array}{l}3.63 \\
(.52)\end{array}$ & .77 & .00 \\
\hline Gender typicality & $\begin{array}{l}2.86 \\
(.61)\end{array}$ & $\begin{array}{l}2.90 \\
(.51)\end{array}$ & $\begin{array}{l}2.80 \\
(.69)\end{array}$ & $\begin{array}{l}3.08 \\
(.54)\end{array}$ & $\begin{array}{l}2.68 \\
(.63)\end{array}$ & $\begin{array}{l}2.77 \\
(.62)\end{array}$ & $\begin{array}{l}2.96 \\
(.61)\end{array}$ & 1.09 & .00 \\
\hline Left 2D:4D & $\begin{array}{l}1.03 \\
(.12)\end{array}$ & $\begin{array}{l}1.03 \\
(.11)\end{array}$ & $\begin{array}{l}1.02 \\
(.11)\end{array}$ & $\begin{array}{l}1.03 \\
(.11)\end{array}$ & $\begin{array}{l}1.02 \\
(.12)\end{array}$ & $\begin{array}{l}1.02 \\
(.09)\end{array}$ & $\begin{array}{l}1.03 \\
(.15)\end{array}$ & .17 & .00 \\
\hline Right 2D:4D & $\begin{array}{l}1.03 \\
(.11)\end{array}$ & $\begin{array}{l}1.02 \\
(.09)\end{array}$ & $\begin{array}{l}1.03 \\
(.11)\end{array}$ & $\begin{array}{l}1.02 \\
(.13)\end{array}$ & $\begin{array}{l}1.02 \\
(.09)\end{array}$ & $\begin{array}{l}1.03 \\
(.10)\end{array}$ & $\begin{array}{l}1.03 \\
(.11)\end{array}$ & .17 & .00 \\
\hline $\begin{array}{l}\text { Focus on } \\
\text { opportunities }\end{array}$ & $\begin{array}{c}4.67 \\
(1.41)\end{array}$ & $\begin{array}{c}5.29 \\
(1.06)\end{array}$ & $\begin{array}{c}4.30 \\
(1.44)\end{array}$ & $\begin{array}{c}4.15 \\
(1.40)\end{array}$ & $\begin{array}{c}5.28 \\
(1.27)\end{array}$ & $\begin{array}{c}4.68 \\
(1.40)\end{array}$ & $\begin{array}{c}4.15 \\
(1.44)\end{array}$ & 1.27 & .00 \\
\hline $\begin{array}{l}\text { Focus on } \\
\text { limitations }\end{array}$ & $\begin{array}{c}4.50 \\
(1.43)\end{array}$ & $\begin{array}{c}3.95 \\
(1.42)\end{array}$ & $\begin{array}{c}4.89 \\
(1.37)\end{array}$ & $\begin{array}{c}4.88 \\
(1.28)\end{array}$ & $\begin{array}{c}3.86 \\
(1.36)\end{array}$ & $\begin{array}{c}4.68 \\
(1.28)\end{array}$ & $\begin{array}{c}4.92 \\
(1.54)\end{array}$ & .40 & .00 \\
\hline Affect heuristic & $\begin{array}{l}2.66 \\
(.90)\end{array}$ & $\begin{array}{c}2.64 \\
(1.01)\end{array}$ & $\begin{array}{l}2.58 \\
(.87)\end{array}$ & $\begin{array}{l}2.38 \\
(.94)\end{array}$ & $\begin{array}{l}2.78 \\
(.83)\end{array}$ & $\begin{array}{l}2.73 \\
(.78)\end{array}$ & $\begin{array}{l}2.87 \\
(.94)\end{array}$ & 2.32 & .01 \\
\hline Numeracy & $\begin{array}{c}1.14 \\
(1.21)\end{array}$ & $\begin{array}{c}1.34 \\
(1.26)\end{array}$ & $\begin{array}{c}1.56 \\
(1.34)\end{array}$ & $\begin{array}{c}1.17 \\
(1.29)\end{array}$ & $\begin{array}{c}1.09 \\
(1.13)\end{array}$ & $\begin{array}{c}1.02 \\
(1.20)\end{array}$ & $\begin{array}{c}.77 \\
(.89)\end{array}$ & .76 & .00 \\
\hline Income & $\begin{array}{c}4.23 \\
(2.34)\end{array}$ & $\begin{array}{c}4.58 \\
(2.30)\end{array}$ & $\begin{array}{c}4.80 \\
(2.40)\end{array}$ & $\begin{array}{c}4.89 \\
(2.33)\end{array}$ & $\begin{array}{c}3.75 \\
(2.14)\end{array}$ & $\begin{array}{c}3.69 \\
(2.26)\end{array}$ & $\begin{array}{c}3.62 \\
(1.99)\end{array}$ & .48 & .00 \\
\hline
\end{tabular}




\begin{tabular}{lccccccccc}
\hline & & & & & & & & & \\
Education & 4.19 & 4.17 & 4.09 & 4.39 & 4.18 & 4.27 & 3.99 & 1.95 & .01 \\
& $(1.45)$ & $(1.41)$ & $(1.37)$ & $(1.60)$ & $(1.49)$ & $(1.43)$ & $(1.38)$ & & \\
\hline
\end{tabular}

Note. $\mathrm{YA}=$ young adult, $\mathrm{MA}=$ middle-aged, $\mathrm{OA}=$ older adult. Means are presented within the cells with standard deviations in parentheses. There were 2 between-subjects degree of freedom and 572 error degrees of freedom in each $F$ test. None of the gender by age group interactions was significant. 
Table 5

Correlations for Variables of Interest: Overall Sample

\begin{tabular}{|c|c|c|c|c|c|c|c|c|c|c|c|c|c|c|}
\hline & 2 & 3 & 4 & 5 & 6 & 7 & 8 & 9 & 10 & 11 & 12 & 13 & 14 & 15 \\
\hline 1. Age & $-.09_{\mathrm{a}}$ & .01 & -.02 & -.04 & .04 & $.13_{\mathrm{b}}$ & .00 & .03 & $-.36_{\mathrm{c}}$ & $.31_{\mathrm{c}}$ & -.06 & -.07 & .00 & .00 \\
\hline $\begin{array}{l}\text { 2. Financial risk } \\
\text { tolerance }\end{array}$ & -- & $.31_{\mathrm{c}}$ & $-.14_{b}$ & $.41_{\mathrm{c}}$ & .04 & .04 & -.04 & -.03 & $.33_{\mathrm{c}}$ & $-.20_{c}$ & $-.11_{\mathrm{b}}$ & .06 & $.31_{\mathrm{c}}$ & $.16_{\mathrm{c}}$ \\
\hline 3. Masculine traits & & -- & $.09_{\mathrm{a}}$ & $.30_{\mathrm{c}}$ & $.26_{\mathrm{c}}$ & $.21_{\mathrm{c}}$ & .04 & .03 & $.39_{\mathrm{c}}$ & $-.18_{\mathrm{c}}$ & $.08_{\mathrm{a}}$ & -.07 & $.32_{\mathrm{c}}$ & $.13_{\mathrm{b}}$ \\
\hline 4. Feminine traits & & & -- & $-.47_{\mathrm{c}}$ & $.27_{\mathrm{c}}$ & $.25_{\mathrm{c}}$ & .06 & -.02 & $.27_{\mathrm{c}}$ & -.06 & $.21_{\mathrm{c}}$ & $-.19 \mathrm{c}$ & -.05 & -.05 \\
\hline 5. Masculine roles & & & & -- & .03 & -.02 & -.02 & .04 & .00 & -.03 & $-.27_{\mathrm{c}}$ & .05 & $.17_{\mathrm{c}}$ & .05 \\
\hline $\begin{array}{l}\text { 6. Gender } \\
\text { identification }\end{array}$ & & & & & -- & $.57_{\mathrm{c}}$ & .02 & .01 & $.21_{\mathrm{c}}$ & -.08 & $.18_{\mathrm{c}}$ & .08 & $.11_{\mathrm{b}}$ & $-.099_{\mathrm{a}}$ \\
\hline 7. Gender typicality & & & & & & -- & .06 & .01 & $.19_{\mathrm{c}}$ & -.07 & .06 & $-.21_{\mathrm{c}}$ & $.15_{\mathrm{c}}$ & -.04 \\
\hline 8. Left 2D:4D & & & & & & & -- & $.45_{\mathrm{c}}$ & .05 & -.03 & .06 & $-.08_{\mathrm{a}}$ & -.03 & -.05 \\
\hline 9. Right 2D:4D & & & & & & & & -- & .01 & -.04 & .03 & $-.08_{\mathrm{a}}$ & .01 & -.04 \\
\hline $\begin{array}{l}\text { 10. Focus on } \\
\text { opportunities }\end{array}$ & & & & & & & & & -- & $-.60_{\mathrm{c}}$ & $.09_{\mathrm{a}}$ & $-.11_{\mathrm{b}}$ & $.20_{\mathrm{c}}$ & .05 \\
\hline 11. Focus on limitations & & & & & & & & & & -- & .06 & .07 & $-.18_{\mathrm{c}}$ & $-.11_{\mathrm{b}}$ \\
\hline 12. Affect heuristic & & & & & & & & & & & -- & .06 & -.01 & .00 \\
\hline 13. Numeracy & & & & & & & & & & & & -- & .04 & $.21_{\mathrm{c}}$ \\
\hline 14. Income & & & & & & & & & & & & & -- & $.34_{\mathrm{c}}$ \\
\hline 15. Education & & & & & & & & & & & & & & -- \\
\hline
\end{tabular}

${ }^{\mathrm{a}} p<.05,{ }^{\mathrm{b}} p<.01,{ }^{\mathrm{c}} p<.001$ 
Table 6

Correlations for Variables of Interest by Gender

\begin{tabular}{|c|c|c|c|c|c|c|c|c|c|c|c|c|c|c|c|}
\hline & 1 & 2 & 3 & 4 & 5 & 6 & 7 & 8 & 9 & 10 & 11 & 12 & 13 & 14 & 15 \\
\hline 1. Age & -- & $-.16_{\mathrm{b}}$ & -.03 & .05 & -.11 & -.01 & .10 & -.04 & .00 & $-.39_{\mathrm{c}}$ & $.31_{\mathrm{c}}$ & $-.13_{\mathrm{a}}$ & -.05 & .03 & .06 \\
\hline $\begin{array}{l}\text { 2. Financial risk } \\
\text { tolerance }\end{array}$ & -.04 & -- & $.25_{\mathrm{c}}$ & -.01 & $.38_{\mathrm{c}}$ & .02 & .07 & -.02 & -.03 & $.37_{\mathrm{c}}$ & $-.20_{\mathrm{b}}$ & $-.14_{\mathrm{a}}$ & .01 & $.24_{\mathrm{c}}$ & .09 \\
\hline 3. Masculine traits & .04 & $.30_{\mathrm{c}}$ & -- & $.35_{\mathrm{c}}$ & $.22_{\mathrm{c}}$ & $.45_{\mathrm{c}}$ & $.46_{\mathrm{c}}$ & .06 & .05 & $.44_{\mathrm{c}}$ & $-.13_{\mathrm{a}}$ & $.16_{\mathrm{b}}$ & -.11 & $.32_{\mathrm{c}}$ & .08 \\
\hline 4. Feminine traits & -.06 & $-.12_{\mathrm{a}}$ & .05 & -- & $-.33_{\mathrm{c}}$ & $.24_{\mathrm{c}}$ & $.22_{\mathrm{c}}$ & .00 & -.08 & $.25_{\mathrm{c}}$ & .02 & .11 & $-.14_{a}$ & .05 & -.05 \\
\hline 5. Masculine roles & .02 & $.35_{\mathrm{c}}$ & $.23_{\mathrm{c}}$ & $-.41_{c}$ & -- & $.13_{\mathrm{a}}$ & .11 & .01 & $.13_{\mathrm{a}}$ & .10 & -.06 & $-.17_{\mathrm{b}}$ & -.08 & .06 & .01 \\
\hline $\begin{array}{l}\text { 6. Gender } \\
\text { identification }\end{array}$ & .08 & .02 & .01 & $.40_{\mathrm{c}}$ & $-.19 \mathrm{~b}$ & -- & $.58_{\mathrm{c}}$ & -.05 & .01 & $.25_{\mathrm{c}}$ & -.07 & $.19_{\mathrm{b}}$ & -.08 & $.14_{\mathrm{a}}$ & -.10 \\
\hline 7. Gender typicality & $.16_{b}$ & -.03 & -.03 & $.39_{\mathrm{c}}$ & $-.26_{c}$ & $.57_{\mathrm{c}}$ & -- & .01 & -.01 & $.32_{\mathrm{c}}$ & $-.18_{\mathrm{b}}$ & .02 & $-.28_{\mathrm{c}}$ & $.18_{\mathrm{b}}$ & -.01 \\
\hline 8. Left 2D:4D & .03 & -.05 & .02 & $.12_{\mathrm{a}}$ & -.07 & .09 & .10 & -- & $.57_{\mathrm{c}}$ & .04 & .00 & .02 & -.06 & .00 & -.03 \\
\hline 9. Right 2D:4D & .05 & -.03 & .00 & .03 & -.05 & .03 & .03 & $.35_{\mathrm{c}}$ & -- & -.02 & .00 & .04 & -.05 & .03 & -.02 \\
\hline $\begin{array}{l}\text { 10. Focus on } \\
\text { opportunities }\end{array}$ & $-.33_{\mathrm{c}}$ & $.32_{\mathrm{c}}$ & $.39_{\mathrm{c}}$ & $.28_{\mathrm{c}}$ & -.05 & $.19_{\mathrm{b}}$ & .10 & .06 & .03 & -- & $-.56_{\mathrm{c}}$ & .07 & -.11 & $.26_{\mathrm{c}}$ & .00 \\
\hline 11. Focus on limitations & $.32_{\mathrm{c}}$ & $-.22_{c}$ & $-.25_{\mathrm{c}}$ & -.10 & -.03 & -.09 & .01 & -.05 & -.08 & $-.63_{\mathrm{c}}$ & -- & .07 & .06 & $-.16_{a}$ & -.09 \\
\hline 12. Affect heuristic & .01 & -.02 & .08 & $.23_{\mathrm{c}}$ & $-.30_{c}$ & $.19_{\mathrm{b}}$ & $.14_{\mathrm{a}}$ & .11 & .02 & .11 & .05 & -- & $.14_{\mathrm{a}}$ & .03 & -.02 \\
\hline 13. Numeracy & -.10 & .04 & -.10 & $-.16_{b}$ & .06 & -.11 & $-.20_{\mathrm{b}}$ & -.11 & $-.13_{\mathrm{a}}$ & -.10 & .08 & .01 & -- & .03 & $.16_{\mathrm{b}}$ \\
\hline 14. Income & -.04 & $.30_{\mathrm{c}}$ & $.24_{c}$ & .03 & .09 & .04 & .09 & -.07 & -.01 & $.19_{\mathrm{b}}$ & $-.23_{\mathrm{c}}$ & .02 & -.02 & -- & $.35_{\mathrm{c}}$ \\
\hline 15. Education & -.06 & $.23_{\mathrm{c}}$ & $.17_{\mathrm{b}}$ & -.04 & .07 & -.08 & -.06 & -.08 & -.07 & .10 & $-.13_{\mathrm{a}}$ & .03 & $.25_{\mathrm{c}}$ & $.34_{c}$ & -- \\
\hline
\end{tabular}

Note. Men are above the diagonal, and women below. ${ }^{\mathrm{a}} p<.05,{ }^{\mathrm{b}} p<.01,{ }^{\mathrm{c}} p<.001$ 
Table 7

Correlations for Variables of Interest: Young Adults

\begin{tabular}{|c|c|c|c|c|c|c|c|c|c|c|c|c|c|c|c|}
\hline & 1 & 2 & 3 & 4 & 5 & 6 & 7 & 8 & 9 & 10 & 11 & 12 & 13 & 14 & 15 \\
\hline 1. Age & -- & -.05 & .05 & -.01 & -.04 & .07 & .08 & -.12 & -.11 & -.06 & .07 & $-.30_{\mathrm{b}}$ & -.11 & .08 & .05 \\
\hline $\begin{array}{l}\text { 2. Financial risk } \\
\text { tolerance }\end{array}$ & .16 & -- & $.25_{\mathrm{a}}$ & .05 & $.36_{\mathrm{c}}$ & .04 & -.01 & .03 & .10 & $.24_{\mathrm{a}}$ & .03 & -.01 & -.01 & .18 & .04 \\
\hline 3. Masculine traits & -.16 & $.37_{\mathrm{c}}$ & -- & $.35_{\mathrm{c}}$ & $.28_{\mathrm{b}}$ & $.40_{\mathrm{c}}$ & $.43_{\mathrm{c}}$ & .02 & -.10 & $.53_{\mathrm{c}}$ & -.14 & .05 & -.08 & $.39_{\mathrm{c}}$ & .18 \\
\hline 4. Feminine traits & .02 & -.06 & .13 & -- & $-.32_{b}$ & $.21_{\mathrm{a}}$ & $.23_{\mathrm{a}}$ & -.03 & -.05 & $.38_{\mathrm{c}}$ & -.03 & -.03 & $-.25 \mathrm{a}$ & .10 & -.05 \\
\hline 5. Masculine roles & .03 & $.40_{\mathrm{c}}$ & $.26_{\mathrm{b}}$ & $-.40_{\mathrm{c}}$ & -- & $.22_{\mathrm{a}}$ & $.20 \mathrm{a}$ & .06 & .02 & .04 & -.06 & -.14 & -.09 & .00 & -.08 \\
\hline $\begin{array}{l}\text { 6. Gender } \\
\text { identification }\end{array}$ & -.04 & .07 & .04 & $.44_{\mathrm{c}}$ & -.17 & -- & $.69 \mathrm{c}$ & -.13 & -.17 & $.33_{\mathrm{b}}$ & -.11 & .08 & -.17 & .17 & -.05 \\
\hline 7. Gender typicality & $-.23_{\mathrm{a}}$ & .07 & .07 & $.39 \mathrm{c}$ & -.18 & $.58_{\mathrm{c}}$ & -- & .00 & -.12 & $.38_{\mathrm{c}}$ & $-.22_{\mathrm{a}}$ & -.01 & $-.40_{\mathrm{c}}$ & $.21_{\mathrm{a}}$ & .06 \\
\hline 8. Left 2D:4D & .09 & -.17 & -.14 & .04 & $-.20_{\mathrm{a}}$ & .08 & .11 & -- & $.63_{\mathrm{c}}$ & -.03 & .01 & .06 & -.02 & .10 & -.05 \\
\hline 9. Right 2D:4D & .04 & -.09 & -.04 & .11 & -.13 & $.22_{\mathrm{a}}$ & .02 & $.36_{\mathrm{c}}$ & -- & -.13 & .04 & .07 & .03 & .08 & -.08 \\
\hline $\begin{array}{l}\text { 10. Focus on } \\
\text { opportunities }\end{array}$ & -.03 & $.35_{\mathrm{c}}$ & $.46_{\mathrm{c}}$ & $.28_{\mathrm{b}}$ & -.13 & $.22_{\mathrm{a}}$ & .18 & -.08 & -.01 & -- & $-.46_{\mathrm{c}}$ & .12 & -.17 & .11 & .00 \\
\hline 11. Focus on limitations & .04 & -.15 & $-.34_{c}$ & -.15 & .04 & -.17 & -.15 & .02 & -.10 & $-.49_{\mathrm{c}}$ & -- & .04 & .10 & -.01 & -.05 \\
\hline 12. Affect heuristic & -.08 & -.04 & .07 & $.34_{\mathrm{c}}$ & $-.32_{b}$ & $.27_{\mathrm{b}}$ & $.21_{\mathrm{a}}$ & .03 & .10 & .15 & .04 & -- & .17 & .02 & -.03 \\
\hline 13. Numeracy & .14 & .04 & -.10 & -.09 & -.01 & -.02 & -.11 & -.04 & -.05 & -.03 & $.19 \mathrm{a}$ & .14 & -- & .05 & $.26_{\mathrm{a}}$ \\
\hline 14. Income & .04 & $.31_{\mathrm{b}}$ & $.45_{\mathrm{c}}$ & .05 & .16 & .06 & .07 & -.09 & .04 & .19 & $-.30_{b}$ & .06 & -.04 & -- & $.47_{\mathrm{c}}$ \\
\hline 15. Education & -.13 & .16 & .16 & .02 & .07 & .08 & .18 & .10 & .07 & -.07 & -.12 & .11 & .11 & .41 & -- \\
\hline
\end{tabular}

Note. Men are above the diagonal, and women below. ${ }^{\mathrm{a}} p<.05,{ }^{\mathrm{b}} p<.01,{ }^{\mathrm{c}} p<.001$ 
Table 8

Correlations for Variables of Interest: Middle-aged Adults

\begin{tabular}{|c|c|c|c|c|c|c|c|c|c|c|c|c|c|c|c|}
\hline & 1 & 2 & 3 & 4 & 5 & 6 & 7 & 8 & 9 & 10 & 11 & 12 & 13 & 14 & 15 \\
\hline 1. Age & -- & -.07 & $-.25_{\mathrm{a}}$ & -.01 & -.15 & -.02 & $-.23_{\mathrm{a}}$ & -.10 & -.01 & $-.45_{c}$ & $.36_{b}$ & .11 & .04 & $-.40_{c}$ & .01 \\
\hline $\begin{array}{l}\text { 2. Financial risk } \\
\text { tolerance }\end{array}$ & -.03 & -- & $.34_{b}$ & -.09 & $.43_{\mathrm{c}}$ & .10 & $.27_{\mathrm{a}}$ & $-.31_{b}$ & -.21 & $.37_{\mathrm{b}}$ & -.17 & $-.24_{\mathrm{a}}$ & -.10 & $.27_{\mathrm{a}}$ & .09 \\
\hline 3. Masculine traits & -.17 & $.27_{\mathrm{b}}$ & -- & .09 & $.30_{\mathrm{b}}$ & $.43_{\mathrm{c}}$ & $.51_{c}$ & .19 & $.22_{\mathrm{a}}$ & $.49_{\mathrm{c}}$ & -.21 & .03 & -.19 & $.23_{\mathrm{a}}$ & -.16 \\
\hline 4. Feminine traits & -.04 & -.11 & -.01 & -- & $-.49_{\mathrm{c}}$ & .11 & .06 & .14 & .00 & .20 & .02 & .05 & -.16 & -.07 & $-.31_{b}$ \\
\hline 5. Masculine roles & -.05 & $.30_{\mathrm{b}}$ & $.28_{\mathrm{b}}$ & $-.43_{\mathrm{c}}$ & -- & .17 & $.24_{\mathrm{a}}$ & -.19 & .02 & .18 & -.12 & -.11 & -.03 & .05 & .04 \\
\hline $\begin{array}{l}\text { 6. Gender } \\
\text { identification }\end{array}$ & .08 & -.05 & .03 & $.39_{\mathrm{c}}$ & -.17 & -- & $.63_{\mathrm{c}}$ & .10 & .14 & $.26_{\mathrm{a}}$ & -.19 & .19 & -.15 & .12 & -.13 \\
\hline 7. Gender typicality & .18 & -.04 & -.08 & $.41_{\mathrm{c}}$ & $-.31_{b}$ & $.56_{\mathrm{c}}$ & -- & .06 & .13 & $.49_{\mathrm{c}}$ & $-.44_{c}$ & -.07 & $-.25_{\mathrm{a}}$ & $.29_{\mathrm{b}}$ & .03 \\
\hline 8. Left 2D:4D & .05 & -.09 & .02 & .07 & -.10 & .02 & .06 & -- & $.66_{\mathrm{c}}$ & .01 & .03 & .14 & -.14 & .06 & -.03 \\
\hline 9. Right 2D:4D & .08 & .07 & .02 & -.03 & -.02 & .13 & -.04 & $.58_{\mathrm{c}}$ & -- & .01 & -.04 & .17 & -.10 & .00 & -.06 \\
\hline $\begin{array}{l}\text { 10. Focus on } \\
\text { opportunities }\end{array}$ & -.18 & $.31_{\mathrm{c}}$ & $.46_{\mathrm{c}}$ & $.37 \mathrm{c}$ & -.04 & $.27_{\mathrm{b}}$ & $.26_{\mathrm{b}}$ & .12 & .05 & -- & $-.61_{c}$ & .02 & -.17 & $.51_{\mathrm{c}}$ & -.06 \\
\hline $\begin{array}{l}\text { 11. Focus on } \\
\text { limitations }\end{array}$ & $.22_{\mathrm{a}}$ & $-.29_{b}$ & $-.21_{\mathrm{a}}$ & -.11 & -.15 & -.08 & -.01 & -.10 & -.09 & $-.56_{\mathrm{c}}$ & -- & .15 & .07 & $-.47_{\mathrm{c}}$ & -.20 \\
\hline 12. Affect heuristic & -.04 & .02 & .03 & $.21_{\mathrm{a}}$ & $-.34_{c}$ & $.22_{\mathrm{a}}$ & $.18_{\mathrm{a}}$ & .12 & -.05 & $.23_{\mathrm{a}}$ & .03 & -- & .09 & .08 & .05 \\
\hline 13. Numeracy & -.12 & .10 & -.06 & $-.32_{\mathrm{c}}$ & .16 & $-.28_{\mathrm{b}}$ & $-.34_{c}$ & -.15 & $-.18_{\mathrm{a}}$ & $-.23_{\mathrm{a}}$ & .04 & .00 & -- & .10 & .21 \\
\hline 14. Income & -.08 & $.34_{c}$ & .11 & -.01 & .08 & .03 & .09 & -.08 & -.07 & $.19 \mathrm{a}$ & $-.20_{\mathrm{a}}$ & -.03 & .06 & -- & $.29_{b}$ \\
\hline 15. Education & -.03 & $.33_{\mathrm{c}}$ & $.21_{\mathrm{a}}$ & .06 & .11 & $-.22_{\mathrm{a}}$ & -.17 & -.17 & -.15 & $.19_{a}$ & -.16 & .00 & $.36_{c}$ & $.25_{\mathrm{b}}$ & -- \\
\hline
\end{tabular}

Note. Men are above the diagonal, and women below. ${ }^{\mathrm{a}} p<.05,{ }^{\mathrm{b}} p<.01,{ }^{\mathrm{c}} p<.001$ 
Table 9

Correlations for Variables of Interest: Older Adults

\begin{tabular}{|c|c|c|c|c|c|c|c|c|c|c|c|c|c|c|c|}
\hline & 1 & 2 & 3 & 4 & 5 & 6 & 7 & 8 & 9 & 10 & 11 & 12 & 13 & 14 & 15 \\
\hline 1. Age & -- & .01 & .05 & .01 & -.11 & -.04 & .00 & -.03 & .02 & -.11 & -.01 & .09 & .16 & .18 & -.11 \\
\hline 2. Financial risk tolerance & -.08 & -- & .15 & .01 & $.33_{b}$ & -.04 & -.07 & .16 & .06 & $.36_{\mathrm{c}}$ & $-.31_{b}$ & $-.25_{\mathrm{a}}$ & .14 & $.32_{\mathrm{b}}$ & .14 \\
\hline 3. Masculine traits & -.06 & $.28_{\mathrm{a}}$ & -- & $.62_{\mathrm{c}}$ & .11 & $.55_{\mathrm{c}}$ & $.42_{\mathrm{c}}$ & -.04 & .01 & $.37_{\mathrm{c}}$ & .01 & $.37_{\mathrm{c}}$ & -.03 & $.36_{\mathrm{c}}$ & .18 \\
\hline 4. Feminine traits & -.02 & $-.23_{\mathrm{a}}$ & .02 & -- & -.16 & $.42_{\mathrm{c}}$ & $.39_{\mathrm{c}}$ & -.13 & -.16 & .28 & .08 & $.34_{b}$ & .01 & .12 & .08 \\
\hline 5. Masculine roles & .09 & $.33_{\mathrm{b}}$ & .11 & $-.44_{c}$ & -- & .02 & -.11 & .14 & $.30_{\mathrm{b}}$ & .00 & .07 & $-.28_{b}$ & -.12 & .15 & .09 \\
\hline 6. Gender identification & -.06 & .06 & -.10 & $.40_{\mathrm{c}}$ & -.25 & -- & $.51_{\mathrm{c}}$ & -.06 & .00 & $.23_{\mathrm{a}}$ & .06 & $.30_{\mathrm{b}}$ & .04 & .13 & -.12 \\
\hline 7. Gender typicality & .11 & -.08 & -.18 & $.41_{\mathrm{c}}$ & $-.30_{b}$ & $.57_{\mathrm{c}}$ & -- & -.05 & -.05 & $.24 \mathrm{a}$ & .07 & $.20 \mathrm{a}$ & -.15 & .03 & -.16 \\
\hline 8. Left 2D:4D & -.08 & .12 & .21 & $.26_{\mathrm{a}}$ & .10 & .16 & .12 & -- & $.47 \mathrm{c}$ & .06 & .02 & -.12 & -.01 & -.13 & -.01 \\
\hline 9. Right 2D:4D & -.01 & -.09 & .03 & .03 & -.03 & .05 & .11 & .16 & -- & .04 & -.02 & -.06 & -.08 & .01 & .05 \\
\hline 10. Focus on opportunities & -.09 & $.31_{b}$ & $.40_{\mathrm{c}}$ & .14 & .04 & .19 & .00 & .17 & .08 & -- & $-.48 c$ & -.02 & -.05 & $.27 \mathrm{~b}$ & .10 \\
\hline 11. Focus on limitations & .12 & $-.25_{\mathrm{a}}$ & $-.33_{b}$ & -.01 & -.01 & -.13 & .05 & -.09 & -.12 & $-.74_{c}$ & -- & .14 & .00 & -.11 & -.10 \\
\hline 12. Affect heuristic & -.08 & -.04 & .15 & .13 & $-.23_{\mathrm{a}}$ & .08 & -.02 & .17 & .00 & -.03 & .08 & -- & .13 & .03 & -.04 \\
\hline 13. Numeracy & .04 & -.12 & -.15 & .00 & -.06 & .11 & .03 & -.17 & -.11 & -.14 & .14 & -.13 & -- & -.03 & .08 \\
\hline 14. Income & .09 & $.23_{\mathrm{a}}$ & .13 & .05 & .01 & .04 & .12 & -.05 & .05 & $-.23_{\mathrm{a}}$ & -.20 & .02 & -.17 & -- & $.28_{\mathrm{b}}$ \\
\hline 15. Education & -.05 & .17 & .16 & -.11 & -.01 & -.06 & -.19 & -.18 & -.09 & .12 & -.11 & .01 & .21 & $.39_{\mathrm{c}}$ & -- \\
\hline
\end{tabular}

Note. Men are above the diagonal, and women below. ${ }^{\mathrm{a}} p<.05,{ }^{\mathrm{b}} p<.01,{ }^{\mathrm{c}} p<.001$ 
Table 10

Hierarchical Linear Regression of Financial Risk Tolerance: Psychological Gender Mechanisms (Full Model)

\begin{tabular}{|c|c|c|c|c|c|}
\hline & $R^{2}\left(\Delta R^{2}\right)$ & $B$ & $S E$ & $\beta$ & $p$ \\
\hline Step 1 & .06 & & & & $<.001$ \\
\hline Gender & & .02 & .15 & .02 & .874 \\
\hline Age & & .00 & .01 & -.12 & .617 \\
\hline Step 2 & $.13(.07)$ & & & & $<.001$ \\
\hline Numeracy & & .01 & .02 & .03 & .485 \\
\hline Income & & .04 & .01 & .19 & $<.001$ \\
\hline Education & & .02 & .01 & .05 & .208 \\
\hline Step 3 & $.26(.13)$ & & & & $<.001$ \\
\hline Masculine traits & & .09 & .04 & .15 & .025 \\
\hline Feminine traits & & .01 & .03 & .02 & .710 \\
\hline Masculine roles & & .59 & .08 & .35 & $<.001$ \\
\hline Gender identification & & -.11 & .06 & -.11 & .074 \\
\hline Gender typicality & & .02 & .06 & .02 & .790 \\
\hline Right 2D:4D & & -.20 & .17 & -.04 & .256 \\
\hline Step 4 & $.27(.01)$ & & & & .298 \\
\hline Gender $\mathrm{x}$ age & & .00 & .02 & -.02 & .964 \\
\hline Gender $\mathrm{x}$ masculine traits & & .02 & .05 & .02 & .725 \\
\hline Age $\mathrm{x}$ masculine traits & & .00 & .00 & -.02 & .716 \\
\hline Gender $\mathrm{x}$ gender identification & & .16 & .09 & .11 & .060 \\
\hline Age x gender identification & & .00 & .00 & -.01 & .854 \\
\hline Gender x gender typicality & & .00 & .08 & .00 & .991 \\
\hline Age x gender typicality & & .00 & .01 & .01 & .984 \\
\hline Step 5 & $.27(.00)$ & & & & .976 \\
\hline Gender $\mathrm{x}$ age $\mathrm{x}$ masculine traits & & .00 & .00 & .01 & .827 \\
\hline Gender $\mathrm{x}$ age $\mathrm{x}$ gender identification & & .00 & .01 & .15 & .738 \\
\hline Gender $\mathrm{x}$ age $\mathrm{x}$ gender typicality & & .00 & .01 & -.08 & .715 \\
\hline
\end{tabular}


Note. Statistics are reported from the final step of the model. This was called the "full model" because it includes all hypothesized interactions, even those that were not significant. 
Table 11

Hierarchical Linear Regression of Financial Risk Tolerance: Psychological Gender Mechanisms (Trimmed Model)

\begin{tabular}{|c|c|c|c|c|c|}
\hline & $R^{2}\left(\Delta R^{2}\right)$ & $B$ & $S E$ & $\beta$ & $p$ \\
\hline Step 1 & .06 & & & & $<.001$ \\
\hline Gender & & .03 & .04 & .02 & .585 \\
\hline Age & & .00 & .00 & -.08 & .022 \\
\hline Step 2 & $.13(.07)$ & & & & $<.001$ \\
\hline Numeracy & & .01 & .02 & .03 & .525 \\
\hline Income & & .04 & .01 & .18 & $<.001$ \\
\hline Education & & .02 & .01 & .05 & .206 \\
\hline Step 3 & $.26(.13)$ & & & & $<.001$ \\
\hline Masculine traits & & .10 & .03 & .17 & $<.001$ \\
\hline Feminine traits & & .01 & .03 & .01 & .798 \\
\hline Masculine roles & & .59 & .08 & .36 & $<.001$ \\
\hline Gender identification & & -.11 & .05 & -.12 & .029 \\
\hline Gender typicality & & .02 & .04 & .02 & .681 \\
\hline Right 2D:4D & & -.19 & .17 & -.04 & .269 \\
\hline Step 4 & $.27(.01)$ & & & & .011 \\
\hline Gender $\mathrm{x}$ gender identification & & .18 & .07 & .13 & .011 \\
\hline
\end{tabular}

Note. Statistics are reported from the final step of the model. This was called the "trimmed model" because results are presented after removing non-significant interaction terms from the "full model" (Table 10). 
Table 12

Hierarchical Linear Regression of Financial Risk Tolerance: Psychological Gender Mechanisms with Individually Added Masculine Roles Subscales

\begin{tabular}{|c|c|c|c|c|c|}
\hline & $R^{2}\left(\Delta R^{2}\right)$ & $B$ & $S E$ & $\beta$ & $p$ \\
\hline Step 1 & .06 & & & & $<.001$ \\
\hline Gender & & .03 & .04 & .02 & .585 \\
\hline Age & & .00 & .00 & -.08 & .022 \\
\hline Step 2 & $.13(.07)$ & & & & $<.001$ \\
\hline Numeracy & & .01 & .02 & .03 & .525 \\
\hline Income & & .04 & .01 & .18 & $<.001$ \\
\hline Education & & .02 & .01 & .05 & .206 \\
\hline Step 3 & $.17(.05)$ & & & & $<.001$ \\
\hline Masculine traits & & .10 & .03 & .17 & $<.001$ \\
\hline Feminine traits & & .01 & .03 & .01 & .798 \\
\hline Gender identification & & -.11 & .05 & -.12 & .029 \\
\hline Gender typicality & & .02 & .04 & .02 & .681 \\
\hline Right 2D:4D & & -.19 & .17 & -.04 & .269 \\
\hline \multicolumn{6}{|l|}{ Step 4} \\
\hline Masculine roles: winning & $20(.03)$ & .19 & .04 & .20 & $<.001$ \\
\hline Masculine roles: emotional control & $.17(.00)$ & .02 & .04 & .02 & .751 \\
\hline Masculine roles: risk taking & $.48(.29)$ & .61 & .03 & .61 & $<.001$ \\
\hline Masculine roles: violence & $.21(.02)$ & .15 & .04 & .17 & $<.001$ \\
\hline Masculine roles: power over women & $.22(.03)$ & .19 & .04 & .18 & $<.001$ \\
\hline Masculine roles: dominance & $.20(.02)$ & .13 & .04 & .14 & .001 \\
\hline Masculine roles: playboy & $.21(.02)$ & .16 & .04 & .19 & $<.001$ \\
\hline Masculine roles: self-reliance & $.19(.00)$ & .02 & .04 & .02 & .627 \\
\hline Masculine roles: primacy of work & $.19(.00)$ & .03 & .04 & .03 & .420 \\
\hline $\begin{array}{l}\text { Masculine roles: disdain for } \\
\text { homosexuality }\end{array}$ & $.19(.00)$ & .00 & .03 & .00 & .992 \\
\hline Masculine roles: pursuit of status & $.20(.01)$ & .13 & .04 & .12 & .004 \\
\hline
\end{tabular}


Note. Due to multicollinearity, masculine roles subscales were entered individually into the final step of separate regression models. 
Table 13

Hierarchical Linear Regression of Financial Risk Tolerance: Psychological Gender Mechanisms (Trimmed Model for Men)

\begin{tabular}{|c|c|c|c|c|c|}
\hline & $R^{2}\left(\Delta R^{2}\right)$ & $B$ & $S E$ & $\beta$ & $p$ \\
\hline Step 1 & .03 & & & & .008 \\
\hline Age & & .00 & .00 & -.13 & .023 \\
\hline Step 2 & $.09(.06)$ & & & & .001 \\
\hline Numeracy & & .02 & .02 & .04 & .487 \\
\hline Income & & .04 & .01 & .19 & .002 \\
\hline Education & & .00 & .02 & -.01 & .894 \\
\hline Step 3 & $.24(.15)$ & & & & $<.001$ \\
\hline Masculine traits & & .07 & .04 & .13 & .080 \\
\hline Feminine traits & & .07 & .05 & .10 & .144 \\
\hline Masculine roles & & .66 & .11 & .38 & $<.001$ \\
\hline Gender identification & & -.13 & .06 & -.15 & .034 \\
\hline Gender typicality & & .02 & .06 & .02 & .750 \\
\hline Right 2D:4D & & -.32 & .25 & -.07 & .208 \\
\hline
\end{tabular}

Note. Statistics are reported from the final step of the model. This was called the "trimmed model" because results are presented after removing non-significant interaction terms from the "full model." 


\section{Table 14}

Hierarchical Linear Regression of Financial Risk Tolerance: Psychological Gender Mechanisms (Trimmed Model for Women)

\begin{tabular}{|c|c|c|c|c|c|}
\hline & $R^{2}\left(\Delta R^{2}\right)$ & $B$ & $S E$ & $\beta$ & $p$ \\
\hline Step 1 & .00 & & & & .472 \\
\hline Age & & .00 & .00 & -.05 & .311 \\
\hline Step 2 & $.11(.11)$ & & & & $<.001$ \\
\hline Numeracy & & .01 & .02 & .01 & .798 \\
\hline Income & & .04 & .01 & .19 & .001 \\
\hline Education & & .04 & .02 & .11 & .046 \\
\hline Step 3 & $.24(.14)$ & & & & $<.001$ \\
\hline Masculine traits & & .10 & .03 & .18 & .001 \\
\hline Feminine traits & & -.04 & .04 & -.06 & .352 \\
\hline Masculine roles & & .55 & .11 & .28 & $<.001$ \\
\hline Gender identification & & .08 & .06 & .08 & .190 \\
\hline Gender typicality & & .03 & .05 & .03 & .618 \\
\hline Right 2D:4D & & -.03 & .25 & -.01 & .912 \\
\hline
\end{tabular}

Note. Statistics are reported from the final step of the model. This was called the "trimmed model" because results are presented after removing non-significant interaction terms from the "full model." 
Table 15

Indirect Effects of Age on Financial Risk Tolerance through Psychological Gender Mechanisms

\begin{tabular}{lccccc}
\hline Mediating Variable & Indirect Effect & $S E$ & $95 \%$ CI & Sobel test & $p$ \\
\hline Masculine traits & .000 & .001 & {$[.000, .001]$} & .251 & .802 \\
Feminine traits & .000 & .000 & {$[.000, .000]$} & -.184 & .854 \\
Masculine roles & -.001 & .000 & {$[-.002, .001]$} & -.902 & .367 \\
Gender identification & .000 & .000 & {$[-.001, .000]$} & -.485 & .628 \\
Gender typicality & .000 & .000 & {$[.000, .001]$} & .556 & .578 \\
& & & & & \\
\hline
\end{tabular}


Table 16

Hierarchical Linear Regression of Financial Risk Tolerance: Future Time Perspective and the Affect Heuristic

\begin{tabular}{|c|c|c|c|c|c|}
\hline & $R^{2}\left(\Delta R^{2}\right)$ & $B$ & $S E$ & $\beta$ & $p$ \\
\hline Step 1 & .06 & & & & $<.001$ \\
\hline Gender & & -.17 & .04 & -.17 & $<.001$ \\
\hline Age & & .00 & .00 & .01 & .855 \\
\hline Step 2 & $.13(.07)$ & & & & $<.001$ \\
\hline Numeracy & & .02 & .02 & .05 & .246 \\
\hline Income & & .04 & .01 & .17 & $<.001$ \\
\hline Education & & .03 & .01 & .08 & .060 \\
\hline Step 3 & $.22(.09)$ & & & & $<.001$ \\
\hline Focus on opportunities & & .12 & .02 & .34 & $<.001$ \\
\hline Focus on limitations & & .01 & .02 & .04 & .426 \\
\hline Affect heuristic & & -.07 & .02 & -.12 & .001 \\
\hline
\end{tabular}

Note. Statistics are reported from the final step of the model. 
Table 17

Indirect Effects of Age on Financial Risk Tolerance through Focus on Opportunities, Focus on Limitations, and Reliance on the Affect Heuristic

\begin{tabular}{lccccc}
\hline Mediating Variable & Indirect Effect & $S E$ & $95 \%$ CI & Sobel test & $p$ \\
\hline Focus on opportunities & -.004 & .001 & {$[-.006,-.003]$} & -5.31 & $<.001$ \\
$\begin{array}{l}\text { Focus on limitations } \\
\begin{array}{l}\text { Reliance on the affect } \\
\text { heuristic }\end{array}\end{array}$ & .001 & .001 & {$[-.001, .001]$} & .88 & .381 \\
\end{tabular}




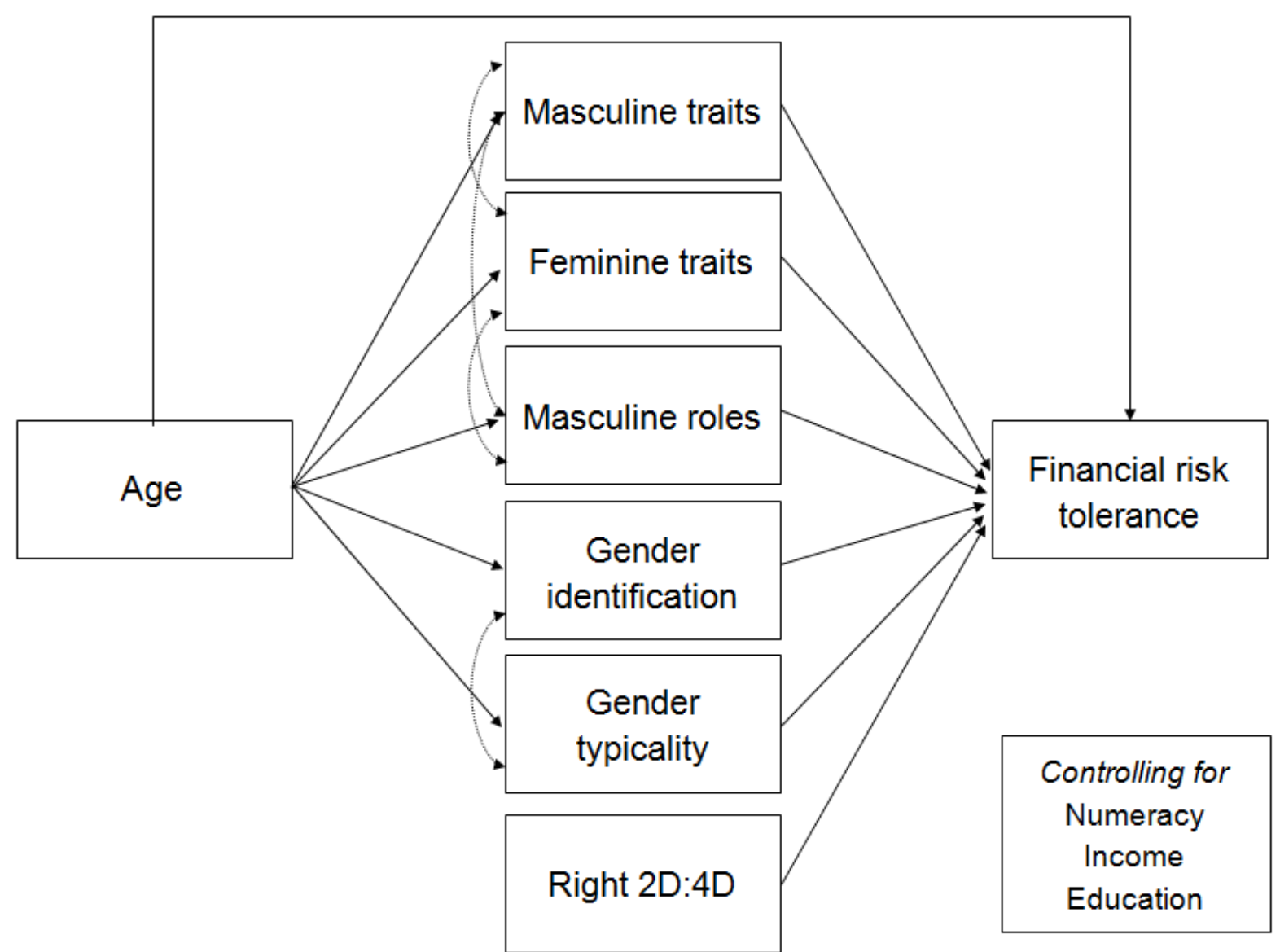

Figure 1. A conceptual model of psychological gender mechanisms accounting for age-related differences in financial risk tolerance. 


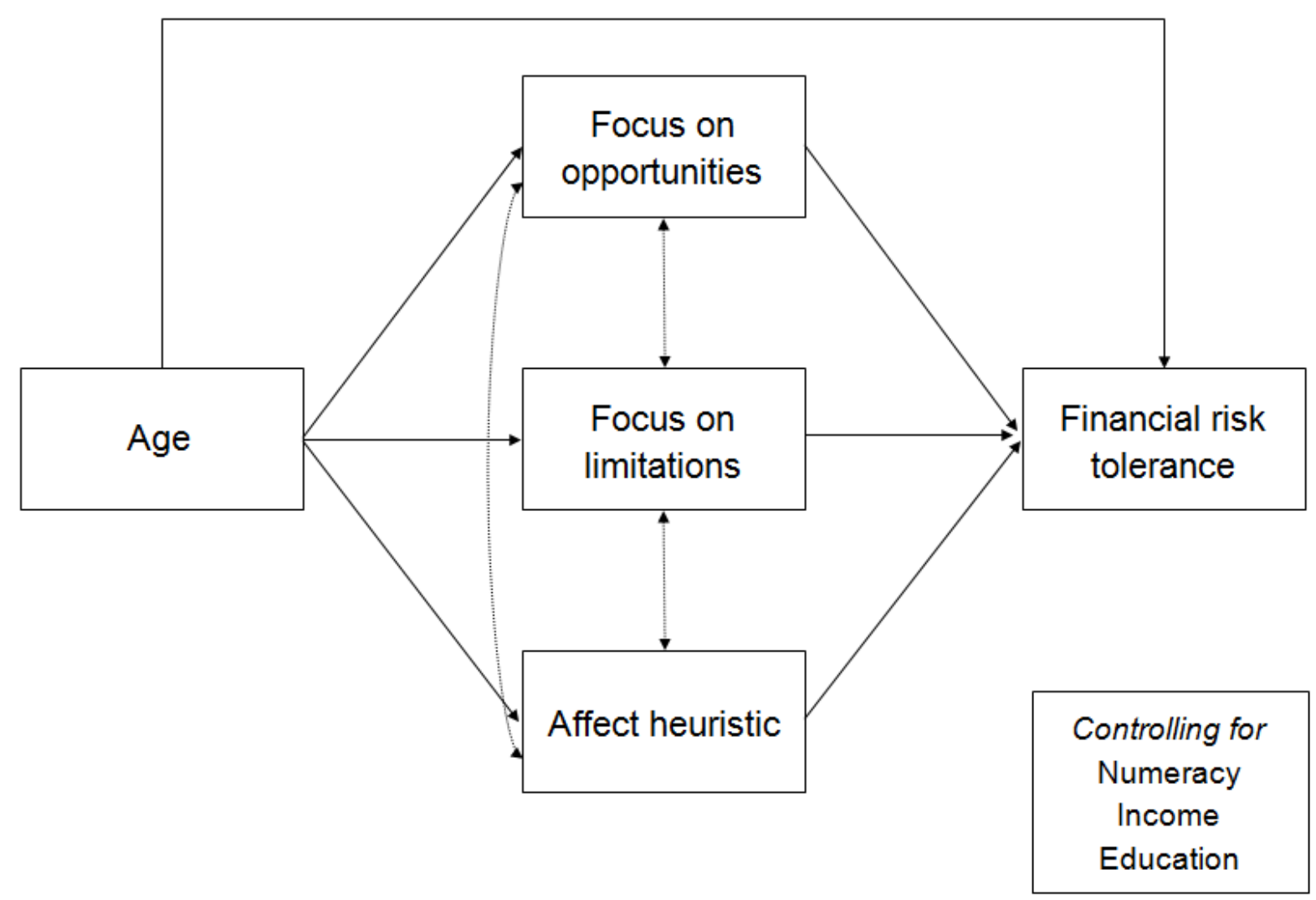

Figure 2. A conceptual model of future time perspective and the affect heuristic accounting for age-related differences in financial risk tolerance. 


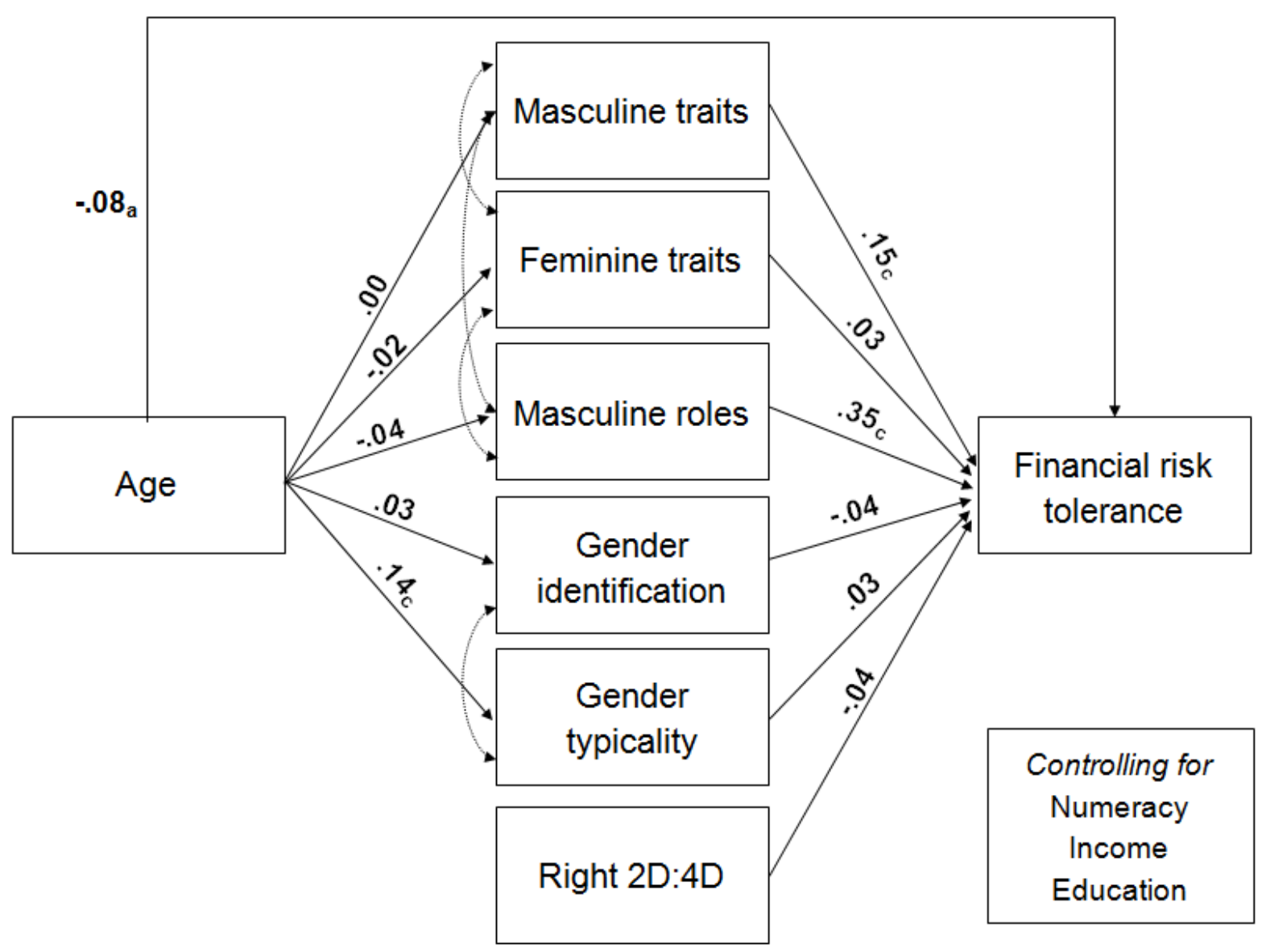

Figure 3. The model of age and financial risk tolerance with psychological gender mechanisms. $\chi^{2}(34)=246.77, \mathrm{CMIN} / \mathrm{df}=7.26 ; \mathrm{CFI}=.776$; $\mathrm{RMSEA}=.104 ;{ }^{\mathrm{a}} p<.05,{ }^{\mathrm{b}} p<.01,{ }^{\mathrm{c}} p<.001$. This model was not probed further for a better fit. Mediation analyses from this model may be found in Table 15. 


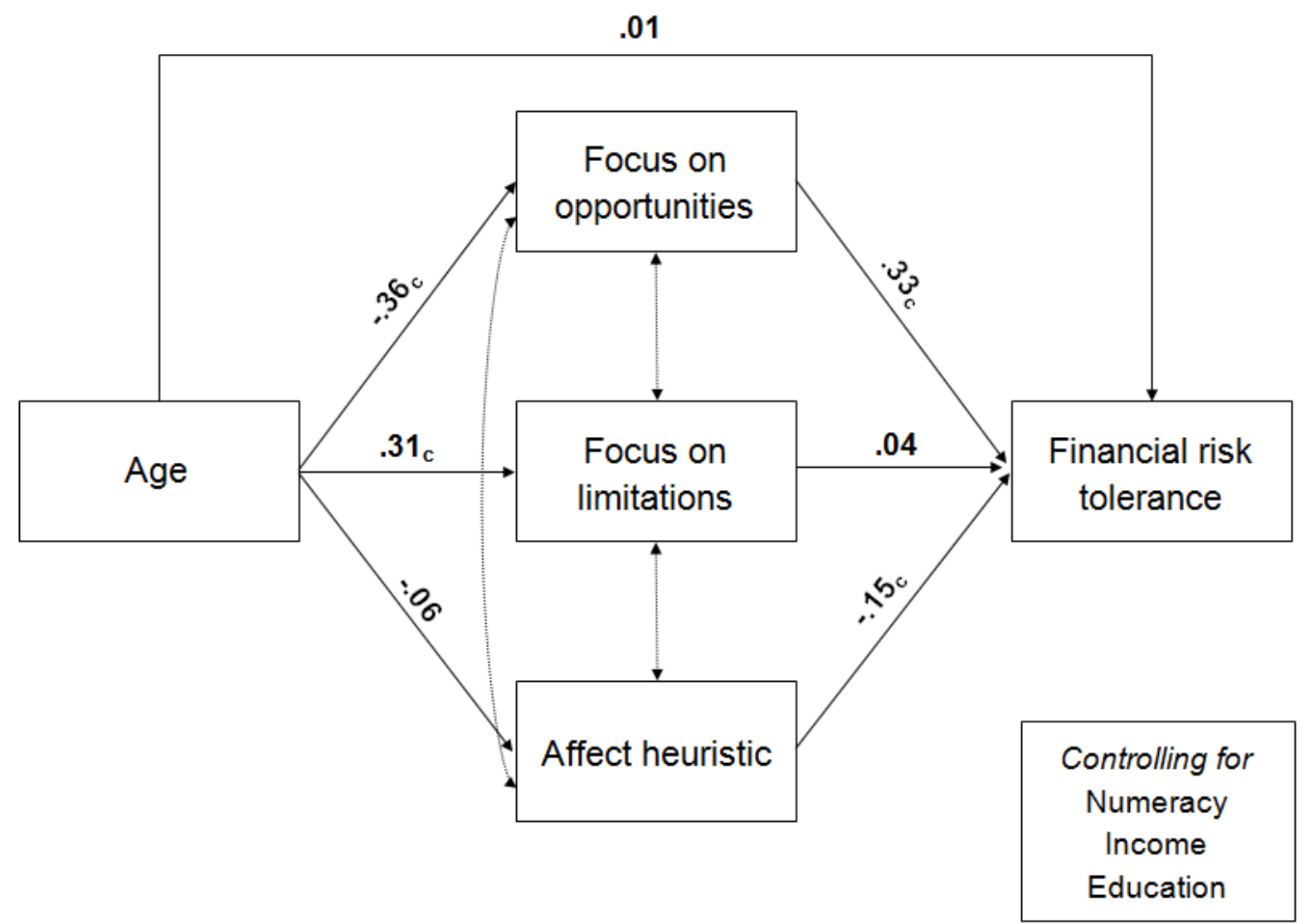

Figure 4. The model of age and financial risk tolerance with future time perspective and the affect heuristic. $\chi^{2}(13)=64.08, \mathrm{CMIN} / \mathrm{df}=4.93 ; \mathrm{CFI}=.918$; RMSEA $=.082 ;{ }^{\mathrm{a}} p<.05,{ }^{\mathrm{b}} p<.01$, ${ }^{c} p<.001$. This model did not differ by gender, age group, or gender by age group. Mediation analyses may be found in Table 17. Focus on opportunities mediated the association between age and financial risk tolerance. 


\section{Appendix A}

\section{Demographics Questionnaire}

1. Please indicate your sex: $(\operatorname{sex}) \_$Male ___ Female __ Other

2. Please indicate your marital status: never married married for ___ years and ___ months not married, but living together for ___ years and ___ months widowed/widower, married for divorced, married for _ other (please specify ___ _ _ ) months years and months years and

3. Please indicate your age (in years; e.g. "22")

4. Please indicate your ethnicity: Hispanic or Latino Not Hispanic or Latino Prefer not to answer

5. Please indicate your race:

White or Caucasian Black or African-American Asian American Indian or Alaska Native Native Hawaiian or Other Pacific Islander Biracial or Multi-racial Other Prefer not to answer

6. What is your current employment status?

Employed full time Employed part time Partially retired (retired, but working part-time) Fully retired (no longer working) Unemployed Other (please specify

7. If you are currently working, how long do you think it will be before you retire (in years)? years Does not apply 
8. Please indicate your highest level of education:

Did not graduate high school

High school diploma or GED

Some college

Associate's degree

Bachelor's degree

Master's degree

Doctoral degree

9. How much financial difficulty do you have paying your bills?

_ a great deal of difficulty

some difficulty

a little difficulty

no difficulty

10. Please estimate your gross income from the past 12 months (including wages, social security earnings, tips, etc.).

Less than $\$ 10,000$
$\$ 10,000-19,000$
$\$ 20,000-29,000$
$\$ 30,000-39,000$
$\$ 40,000-49,000$
$\$ 50,000-59,000$
$\$ 60,000-69,000$
$\$ 70,000$ or more
I don't know

11. If you are working, please indicate your current or former occupation. If you are a full-time student, please write student.

12. If you are working, how long have you spent at this occupation? If you are a full-time student, please leave this question blank. 
13. If you are currently retired, please estimate the gross annual income you were earning immediately before you retired (including wages, social security earnings, tips, etc.)

Less than $\$ 10,000$

$\$ 10,000-19,000$

$\$ 20,000-29,000$

$\$ 30,000-39,000$

$\$ 40,000-49,000$

$\$ 50,000-59,000$

\$60,000-69,000

$\$ 70,000$ or more

I don't know

14. Do you invest any portion of your income?

Yes

No 


\section{Appendix B}

FinaMetrica Risk Tolerance Profile

1. Compared to others, how do you rate your willingness to take financial risks?

$1=$ Extremely low risk taker

$2=$ Very low risk taker

$3=$ Low risk taker

$4=$ Average risk taker

$5=$ High risk taker

$6=$ Very high risk taker

$7=$ Extremely high risk taker

2. How easily do you adapt when things go wrong financially?

$1=$ Very uneasily

$2=$ Somewhat uneasily

$3=$ Somewhat easily

$4=$ Very easily

3. When you think of the word "risk" in a financial context, which of the following words comes to mind first?

$1=$ Danger

$2=$ Uncertainty

$3=$ Opportunity

$4=$ Thrill

4. Have you ever invested a large sum in a risky investment mainly for the "thrill" of seeing whether it went up or down in value?

$1=$ No

$2=$ Yes, very rarely

$3=$ Yes, somewhat rarely

$4=$ Yes, somewhat frequently

$5=$ Yes, very frequently

5. If you had to choose between more job security with a small pay rise and less job security with a big pay increase, which would you choose?

$1=$ Definitely more job security with a small pay increase

$2=$ Probably more job security with a small pay increase

$3=$ Not sure

$4=$ Probably less job security with a big pay increase

$5=$ Definitely less job security with a big pay increase 
6. When faced with a major financial decision, are you more concerned about the possible losses or the possible gains?

$1=$ Always the possible losses

$2=$ Usually the possible losses

3 = Usually the possible gains

$4=$ Always the possible gains

7. How do you usually feel about your major financial decisions after you make them?

$1=$ Very pessimistic

$2=$ Somewhat pessimistic

$3=$ Somewhat optimistic

$4=$ Very optimistic

8. Imagine you were in a job where you could choose whether to be paid salary, commission, or a mix of both. Which would you pick?

$1=$ All salary

2 = Mainly salary

$3=$ Equal mix of salary and commission

$4=$ Mainly commission

$5=$ All commission

9. What degree of risk have you taken with your financial decisions in the past?

$1=$ Very small

$2=$ Small

$3=$ Medium

$4=$ Large

$5=$ Very large

10. What degree of risk are you currently prepared to take with your financial decisions?

$1=$ Very small

$2=$ Small

$3=$ Medium

$4=$ Large

$5=$ Very large

11. Have you ever borrowed money to make an investment (other than for your home)?

$1=$ No

$2=$ Yes 
12. How much confidence do you have in your ability to make good financial decisions?

$1=$ None

$2=$ A little

$3=$ A reasonable amount

$4=$ A great deal

$5=$ Complete

13. Suppose that 5 years ago you bought shares in a highly regarded company. That same year the company experiences a severe decline in sales due to poor management. The price of the shares dropped drastically and you sold at a substantial loss. The company has been restructured under new management, and most experts now expect it to produce better than average returns. Given your bad past experience with this company, would you buy shares now?

$1=$ Definitely not

$2=$ Probably not

$3=$ Not sure

$4=$ Probably

$5=$ Definitely

14. Investments can go up or down in value, and experts often say you should be prepared to weather a downturn. By how much could the total value of all your investments go down before you would begin to feel uncomfortable?

$1=$ Any fall would make me feel uncomfortable

$2=10 \%$

$3=20 \%$

$4=33 \%$

$5=50 \%$

$6=$ More than $50 \%$

15. Assume that a long-lost relative dies and leaves you a house which is in poor condition but located in a suburb that's becoming popular. As is, the house would probably sell for $\$ 300,000$, but if you were to spend about $\$ 100,000$ on renovations, the selling price would be around $\$ 600,000$. However, there is some talk of constructing a major highway next to the house, and this would lower its value considerably. Which of the following options would you take?

$1=$ Sell it as is

$2=$ Keep it as is, but rent it out

$3=$ Take out a $\$ 100,000$ mortgage and do the renovations

16. Most investment portfolios have a spread of investments - some of the investments may have high expected returns but with high risk, some may have medium expected returns and medium risk, and some may be low-risk/low-return. (For example, shares and property 
would be high-risk/high-return whereas cash and deposits would be low-risk/low-return.) Which spread of investments do you find most appealing? Would you prefer all lowrisk/low-return, all high-risk/high-return, or somewhere in between?

Spread of Investments in Portfolio

\begin{tabular}{|c|c|c|}
\hline sk/Return & $\frac{\text { Medium }}{\text { Risk/Return }}$ & Risk/Return \\
\hline
\end{tabular}

$\begin{array}{lccc}\text { Portfolio 1 } & 0 \% & 0 \% & 100 \% \\ \text { Portfolio 2 } & 0 \% & 30 \% & 70 \% \\ \text { Portfolio 3 } & 10 \% & 40 \% & 50 \% \\ \text { Portfolio 4 } & 30 \% & 40 \% & 30 \% \\ \text { Portfolio 5 } & 50 \% & 40 \% & 10 \% \\ \text { Portfolio 6 } & 70 \% & 30 \% & 0 \% \\ \text { Portfolio 7 } & 100 \% & 0 \% & 0 \%\end{array}$

17. You are considering placing one-quarter of your investment funds into a single investment. This investment is expected to earn about twice the term deposit rate. However, unlike a term deposit, this investment is not protected against loss of the money invested. How low would the chance of a loss have to be for you to make the investment?

$1=$ Zero, no chance of any loss

$2=$ Very low chance of loss

$3=$ Moderately low chance of loss

$4=50 \%$ chance of loss

18. With some types of investment, such as cash and term deposits, the value of the investment is fixed and does not change. However, inflation will cause the purchasing power of this money value to decrease. With other types of investment, such as shares and property, the value is not fixed. It will vary. In the short term, it may even fall below the purchase price. However, over the long term, the value of the shares and property should certainly increase by more than the rate of inflation. With this in mind, which is more important to you - the value of your investments does not fall or that it retains its purchasing power?

$1=$ Much more important that the value does not fall

$2=$ Somewhat more important that the value does not fall

3 = Somewhat more important that the value retains its purchasing power

$4=$ Much more important that the value retains its purchasing power 
19. In recent years, how have your personal investments changed?

$1=$ Always toward lower risk

$2=$ Mostly toward lower risk

$3=$ No changes or changes with no clear direction

$4=$ Mostly toward higher risk

$5=$ Always toward higher risk

20. When making an investment, return and risk usually go hand in hand. Investments which produce above average returns are usually of above-average risk. With this in mind, how much of the funds you have available to invest would you be willing to place in investments where both returns and risks are expected to be above average?

$1=$ None

$2=10 \%$

$3=20 \%$

$4=30 \%$

$5=40 \%$

$6=50 \%$

$7=60 \%$

$8=70 \%$

$9=80 \%$

$10=90 \%$

$11=100 \%$

21. Think of the average rate of return you would expect to earn on an investment portfolio over the next ten years. How does this compare with what you think you would earn if you invested the money in term deposits?

$1=$ About the same rate as from term deposits

$2=$ About one and a half times the rate from term deposits

$3=$ About twice the rate from term deposits

$4=$ About two and a half times the rate from term deposits

$5=$ About three times the rate from term deposits

$6=$ More than three times the rate from term deposits

22. People often arrange their financial affairs to qualify for a government benefit or obtain a tax advantage. However, a change in legislation can leave them worse off than if they'd done nothing. With this in mind, would you take a risk in arranging your affairs to qualify for a government benefit or obtain a tax advantage?

$1=$ I would not take a risk if there was any chance I could finish up worse off.

$2=$ I would take a risk if there was only a small chance I could finish up worse off.

$3=$ I would take a risk as long as there was more than a 50\% chance that I would finish up better off. 
23. Imagine that you are borrowing a large sum of money at some time in the future. It's not clear which way interest rates are going to move - they might go up, they might go down, no one seems to know. You could take a variable interest rate that will rise and fall as the market rate changes. Or you could take a fixed interest rate which is $1 \%$ more than the current variable rate but which won't change as the market rate changes. Or you could take a mix of both. How would you prefer your loan to be made up?

$1=100 \%$ variable

$2=75 \%$ variable, $25 \%$ fixed

$3=50 \%$ variable, $50 \%$ fixed

$4=25 \%$ variable, $75 \%$ fixed

$5=100 \%$ fixed

24. Insurance can cover a wide variety of life's major risks - theft, fire, accident, illness, death, etc. How much cover do you have?

$1=$ Very little

$2=$ Some

$3=$ Considerable

$4=$ Complete

25. This questionnaire is scored on a scale of 0 to 100 . When the scores are graphed, they follow the familiar bell curve of the normal distribution shown below. The average score is 50 .

Two-thirds of all scores are within 10 points of the average? Only 1 in 1000 is less than 20 or more than 80 . What do you think your score will be?

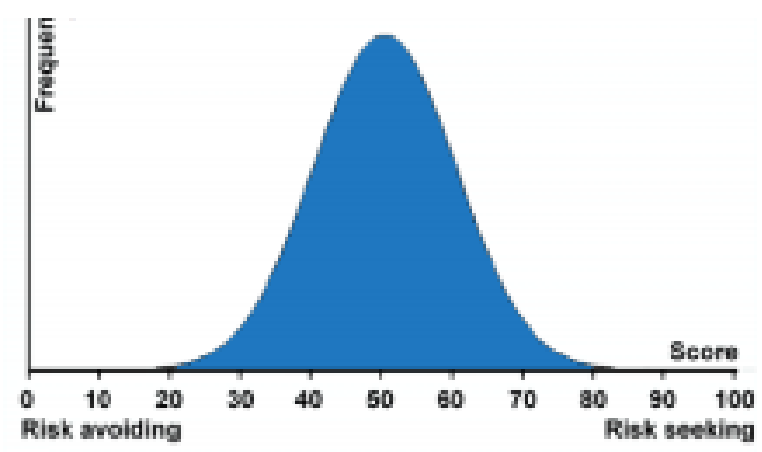




\section{Appendix C}

Future Time Perspective Scale (Carstensen \& Lang, 1996; two additional items added by Cate \& John, 2007, and Lemaster et al., 2012b)

Please read each statement and rate how true or untrue each is for you.

$\begin{array}{cccccc}1 & 2 & 3 & 4 & 5 & 6\end{array}$

1. Many opportunities await me in the future.

2. There are only limited possibilities in my future. ${ }^{R}$

3. I expect that I set many new goals in the future.

4. My future is filled with possibilities.

5. Most of my life still lies ahead of me.

6. My future seems infinite to me.

7. I have limited time left to live my life.*

8. I could do anything I want in the future.

9. There is plenty of time left in my life to make new plans.

10. I have the sense that time is running out.

11. As I get older, I begin to experience that time is limited.

12. I feel the importance of time's passing.*

*Item was added by Cate \& John (2007) or Lemaster et al. (2012b)

$\underline{\text { Scoring }}$

$\mathrm{R}=$ reverse scored

Focus on opportunities $=$ Items 1, 2, 3, 4, 5, 6, 8, 9

Focus on limitations $=$ Items 7, 10, 11, 12 


\section{Appendix D}

Bem Sex Role Inventory (Bem, 1974)

This survey consists of several adjectives. For each, you must indicate on a scale of 1 to 7 how much like you the word is $(1=\underline{\text { never like me }}, 2=\underline{\text { rarely like me }}, 3=\underline{\text { sometimes like me }}, 4=$ equally like and unlike me $, 5=\underline{\text { like me }}, 6=$ frequently like me, $7=\underline{\text { always like me }}$.

1. Self reliant ${ }^{\mathrm{M}}$

2. Yielding ${ }^{\mathrm{F}}$

3. Helpful

4. Defends own beliefs ${ }^{\mathrm{M}}$

5. Cheerful ${ }^{\mathrm{F}}$

6. Moody

7. Independent ${ }^{\mathrm{M}}$

8. Shy $^{\mathrm{F}}$

9. Conscientious

10. Athletic ${ }^{\mathrm{M}}$

11. Affectionate ${ }^{\mathrm{F}}$

12. Theatrical

13. Assertive ${ }^{\mathrm{M}}$

14. Flatterable ${ }^{\mathrm{F}}$

15. Happy

16. Strong personality ${ }^{\mathrm{M}}$

17. Loyal ${ }^{\mathrm{F}}$

18. Unpredictable

19. Forceful $^{\mathrm{M}}$

20. Feminine $^{\mathrm{F}}$

21. Reliable

22. Analytical ${ }^{\mathrm{M}}$

23. Sympathetic ${ }^{F}$

24. Jealous

25. Has leadership abilities ${ }^{\mathrm{M}}$

26. Sensitive to other's needs ${ }^{\mathrm{F}}$

27. Truthful

28. Willing to take risks ${ }^{\mathrm{M}}$

29. Understanding ${ }^{\mathrm{F}}$

30. Secretive

31. Makes decisions easily ${ }^{\mathrm{M}}$

32. Compassionate ${ }^{\mathrm{F}}$

33. Sincere

34. Self-sufficient ${ }^{\mathrm{M}}$

35. Eager to soothe hurt feelings ${ }^{\mathrm{F}}$

36. Conceited

37. Dominant ${ }^{\mathrm{M}}$

38. Soft spoken $^{\mathrm{F}}$ 
39. Likable

40. Masculine ${ }^{\mathrm{M}}$

41. Warm $^{\mathrm{F}}$

42. Solemn

43. Willing to take a stand ${ }^{\mathrm{M}}$

44. Tender ${ }^{\mathrm{F}}$

45. Friendly

46. Aggressive ${ }^{\mathrm{M}}$

47. Gullible ${ }^{\mathrm{F}}$

48. Inefficient

49. Acts as a leader ${ }^{\mathrm{M}}$

50. Childlike ${ }^{\mathrm{F}}$

51. Adaptable

52. Individualistic ${ }^{\mathrm{M}}$

53. Does not use harsh language $\mathrm{F}^{\mathrm{F}}$

54. Unsystematic

55. Competitive ${ }^{\mathrm{M}}$

56. Loves children ${ }^{\mathrm{F}}$

57. Tactful

58. Ambitious ${ }^{\mathrm{M}}$

59. Gentle ${ }^{\mathrm{F}}$

60. Conventional

Scoring

$\mathrm{M}=$ Masculine trait

$\mathrm{F}=$ Feminine trait 


\section{Appendix E}

Affect Heuristic Measure

In general, how risky do you consider each of the following items to be for the United States society as a whole?

$1=\underline{\text { not at all risky }}$

$7=\underline{\text { very risky }}$

In general, how beneficial do you consider each of the following items to be for the United States society as a whole?

$1=$ not at all beneficial

$7=\underline{\text { very beneficial }}$

1. Cigarette smoking

2. Pesticides

3. Nuclear power

4. Alcohol

5. Sleeping pills

6. Tranquilizers

7. Antidepressants

8. Heart surgery

9. IUDs (a birth control method where a device is placed in the uterus)

10. Cancer drugs

11. AIDS drugs

12. Birth control pills

13. Food additives

14. Automobiles

15. Cleansers

16. Menopause drugs (medications such as hormone replacement therapy)

17. Nonprescription drugs (over-the-counter medications)

18. X-rays

19. Antihypertensives (medication to treat high blood pressure)

20. Airplane travel

21. Artificial sweeteners

22. Biotech drugs

23. Prescription drugs

24. Antibiotics

25. Antiarthritics (medication to treat arthritis)

26. Laxatives

27. Insulin (medication to treat diabetes)

28. Aspirin

29. Appendectomy (surgery to remove a person's appendix)

30. Acupuncture

31. Vaccines

32. Herbal medicines 
33. Vitamin pills 
Appendix F

Conformity to Masculine Norms Inventory (Mahalik et al., 2003)

The following pages contain a series of statements about how people might think, feel, or behave. The statements are designed to measure attitudes, beliefs, and behaviors associated with gender roles.

Thinking about your own actions, feelings, and beliefs, please indicate how much you personally agree or disagree with each statement by selecting $\underline{\mathrm{SD}}$ for "Strongly Disagree," $\underline{\mathrm{D}}$

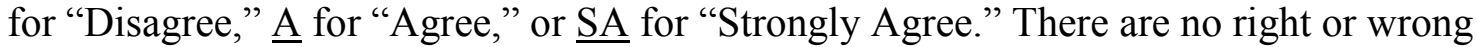
responses to the statements. You should give the responses that most accurately describe your personal actions, feelings, and beliefs. It is best if you respond with your first impression when answering.

1. It is best to keep your emotions hidden.

2. In general, I will do anything to win.

3. If I could, I would frequently change sexual partners.

4. If there is going to be violence, I find a way to avoid it. ${ }^{\mathrm{R}}$

5. It is important to me that people think I am heterosexual.

6. In general, I must get my way.

7. Trying to be important is the greatest waste of time. ${ }^{R}$

8. I am often absorbed in my work.

9. I will only be satisfied when women are equal to men. ${ }^{\mathrm{R}}$

10. I hate asking for help.

11. Taking dangerous risks helps me to prove myself.

12. In general, I do not expend a lot of energy trying to win at things. ${ }^{R}$

13. An emotional bond with a partner is the best part of sex. ${ }^{R}$

14. I should take every opportunity to show my feelings. ${ }^{\mathrm{R}}$

15. I believe that violence is never justified. ${ }^{R}$

16. Being thought of as gay is not a bad thing. ${ }^{R}$

17. In general, I do not like risky situations. ${ }^{\mathrm{R}}$

18. I should be in charge.

19. Feelings are important to show. ${ }^{R}$

20. I feel miserable when work occupies all my attention. ${ }^{\mathrm{R}}$

21 . I feel best about my relationships with women when we are equals. ${ }^{R}$

22. Winning is not my first priority. ${ }^{\mathrm{R}}$

23. I make sure that people think I am heterosexual.

24. I enjoy taking risks.

25 . I am disgusted by any kind of violence. ${ }^{\mathrm{R}}$

26. I would hate to me important. ${ }^{\mathrm{R}}$

27. I love to explore my feelings with others. ${ }^{R}$

28. If I could, I would date a lot of different people.

29. I ask for help when I need it. ${ }^{\mathrm{R}}$

30. My work is the most important part of my life.

31. Winning isn't everything; it's the only thing. 
32. I never take chances. ${ }^{\mathrm{R}}$

33. I would only have sex if I was in a committed relationship. ${ }^{\mathrm{R}}$

34. I like fighting.

35. I treat women as equals. ${ }^{R}$

36. I bring up my feelings when talking to others. ${ }^{\mathrm{R}}$

37. I would be furious if something thought I was gay.

38. I only get romantically involved with one person. ${ }^{R}$

39. I don't mind losing. ${ }^{\mathrm{R}}$

40. I take risks.

41. I never do things to be an important person. ${ }^{\mathrm{R}}$

42. It would not bother me at all if someone thought I was gay. ${ }^{R}$

43. I never share my feelings.

44. Sometimes violence action is necessary.

45. Asking for help is a sign of failure.

46. In general, I control the women in my life.

47. I would feel good if I had many sexual partners.

48. It is important for me to win.

49. I don't like giving all my attention to work. ${ }^{\mathrm{R}}$

50. I feel uncomfortable when others see me as important. ${ }^{\mathrm{R}}$

51. It would be awful if people thought I was gay.

52. I like to talk about my feelings.

53. I never ask for help.

54. More often than not, losing does not bother me. ${ }^{\mathrm{R}}$

55. It is foolish to take risks. ${ }^{\mathrm{R}}$

56. Work is not the most important thing in my life. ${ }^{\mathrm{R}}$

57. Men and women should respect each other as equals. ${ }^{R}$

58. Long term relationships are better than casual sexual encounter. ${ }^{\mathrm{R}}$

59. Having status is not very important to me. ${ }^{\mathrm{R}}$

60. I frequently put myself in risky situations.

61. Women should be subservient to men.

62. I am willing to get into a physical fight if necessary.

63. I like having gay friends.

64. I feel good when work is my first priority.

65. I tend to keep my feelings to myself.

66. Emotional involvement should be avoided when having sex.

67. Winning is not important to me. ${ }^{\mathrm{R}}$

68. Violence is almost never justified. ${ }^{\mathrm{R}}$

69. I am comfortable trying to get my way.

70. I am happiest when I'm risking danger.

71. Men should not have power over women. ${ }^{\mathrm{R}}$

72. It would be enjoyable to date more than one person at once.

73. I would feel uncomfortable if someone thought I was gay.

74. I am not ashamed to ask for help. ${ }^{\mathrm{R}}$

75. The best feeling in the world comes from winning.

76. Work comes first.

77. I tend to share my feelings. ${ }^{\mathrm{R}}$ 
78. I like emotional involvement in a romantic relationship. ${ }^{\mathrm{R}}$

79. No matter the situation, I would never act violently. ${ }^{\mathrm{R}}$

80. If someone thought I was gay, I would not argue with them about it. ${ }^{\mathrm{R}}$

81 . Things tend to be better when men are in charge.

82. I prefer to be safe and careful. ${ }^{\mathrm{R}}$

83. A person shouldn't get tied down to dating just one person.

84. I tend to invest my energy in things other than work. ${ }^{R}$

85. It bothers me when I have to ask for help.

86 . I love it when men are in charge of women.

87. It feels good to be important.

88. I hate it when people ask me to talk about my feelings.

89. I work hard to win.

90. I would only be satisfied with sex if there was an emotional bond. ${ }^{\mathrm{R}}$

91. I try to avoid being perceived as gay.

92. I hate any kind of risk. ${ }^{\mathrm{R}}$

93. I prefer to stay unemotional.

94. I make sure people do as I say.

$\underline{\text { Scoring }}$

$\mathrm{R}=$ reverse scored

Winning = Items 2, 12, 22, 31, 39, 48, 54, 67, 75, 89

Emotional control $=$ Items 1, 14, 19, 27, 36, 43, 52, 65, 77, 88, 93

Risk taking $=$ Items 11, 17, 24, 32, 40, 55, 60, 70, 82. 92

Violence $=$ Items 4, 15, 25, 34, 44, 62, 68, 79

Power over women $=$ Items 9, 21, 35, 46, 57, 61, 71, 81, 86

Dominance $=$ Items 6, 18, 69, 94

Playboy = Items 3, 13, 28, 33, 38, 47, 58, 66, 72, 78, 83, 90

Self-reliance $=$ Items 10, 29, 45, 53, 74, 85

Primacy of work $=8,20,30,49,56,64,76,84$

Disdain for homosexuality $=5,16,23,37,42,51,63,73,80,91$

Pursuit of status $=7,26,41,50,59,87$ 


\section{Appendix G}

\section{Gender Identification Measure (Michaelieu, 1997)}

The following statements refer to your sense of self and the group that you feel you most identify with as a female. These statements are not intended to find out about who you are physically attracted to or romantically interested in. The questions are aimed at finding out about your views of your identity as a person. Please rate the following statements. Click the number that best describes how true the statement is for you. Remember, there are no right or wrong answers! Your answers are confidential so please be honest!

$1=\underline{\text { Strongly disagree }}$

$2=\underline{\text { Somewhat disagree }}$

$3=\underline{\text { Neither agree nor disagree }}$

$4=\underline{\text { Somewhat agree }}$

$5=\underline{\text { Strongly agree }}$

1. Being a male/female* is an important part of my identity.

2. Being a male/female is an important part of who I am.

3. Being a male/female is unimportant to my sense of what kind of person I am. ${ }^{\mathrm{R}}$

4. Overall, being a male/female has very little to do with how I feel about myself. ${ }^{R}$

5. Overall, I'm glad to be a male/female.

6. In general, other people respect males/females.

7. Most people consider males/females to be more ineffective than females/males. ${ }^{\mathrm{R}}$

8. Overall, males/females as a group are considered to be good by other people.

9. In general, people think that males/females as a group are unworthy. ${ }^{R}$

10. I think of myself as having more in common with females/males than with males/females. ${ }^{\mathrm{R}}$

11. I think of myself as different than most other males/females. ${ }^{\mathrm{R}}$

12. Usually I identify with males/females more than females/males.

13. I think of myself as having more in common with males/females than with females/males.

*Items are gender specific. Men and women will receive separate versions of the same items.

$\underline{\text { Scoring }}$

$\mathrm{R}=$ reverse scored 


\section{Appendix $\mathrm{H}$}

Gender Typicality Scale (adapted from Egan \& Perry, 2001)

This questionnaire contains some statements that describe things about people, such as who they are and how they feel about various things. We are interested in what kind of person you are like. This is a survey, not a test. There are no right or wrong answers. Some people are very different from one another, and every person will select something different.

Read each statement below and rate how much like you it is.

$1=$ Very untrue for me

$2=\underline{\text { Sort of untrue for me }}$

$3=\underline{\text { Sort of true for me }}$

$4=\underline{\text { Very true for me }}$

1. I feel like I'm just like all the other men/women* my age.

2. I feel like I fit in with other men/women.

3. I think I am a good example of being a man/woman.

4. I feel that the things I like to do in my spare time are similar to what most other men/women like to do in their spare time.

5. I feel that the kinds of things I'm good at are similar to what most men/women are good at.

6. I feel that my personality is similar to most men's/women's personalities.

*Items are gender specific. Men and women will receive separate versions of the same items. 


\section{Appendix I}

\section{Berlin Numeracy Test}

1. Out of 1,000 people in a small town, 500 are members of a choir. Out of these 500 members in the choir, 100 are men. Out of the 500 inhabitants that are not in the choir, 300 are men. What is the probability that a randomly drawn man is a member of the choir? Please indicate the probability in percent.

Answer: $\_\%$

2. Imagine we are throwing a five-sided die 50 times. On average, out of these 50 throws, how many times would this five-sided die show an odd number (1, 3 or 5)?

Answer: out of 50 throws

3. Imagine we are throwing a loaded die ( 6 sides). The probability that the die shows a 6 is twice as high as the probability of each of the other numbers. On average, out of 70 die throws, how many times would the die show the number 6 ?

Answer: out of 70 throws

4. In a forest, $20 \%$ of mushrooms are red, $50 \%$ are brown, and $30 \%$ are white. A red mushroom is poisonous with a probability of $20 \%$. A mushroom that is not red is poisonous with a probability of $5 \%$. What is the probability that a poisonous mushroom in the forest is red?

Answer: $\%$

\section{$\underline{\text { Scoring }}$}

1. Answer $=25 \%$

2. Answer $=30$ out of 50 throws

3. Answer $=20$ out of 70 throws

4. $50 \%$ 


\section{Appendix J}

\section{D:4D Digit Ratio Measurement}

You will now be asked to measure the index finger (your pointing finger) and the ring finger (the finger next to your pinky finger that people often wear rings on) on your left and right hands. You should use the ruler provided below on the screen, or you may use a ruler (using the millimeter side) you have at home. All measurements should be reported in millimeters.

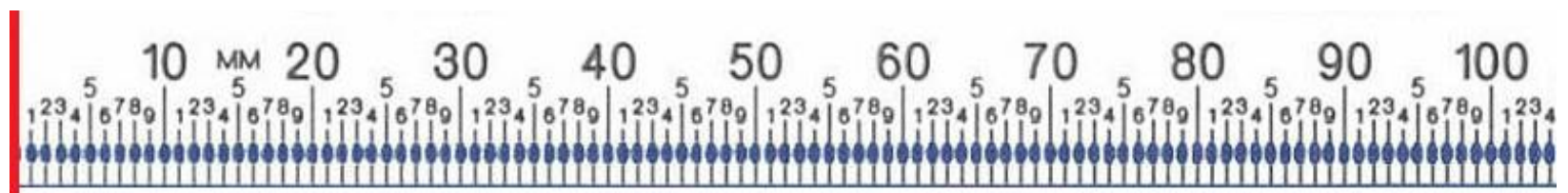


First, you will need to measure your left index finger (the second finger on your left hand that you use to point with). Hold your finger toward the computer screen so that the crease at the bottom of your index finger is aligned with the red line on the left. Stretch your finger out along the ruler, and indicate where the tip of your finger touches the ruler. Here is an example:

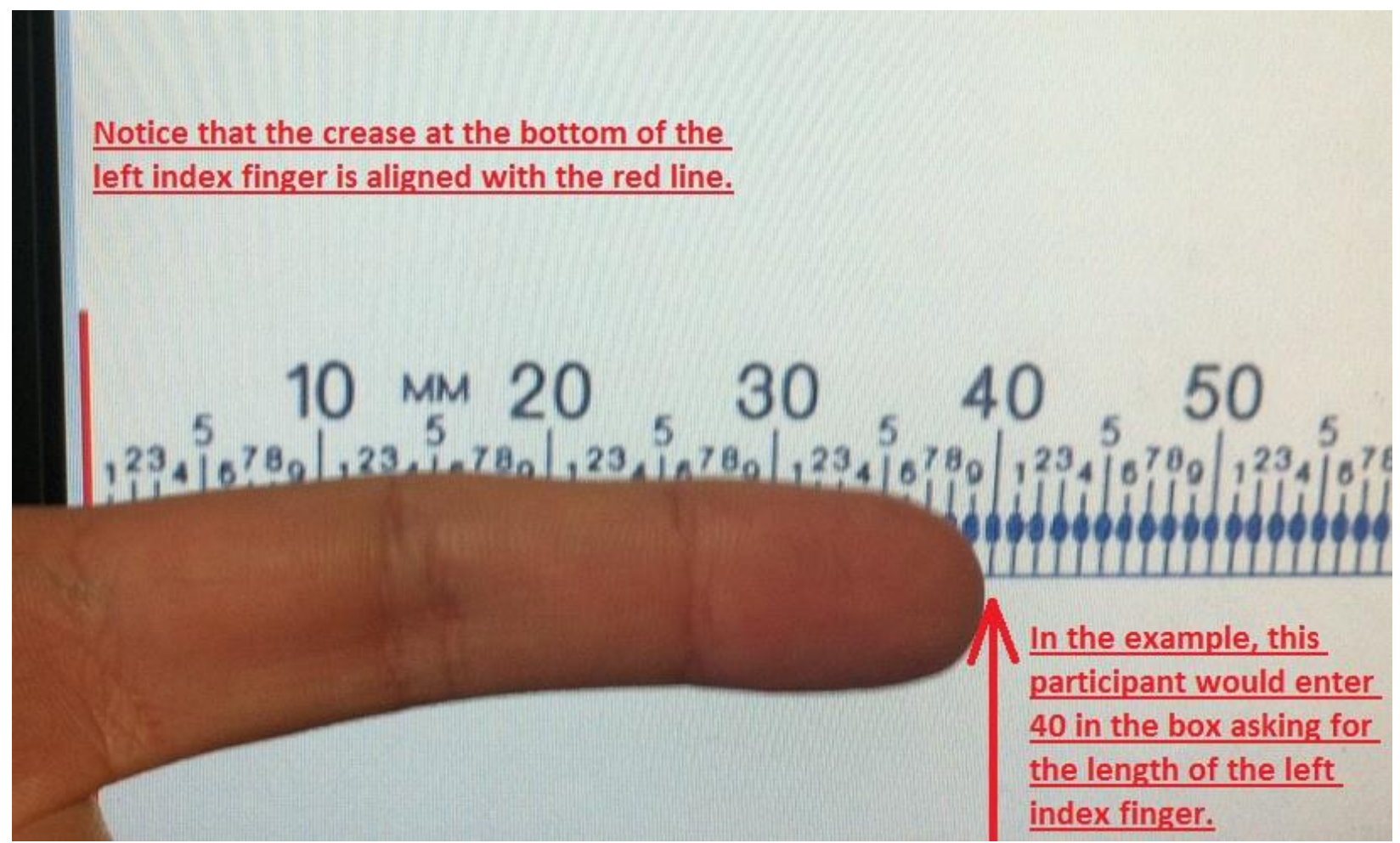

Here is the ruler again. Use it to measure your left index finger (the second finger on your left hand that you use to point with).

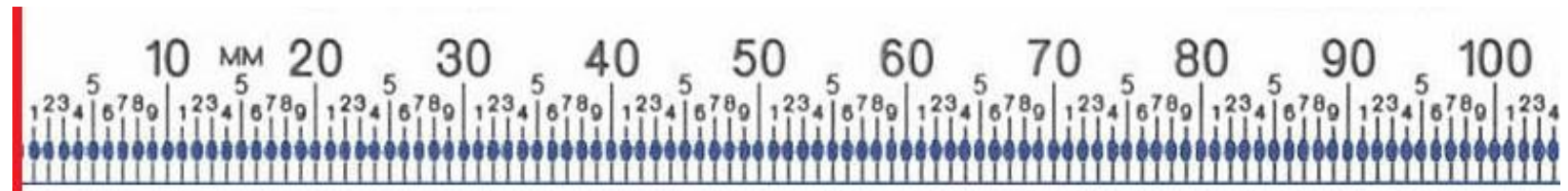

How long is your left index finger (the finger you use to point with on your left hand)? millimeters 
Now you will need to measure you left ring finger (the fourth finger on your left hand next to your pinky finger that people often wear rings on). Here is an example:

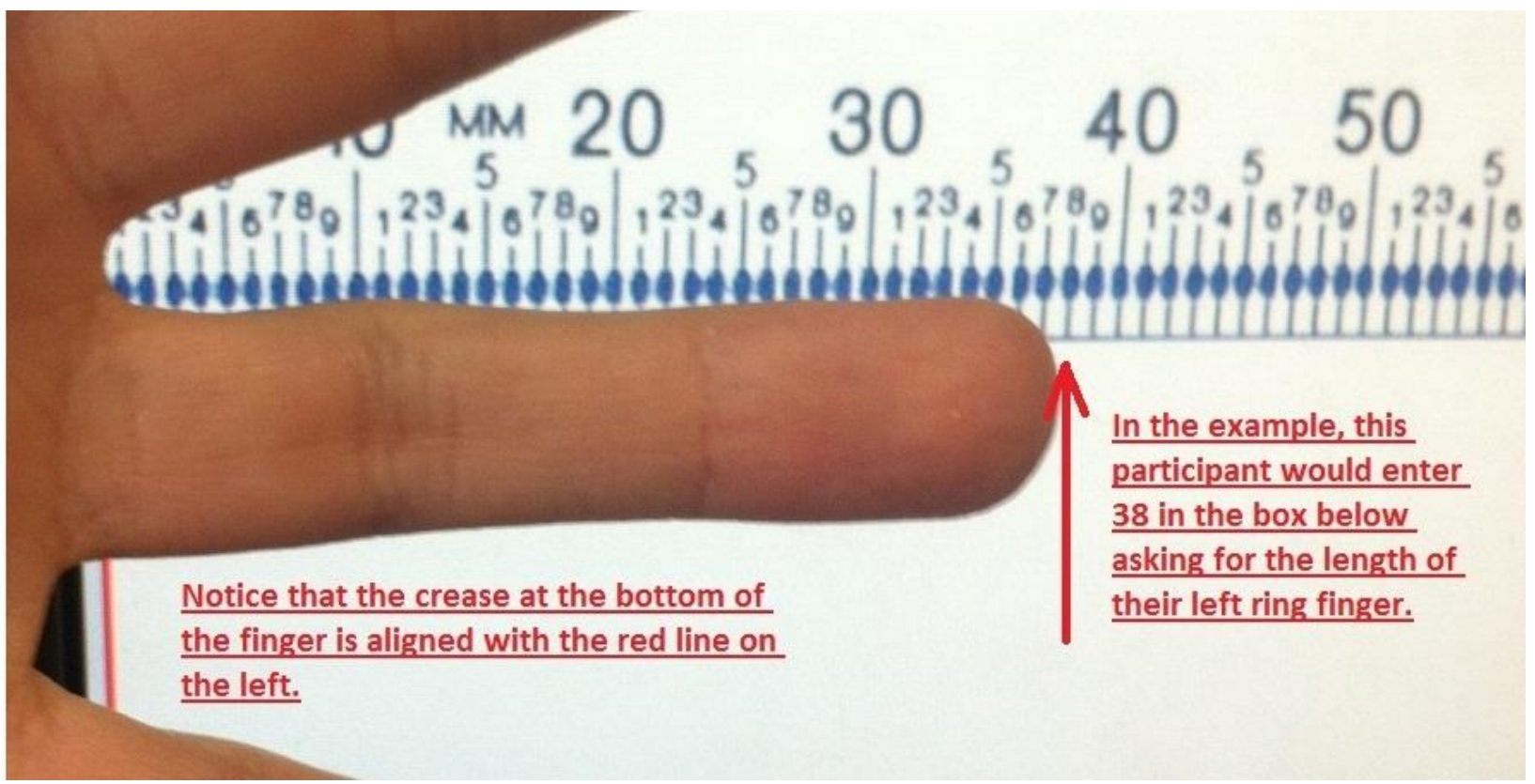

Here is the ruler again. Use it to measure your left ring finger (the fourth finger on your left hand next to your pinky finger that people often wear rings on).

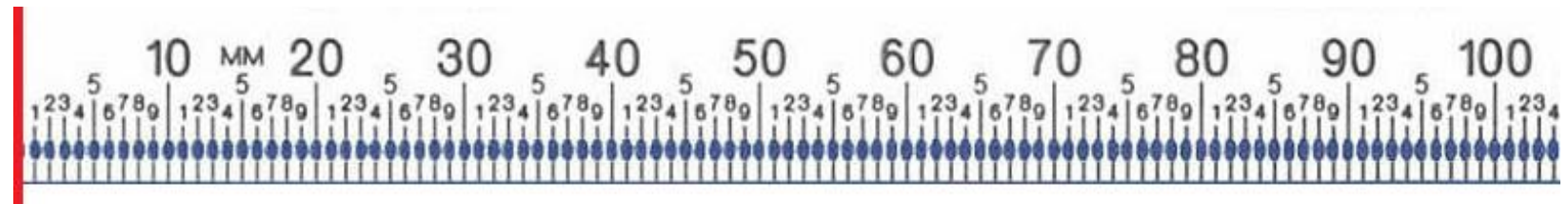

How long is your left ring finger (the fourth finger on your left hand that people often wear rings on)? millimeters 
Next, you will need to measure your right index finger (the second finger on your right hand that you use to point with). The ruler you will use is the same as before, but it is reversed. Here is an example:

Notice that the crease at the bottom of the left index finger is aligned with the red line.

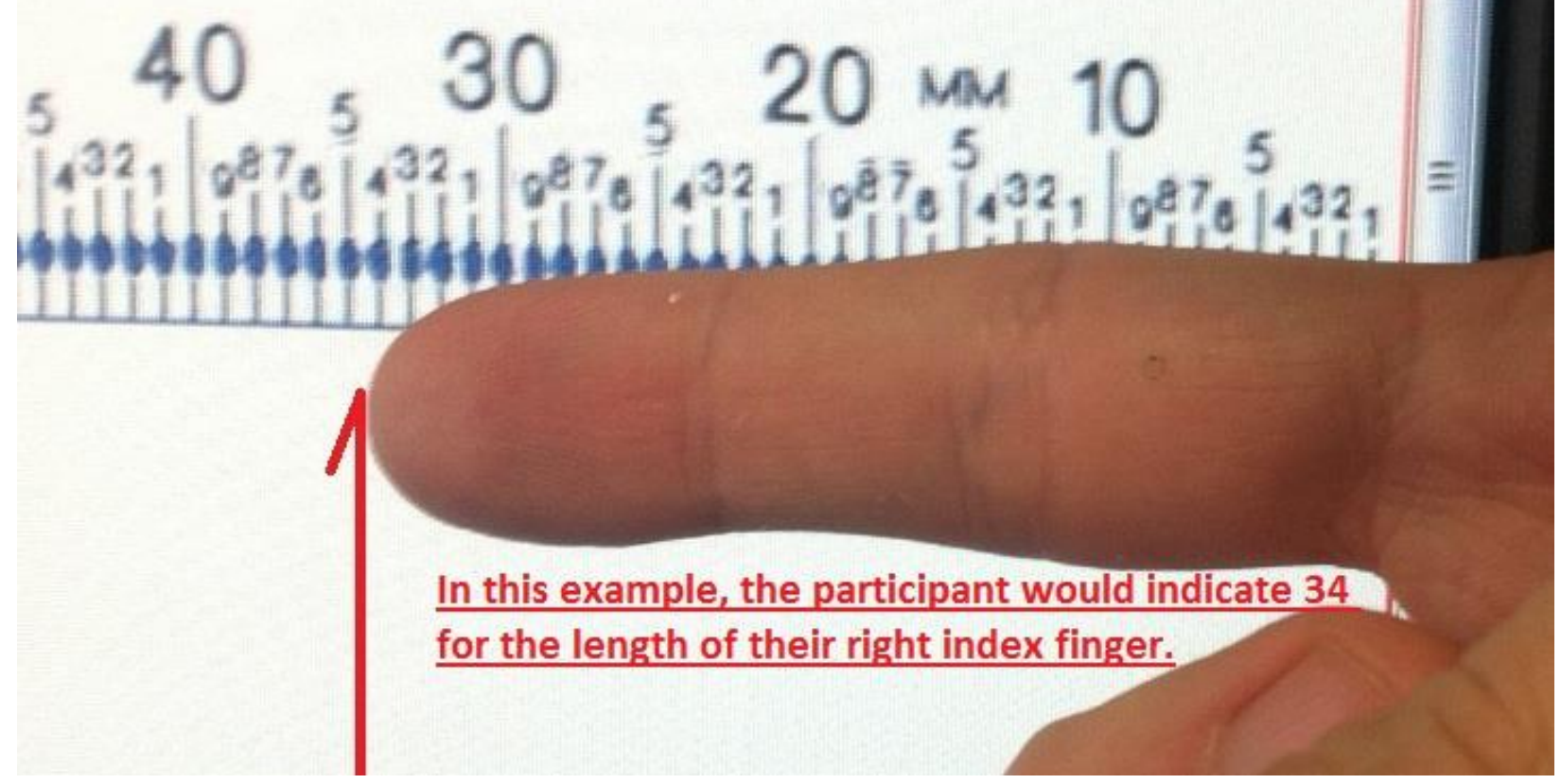

Here is the ruler. Use it to measure your right index finger (the second finger on your right hand that you use to point with).

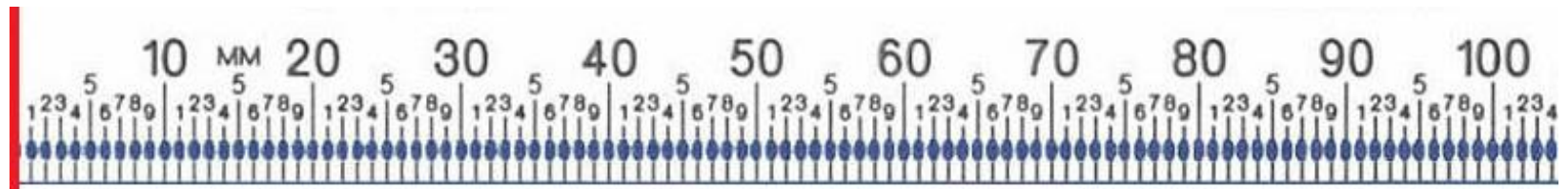

How long is your right index finger (the finger you use to point with on your right hand)? millimeters 
Finally, you will need to indicate the length of your right ring finger (the fourth finger on your right hand next to the pinky finger that people often wear rings on). Here is an example:

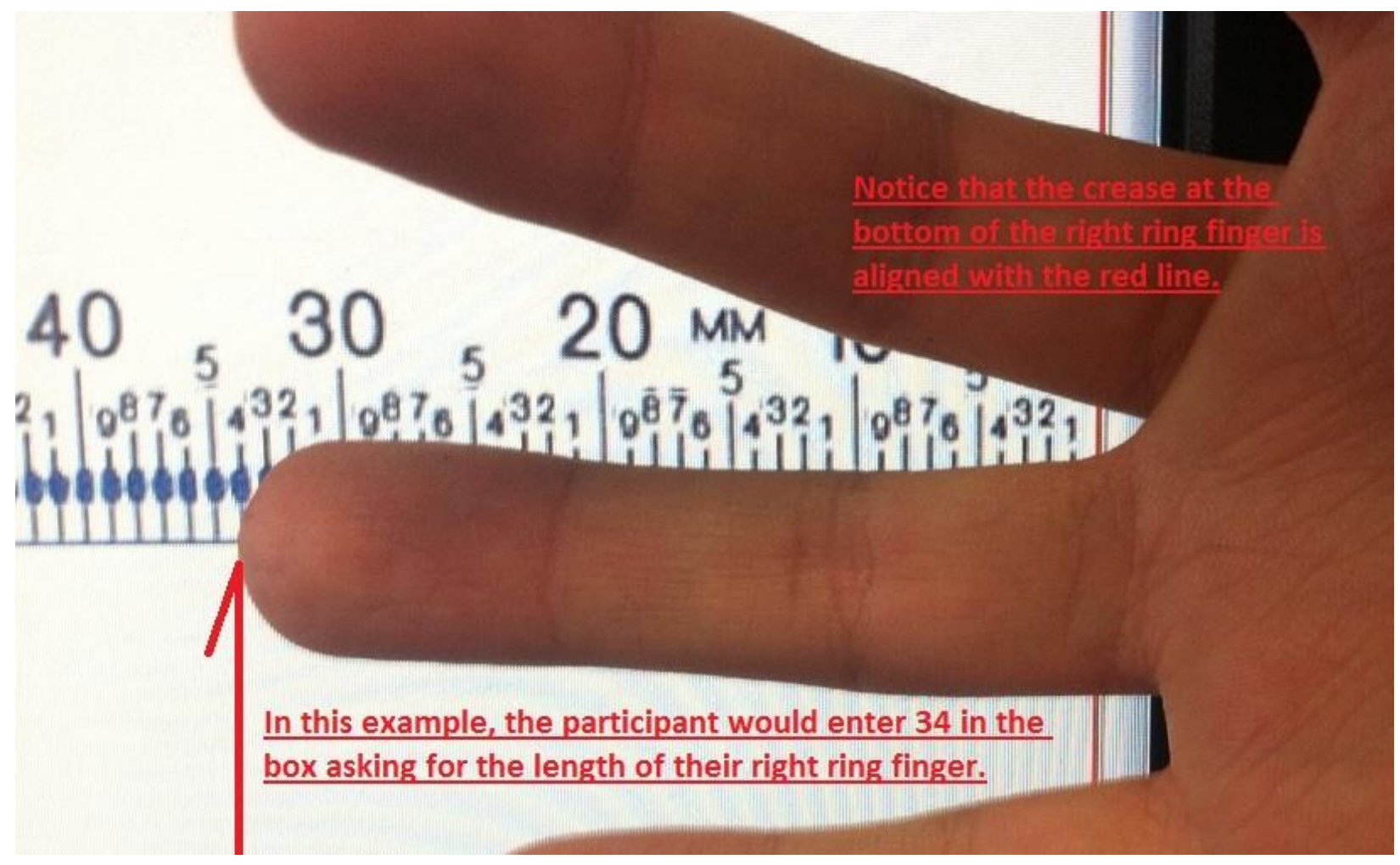

Here is the ruler again. Use it to measure your right ring finger (the fourth finger on your right hand next to the pinky finger that people often wear rings on).

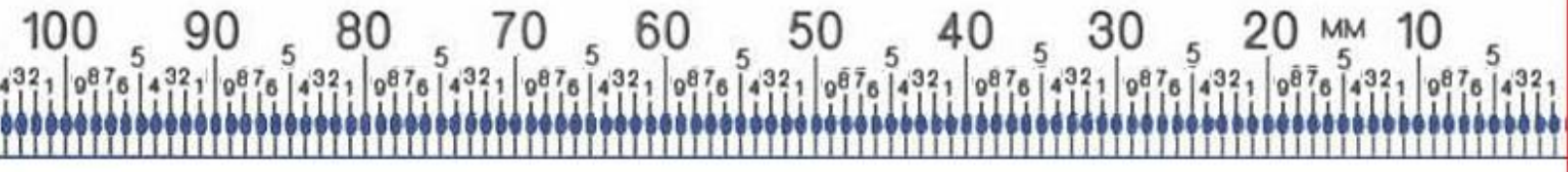

How long is your right ring finger (the fourth finger on your right hand next to your pinky finger that people often wear rings on)? millimeters 